UNIVERSIDADE DE SÃO PAULO

FACULDADE DE ODONTOLOGIA DE BAURU

THAÍS HELENA GASPAROTO

\title{
ESTUDO DA FUNÇÃO DOS NEUTRÓFILOS NOS MECANISMOS DE DEFESA CONTRA A ESTOMATITE POR DENTADURA EM INDIVÍDUOS IDOSOS
}





\section{THAÍS HELENA GASPAROTO}

\section{ESTUDO DA FUNÇÃO DOS NEUTRÓFILOS NOS MECANISMOS DE DEFESA CONTRA A ESTOMATITE POR DENTADURA EM INDIVÍDUOS IDOSOS}

Tese apresentada à Faculdade de Odontologia de Bauru da Universidade de São Paulo para obtenção do título de Doutor em Odontologia.

Área de Concentração: Biologia Oral

Orientadora: Profa. Dra. Vanessa Soares Lara

Co-orientadora: Profa. Dra. Ana Paula Campanelli 

Gasparoto, Thais Helena

G213e Estudo da função dos neutrófilos nos mecanismos de defesa contra a estomatite por dentadura em indivíduos idosos / Thaís Helena Gasparoto. - Bauru, 2009.

126 p. : il. ; $30 \mathrm{~cm}$.

Tese (doutorado) - Faculdade de Odontologia de Bauru. Universidade de São Paulo

Orientador: Profa. Dra Vanessa Soares Lara

Autorizo exclusivamente para fins acadêmicos e científicos, a reprodução total ou parcial desta tese, por processos fotocopiadores e outros meios eletrônicos.

Assinatura

Data

Comitê de Ética da FOB-USP

Protocolo $n^{\circ} 117 / 2005$

Data: 30 de novembro de 2005 



\section{DEDICATÓRIA}

Dedico este trabalho aos meus melhores amigos Jayme W. Gasparoto, Yone M. C. de A. Gasparoto, Carlos T. Gasparoto e Ana Lúcia Gasparoto, minha amada família. Por todo amor, compreensão, fé, paciência e orientação de minha vida toda. Agradeço porque sem vocês eu não seria o que sou e não estaria aqui agora.

Sem vocês ao meu lado a minha vida nunca faria sentido. 


\section{[Digite texto]}




\section{AGRADECIMENTO ESPECIAL}

Agradeço ao meu amado noivo Frederico Castilho da Eira, um homem honesto, forte, corajoso, paciente e companheiro. Com certeza, a melhor pessoa que eu conheci na minha vida. 


\section{[Digite texto]}




\section{AGRADECIMENTOS PESSOAIS}

À minha orientadora Vanessa Soares Lara, por ter acreditado em mim quando a procurei pela primeira vez. Agradeço por todo o respeito, pela orientação, por todo o ensinamento e pela confiança que depositou em mim e no meu trabalho. Uma grande parceira.

À minha co-orientadora Ana Paula Campanelli, por ter me mostrado o caminho todas as vezes que me senti perdida no trabalho e na vida. Agradeço porque muitos têm a orientadora e eu, além disso, tenho uma eterna e maravilhosa amiga. Por me lembrar sempre que fazer o bem nunca é esquecido e sempre vai valer à pena.

Agradeço e engrandeço Jayme Wanderley Gasparoto, Yone M. C. de A. Gasparoto, Ana Lúcia Gasparoto e Carlos Teodoro Gasparoto, exemplos de honestidade, perseverança, respeito ao próximo, dedicação, amizade, amor. Não teria espaço aqui para descrever tudo o que eles são e representam para mim.

À minha grande amiga Valéria Gelani, minha companheira desde a primeira vez que nos falamos, por todas as risadas (e foram muitas), pelas lágrimas compartilhadas, pelas longas e maravilhosas conversas. Entendendo-me até quando eu não me explicava.

À minha amiga tão querida Maria Luisa Franceschini pelas décadas de amizade, pela pessoa gloriosa que eu tenho ao meu lado. Por tudo o que foi, é e sempre será na minha vida.

Ás minhas amigas da pesquisa e da vida Michelle Sabrina da Silva, Carine Ervolino de Oliveira, Hayana Ramos de Lima e Luciana Resende. O dia-a-dia nunca seria tão leve sem vocês ao meu lado. Por me aceitarem como eu sou e me ajudarem em tudo: trabalho, estudo, filmes, novelas, a dar risadas sem fim e sem motivo. Que a vida nos mantenha sempre juntas. Vocês sempre estarão no meu coração!

Ao meu estimado amigo André Luis da Silva, uma pessoa tão boa e companheira. Por acreditar em mim, confiar em mim, me dar o prazer da sua companhia. Você é muito especial na minha vida, meu amigo.

Ao amigo Eduardo Aleixo Figueira, uma pessoa inteligentíssima, divertida, sincera. Eu me sinto honrada por ter convivido com você. 


\section{[Digite texto]}


Ao meu amigo Ronan Jacques Resende que, sem saber, me ensinava todos os dias a ser mais feliz e a acreditar que eu podia confiar nas pessoas. Um presente que a vida me trouxe.

À minha querida amiga Carla Renata Sipert, sempre me animando e pensando positivo, mesmo quando o Universo não conspirava a nosso favor.

À querida Marcela Claudino, sincera, divertida, inteligente e competente. Uma pessoa que eu admiro profundamente.

À querida Dalva de Oliveira, secretária da Microbiologia e Imunologia. Uma mulher forte, dedicada e trabalhadora. Um exemplo a ser seguido.

Ao Professor Vinicius Carvalho Porto, pela convivência e pela ajuda nas pesquisas da minha tese. Muito obrigada.

Ao Professor Sérgio Aparecido Torres, um dedicado e obstinado profissional, por me admitir em seu laboratório e em sua vida.

Ao Professor Carlos Ferreira dos Santos que me estendeu a mão quando eu estava precisando tanto e sem eu ter pedido. Pela generosidade com que trata a todos.

À Marcimara Penitenti, por todo o auxílio e convívio durante a minha pesquisa.

Ao Narciso Almeida Vieira, um profissional com quem eu tive o privilégio de trabalhar.

À Márcia Graeff, uma mulher e profissional maravilhosa, com quem eu tive a felicidade de trabalhar e conviver durante o meu doutorado.

Aos amigos Tatiana Salles de Souza Malaspina, Rodrigo Nalio Ramos e Tiago José Dionísio com quem eu tive o prazer de conviver e trabalhar por anos. Adoro vocês.

Aos alunos de iniciação científica que passaram ou ainda estão no laboratório de Microbiologia e Imunologia da Faculdade de Odontologia de Bauru: Vanessa Tessarolli, Eduardo Clemente de Souza, Rafael Massunari Maenosono, Carollinie Dias Knob e Milena da Silva. Vocês encheram meus dias de alegria, meus queridos. 


\section{[Digite texto]}


Aos colegas de pós-graduação Patrícia Freitas-Faria e Carlos Eduardo Repeke por terem contribuído durante o meu doutorado.

A todos os voluntários que doaram amostras para esta pesquisa, muitos vindos de longe, apenas para contribuir com este trabalho.

A todos que, de alguma maneira, contribuem para que o mundo seja um lugar melhor de se viver. Muito obrigada! 




\section{AGRADECIMENTOS INSTITUCIONAIS}

À Faculdade de Odontologia de Bauru - USP na pessoa do excelentíssimo Diretor, Prof. Dr. Luiz Fernando Pegoraro.

À comissão de pós-graduação da Faculdade de Odontologia de Bauru, na pessoa da Presidente, Profa. Dra. Maria Aparecida de Andrade Moreira Machado.

Ao curso de pós-graduação em Biologia Oral da Faculdade de Odontologia de Bauru-USP, na pessoa do seu Coordenador Prof. Dr. Antônio de Castro Rodrigues.

À Fundação de Amparo à Pesquisa do Estado de São Paulo pela concessão de minha bolsa de doutorado e pelo auxílio à Pesquisa (Proc. 05/60668-9 e 06/59612-1).

Ao Programa de Apoio à Pós-graduação (PROAP), pelo incentivo financeiro.

Ao Hospital Amaral Carvalho de Jaú na pessoa da Diretora de Análises Clínicas, Profa. Dra. Maura Rosane Valerio Ikoma por permitir o uso do citômetro de fluxo durante esta pesquisa.

Ao Hospital de Reabilitação de Anomalias Craniofaciais - Universidade de São Paulo por autorizar a realização de coleta de sangue dos voluntários da pesquisa.

Ao professor Accácio Lins do Valle, pela autorização da realização deste projeto na clínica de Prótese da Faculdade de Odontologia de Bauru.

Aos professores e funcionários da Disciplina de Patologia da Faculdade de Odontologia de Bauru, Prof. Dr. Alberto Consolaro, Prof. Dr. Luís Antonio de Assis Taveira, Profa. Dra. Denise Tostes Oliveira, Fatiminha, Cris e Marilza.

Ao Centro Integrado de Pesquisa, pelo acesso livre a equipamentos utilizados para realização deste trabalho.

À Valquíria, técnica da clínica de Prótese, por todo o apoio.

À Vera L. R. Rosa pela ajuda durante meu doutorado.

As secretárias, porteiros, faxineiros, funcionárias da cantina, e vigias da Faculdade de Odontologia de Bauru. Sem a dedicação e a seriedade de vocês nada disso existiria. 

"Se abolir a escravidão do caboclo brasileiro, "numa" mão educação e na outra dinheiro."

(Samuel Rosa e Chico Amaral) 

Agora é o tempo de transformar em realidade as promessas de democracia.

Agora é o tempo para fazer da justiça uma realidade para todos os filhos de Deus.

Mas, há algo que eu tenho que dizer ao meu povo que se dirige ao portal que conduz ao palácio da justiça. No processo de conquistar nosso legítimo direito, nós não devemos ser culpados de ações de injustiças. Não vamos satisfazer nossa sede de liberdade bebendo da xícara da amargura e do ódio. Nós sempre temos que conduzir nossa luta num alto nível de dignidade e disciplina. Nós não podemos caminhar sozinhos.

E como nós caminhamos, nós temos que fazer a promessa que sempre marcharemos em frente. Nós não podemos retroceder. Há esses que estão perguntando para os devotos dos direitos civis, "Quando vocês estarão satisfeitos?"

Eu digo a vocês hoje, meus amigos que, embora nós enfrentemos as dificuldades de hoje e amanhã, eu ainda tenho um sonho...

Eu tenho um sonho em que um dia esta nação se levantará e viverá o verdadeiro significado de sua crença - nós celebraremos estas verdades e elas serão claras para todos, que os homens serão criados iguais.

Quando nós permitirmos ao sino da liberdade soar, quando nós o deixarmos soar em toda moradia e todo vilarejo, em todo estado e em toda cidade, nós poderemos acelerar aquele dia em que todas as crianças de Deus, homens pretos e homens brancos, judeus e gentios, protestantes e católicos, poderão unir mãos e cantar nas palavras do velho espírito negro: livre afinal, livre afinal.

"Agradeço ao Deus todo-poderoso, nós somos livres afinal."

Trechos do discurso de Martin Luther King (1929-1968) no dia 28/08/1963 na marcha para Washington. Tradução livre 

LISTA DE ABREVIATURAS, SIGLAS E SÍMBOLOS

HIV = human immunodeficience virus (vírus da imunodeficiência humana)

$\mathrm{mg} / \mathrm{L}=$ miligrama por litro

DNA= Desoxiribonucleic acid (ácido desoxirribonucléico)

$\mathrm{X} g=$ vezes o valor da gravidade

$\mathrm{mL}=$ mililitro

$\mu \mathrm{L}=$ microlitro

${ }^{\circ} \mathrm{C}=$ graus Celsius

$\%=$ porcento

$\mathrm{PCR}=$ Polymerase chain reaction (reação em cadeia da polimerase)

HWP1= Hyphal wall protein 1 gene

$\mathrm{MgCl}^{2}=$ cloreto de magnésio

$\mathrm{p} / \mathrm{v}=$ peso por volume

$\mu \mathrm{g} / \mathrm{mL}=$ microgramas por militros

$\mathrm{EPM}=$ erro padrão da média

$\mathrm{EP}=$ estomatite protética

PTS $=$ Prótese total superior

ATCC $=$ American Type Culture Collection

$\mathrm{SFB}=$ soro fetal bovino

RPMI $=$ Roswell Park Memorial Institute

$\mathrm{CXCR} 1=$ chemokine $(\mathrm{C}-\mathrm{X}-\mathrm{C}$ motif $)$ receptor -1

CXCL8 = chemokine $(\mathrm{C}-\mathrm{X}-\mathrm{C}$ motif $)$ ligand -8

PBS = Phosphate Buffer Saline (Tampão fosfato-salina)

$\mathrm{CD}=$ cluster of differentiation

$\mathrm{TLR}=$ Toll like receptor (receptor do tipo Toll)

FITC $=$ fluoresceína isoticianato

$\mathrm{PE}=$ Ficoeritrina

BSA = Bovine Serum Albumin (albumina bovina sérica)

pH = potencial de Hidrogênio iônico

$\mathrm{CO}_{2}=$ dióxido de carbono (gás carbônico)

$\mathrm{H}_{2} \mathrm{O}_{2}=$ peróxido de hidrogênio

$\mathrm{H}_{2} \mathrm{SO}_{4}=$ ácido sulfúrico 

$\mathrm{N}=$ Normal

$\mathrm{nm}=$ namometros

$\mathrm{ng} / \mathrm{mL}=$ nanogramas por mililitros

$\mathrm{pg} / \mathrm{mL}=$ picogramas por mililitros

$\mathrm{pg} / \mathrm{mg}=$ picogramas por miligramas

$\mu \mathrm{M}=$ micromolar

$\mathrm{IL}=$ interleucina

GM-CSF = granulocyte macrophage- colony stimulating factor (fator estimulador de colonias de macrófagos e granulócitos)

TNF- $\alpha=$ Tumoral necrosis factor alpha (Fator de necrose tumoral alfa)

IFN- $\gamma=$ Interferon gama

$\mathrm{EPC}=$ estomatite protitica associada a Candida

MFI= mean fluorescence intensity (média de intensidade de fluorescência)

LPS = lipopolissacarídeo

$\mathrm{NF}-\kappa \mathrm{B}=$ nuclear factor kappa $\mathrm{B}$

$\mathrm{Th}=\mathrm{T}$ helper $(\mathrm{T}$ auxiliar $)$

HTT $=$ Hipersensibilidade do tipo tardia

$\mathrm{NaCl}=$ cloreto de sódio

ELISA = Enzyme-linked immunosorbent assay

$\mathrm{Fc} \gamma \mathrm{RI}=$ human high- affinity $\mathrm{IgG}$ receptor (receptor de IgG humana de alta afinidade)

Fc $\gamma$ RII = human low- affinity IgG receptor (receptor de IgG humana de baixa afinidade)

Fc $\gamma$ RIII = human low- affinity IgG receptor (receptor de IgG humana de baixa afinidade) 



\section{RESUMO GERAL}

Os neutrófilos são as primeiras células a migrar para sítios de infecção e desempenham importante papel na defesa contra vários patógenos, especialmente Candida albicans. A função dos neutrófilos envolve fagocitose e destruição de leveduras e formas filamentosas do fungo, além de produção de citocinas e quimiocinas, capazes de ativar outras células envolvidas na eliminação de $C$. albicans. Recentemente, tem sido mostrado que estas células apresentam prejuízos com o avanço da idade e estes fenômenos fazem parte de uma área da Imunologia conhecida como Imunossenescência. A estomatite protética é a lesão oral mais verificada em idosos e a sua persistência é diretamente relacionada com a presença de espécies de Candida, principalmente $C$. albicans, nas lesões e na superfície interna de próteses, especialmente totais superiores (PTS). Com o objetivo de avaliar possíveis alterações em neutrófilos que poderiam predispor usuários de prótese total superior à estomatite protética, foram analisados neutrófilos de sangue e de saliva de idosos e jovens com estomatite protética associada à Candida (EPC), bem como de indivíduos controles. No primeiro capítulo foi avaliada a positividade de Candida e as diferentes espécies deste patógeno em lesões de estomatite protética e superfície interna de PTS. C. albicans foi a espécie mais detectada em lesões de EP e na PTS. No segundo capítulo, os neutrófilos do sangue dos indivíduos da pesquisa foram caracterizados quanto ao fenótipo ex vivo, função fagocítica e produção de citocinas e quimiocinas após desafio com C. albicans. Neutrófilos do sangue de indivíduos com EPC, bem como de idosos sem EPC, apresentaram características relacionadas com suscetibilidade às doenças causadas por C. albicans. No terceiro capítulo, os neutrófilos salivares dos indivíduos foram caracterizados quanto ao fenótipo ex vivo e função fagocítica após desafio com $C$. albicans. Além disso, níveis de citocinas e quimiocinas relacionadas com resposta imune de proteção ou suscetibilidade à infecções por $C$. albicans foram detectadas nas amostras de saliva. Os resultados indicaram diferenças nos neutrófilos salivares e componentes solúveis da saliva de pacientes com EPC. Também, alterações observadas nos neutrófilos resultantes da imunossenescência podem tornar os idosos mais suscetíveis a infecções por Candida e doenças associadas com a presença deste fungo.

Palavras-chave: Estomatite protética associada a Candida, neutrófilos, idosos. 



\title{
ABSTRACT \\ Study of neutrophils from elderly in the defense mechanisms against Candida-related denture stomatitis
}

\begin{abstract}
Neutrophils are the first line of immune cells to migrate into infection sites, playing an important role against pathogens, especially Candida albicans. These cells phagocytose and destroy yeasts or filamentous forms of this fungus, beyond secrete cytokines and chemokines that activate other immune cells to eliminate $C$. albicans. Nowadays, it has been shown that the ageing damages neutrophil function and such events are described as part of Imunosenescence. Denture stomatitis is the most oral lesion present in elderly, and its persistence is related to Candida species, especially C. albicans, in the lesions and prosthesis fitting surface, particularly maxillary prosthesis (MP). In order to evaluate possible neutrophil alterations predisposing denture wearers to Candida-related denture stomatitis (DS), blood and salivary neutrophils from elderly and younger individuals with DS, as well control ones, were analyzed. Thus, the first chapter addresses the presence of Candida species on the denture stomatitis lesions and MP fitting surface. C. albicans was the most species detected in DS lesions and MP. On the second chapter, blood neutrophils from the individuals were characterized about ex vivo phenotype, phagocytic function, and cytokines and chemokines production after challenged with $C$. albicans. Blood neutrophils from DS individuals, as well elderly without DS, presented characteristics of susceptibility to $C$. albicans diseases. On the third chapter, salivary neutrophils from the individuals were characterized about ex vivo phenotype and phagocytic function against $C$. albicans. In addition, salivary cytokines and chemokines involved with resistance or susceptibility to $C$. albicans infection were detected. Results indicated differences in salivary neutrophils and soluble components from patients with DS. In addition, alterations observed in neutrophils by immunosenescence could facilitate Candida infections and diseases related to the presence of this pathogen in elderly.
\end{abstract}

Key words: Candida-related denture stomatitis, neutrophils, elderly. 


\section{LISTA DE FIGURAS}

\section{CAPÍTULO - I}

Figura 1. Ocorrência de espécies de Candida em lesão ou palato e prótese total superior na estomatite protética.

Figura 2. Ocorrência de Candida dubliniensis na estomatite protética.

\section{CAPÍTULO - II}

Figura 1. Número e função fagocítica de neutrófilos isolados do sangue

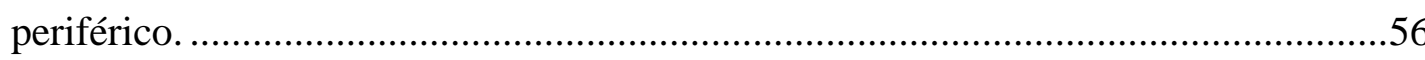

Figura 2. Função fagocítica de neutrófilos isolados do sangue periférico...............................57

Figura 3. Análise do fenótipo de neutrófilos do sangue periférico..........................................61

Figura 4. Análise da média de intensidade de fluorescência de receptores de membrana de neutrófilos do sangue periférico. .....................................................62

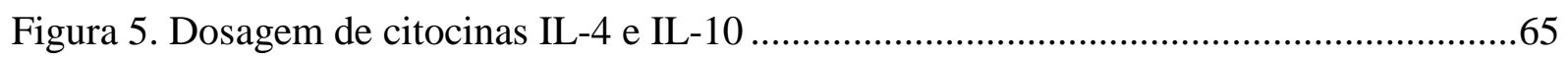

Figura 6. Dosagem de citocinas IL-12 e TNF- $\alpha$................................................................67

Figura 7. Dosagem de citocinas CXCL8 e GM-CSF..........................................................69

\section{CAPÍTULO - III}

Figura 1. Número e função fagocítica de neutrófilos isolados da saliva. ...............................99

Figura 2. Análise do fenótipo de neutrófilos da saliva. ..........................................................101

Figura 3. Análise do fenótipo de neutrófilos obtidos da saliva.............................................103

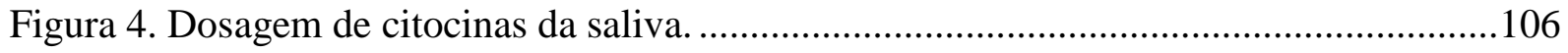

\section{LISTA DE TABELAS}

TABELA 1. Dados demográficos dos indivíduos com estomatite protética (EP) e usuários de prótese total superior sem estomatite EP. 





\section{SUMÁRIO}

1. INTRODUÇÃ

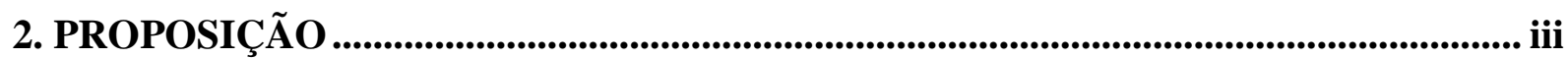

3. MATERIAL E MÉTODOS.................................................................................................. iv

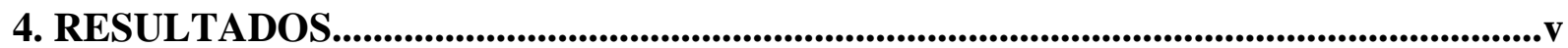

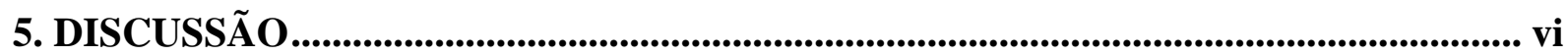

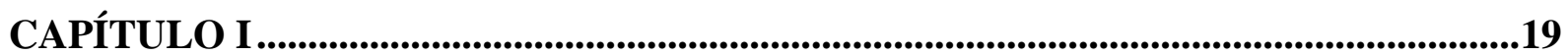

CAPÍTULO II

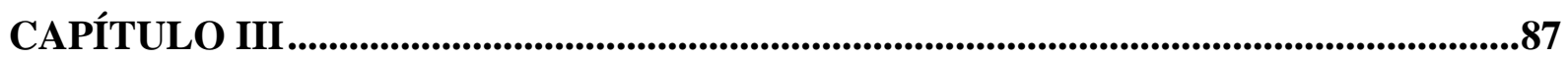

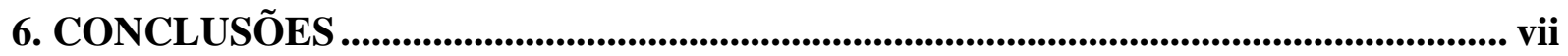

REFERÊNCIAS BIBLIOGRÁFICAS ........................................................................................viii 



\section{Introdução}







\section{INTRODUÇÃO}

Grande parte da população brasileira $(14,4 \%)$ apresenta edentulismo total (Disponível em http:// www.ibge.gov.br; acesso em jul/2005 e jun/2006). O uso de prótese total superior (PTS) é associado com um processo inflamatório na mucosa do palato denominado estomatite protética (EP) (FREITAS et al., 2008). Entre os brasileiros usuários de prótese total, 50\% apresentavam estomatite protética (PIRES et al., 2002), podendo ser considerada um problema de saúde bucal pública. A EP é descrita como uma doença local recorrente caracterizada por atingir a superfície mucosa subjacente ao material resinoso das próteses, popularmente conhecidas como dentaduras, especialmente PTS (BUDTZ-JORGENSEN; STENDERUP; GRABOWSKI, 1975; DAR-ODEH; SHEHABI, 2003). As lesões causadas pelo uso de próteses dentárias acrílicas removíveis têm recebido diferentes denominações com o passar dos anos, sendo atualmente denominadas como estomatite protética (SCALERCIO et al, 2007). Muitos estudos têm discutido o envolvimento de Candida albicans (C. albicans) no estabelecimento e persistência da EP. Um dos principais fatores que apontam para esta hipótese seria a facilidade encontrada pelo microrganismo de aderir na superfície acrílica das dentaduras (MAKIHIRA et al., 2002; MOURA et al., 2006; RAMAGE et al., 2001; WEBB et al., 1998).

Os neutrófilos são granulócitos produzidos na medula óssea, e são rapidamente recrutadas do sangue periférico para os sítios de infecção, onde são capazes de destruir os patógenos pela fagocitose, produção de espécies reativas de oxigênio, ação de peptídeos antimicrobianos e através de armadilhas extracelulares compostas por seu material genético (BRINKMANN; ZYCHLINSKY, 2007; DALE; BOXER; LILES, 2008; NATHAN, 2006). Os neutrófilos são considerados fundamentais na proteção contra infecções fúngicas. Eles são responsáveis pelos principais mecanismos de defesa do hospedeiro contra a candidose disseminada e invasiva (SAUNUS; KAZOULLIS; FARAH, 2008) (KULLBERG et al., 1999). Seu papel em infecções por Candida é evidente, visto que a neutropenia é associada com o estabelecimento de candidose sistêmica, com graves prejuízos ao hospedeiro (KOH et al., 2008; PELTROCHELLACSAHUANGA et al., 2003; SHOHAM; LEVITZ, 2005). Além disso, os neutrófilos estão envolvidos diretamente com a defesa contra infecções localizadas causadas por Candida (KOH et al., 2008; SAUNUS; KAZOULLIS; FARAH, 2008; SCHALLER et al., 2004). 
Durante o envelhecimento, ocorrem inúmeras alterações numéricas e fenotípicas nas células do sistema imune inato ou adaptativo (FULOP et al., 1997; HAYNES; MAUE, 2009; LICASTRO et al., 2005; PANDA et al., 2009; PLACKETT et al., 2004; SHANLEY et al., 2009; WENISCH et al., 2000). Os neutrófilos, por exemplo, são células que podem demonstrar diferenças quanto ao número, ativação e função, na senescência; embora os dados na literatura sejam contrastantes, necessitando um maior esclarecimento quanto à participação desta célula no contexto dos mecanismos de defesa do idoso contra os diferentes patógenos.

A presença de neutrófilos na cavidade bucal está envolvida diretamente com a proteção contra infecções. A infiltração de neutrófilos é a característica marcante nas lesões bucais por Candida albicans (C. albicans), e a sua ausência é relacionada ao agravamento da candidose oral (FARAH et al., 2001).

Esta tese será apresentada em três capítulos, enquadrados no contexto das regras da CPG-FOB-USP. Cada capítulo focará análises realizadas a partir de diferentes amostras; material biológico de palato ou lesões de estomatite protética e superfície interna de prótese total superior, sangue e saliva. No primeiro capítulo foi avaliada a positividade de Candida e as diferentes espécies deste patógeno em lesões de estomatite protética e superfície interna de PTS. No segundo capítulo, os neutrófilos do sangue dos indivíduos com estomatite protética associada a Candida (EPC) foram caracterizados quanto ao fenótipo ex vivo, função fagocítica e produção de citocinas e quimiocinas após desafio com $C$. albicans. No terceiro capítulo, os neutrófilos salivares dos indivíduos com EPC foram caracterizados quanto ao fenótipo ex vivo e função fagocítica após desafio com $C$. albicans. Além disso, níveis de citocinas e quimiocinas relacionadas com resposta imune de proteção ou suscetibilidade à infecções por $C$. albicans foram detectadas nas amostras de saliva.

Nas referências bibliográficas desta tese de doutoramento foram incluídas todas as obras referenciadas na introdução do trabalho.

Em conclusões, além de considerações específicas de cada capítulo apresentado, a finalização conjunta dos resultados foi apresentada. 
2 Proposição 



\section{PROPOSIÇÃO}

A partir do conhecimento obtido na literatura, a proposta deste trabalho foi avaliar a presença de Candida em lesões de estomatite protética e na superfície interna das próteses totais superiores, além de caracterizar fenotípica e funcionalmente os neutrófilos do sangue e da saliva de indivíduos idosos e jovens com estomatite protética associada a Candida. 


3 Material e Métodos 




\section{MATERIAL E MÉTODOS}

O material e os métodos utilizados para as avaliações desta tese estão descritos detalhadamente em cada capítulo.

No primeiro capítulo, as amostras de material microbiológico foram coletadas com o auxilio de cotonete de algodão estéril e identificadas através de CHROMAgar Candida e PCR.

No segundo capítulo, as amostras de sangue venoso braquial foram coletadas com o auxilio de seringa heparinizada; os neutrófilos foram purificados, fenotipados por citometria de fluxo, analisados quanto à função fagocítica e produção de citocinas através de ensaios in vitro.

No terceiro capítulo, as amostras de saliva foram coletadas e níveis de citocinas foram quantificados; os neutrófilos foram isolados, fenotipados por imunofluorescência e analisados quanto à função fagocítica através de ensaios in vitro. 

4 Resultados 



\section{RESULTADOS}

Os resultados obtidos nas avaliações realizadas das diferentes amostras desta tese estão descritos detalhadamente em cada capítulo.

C. albicans foi a espécie mais detectada em lesões de EP e na PTS. Os neutrófilos do sangue de indivíduos com EPC, bem como de idosos sem EPC, apresentaram características relacionadas com suscetibilidade às doenças causadas por C. albicans. Os resultados indicaram diferenças nos neutrófilos salivares e componentes solúveis da saliva de pacientes com EPC. 

5 Discussão 





\section{DISCUSSÃO}

A discussão com relação aos resultados obtidos nos diferentes ensaios realizados neste trabalho está descrita detalhadamente em cada capítulo. 



\section{CAPÍTULO - I}

\section{Imunossenescência e estomatite}

protética associada a Candida: espécies

de Candida spp nas lesões e nas próteses totais superiores 




\section{RESUMO}

A estomatite protética (EP) é uma doença local e persistente que atinge a área mucosa subjacente à prótese dentária, especialmente próteses totais superiores (PTS), sendo muito relacionada com a presença do fungo Candida albicans (C. albicans). O nosso objetivo foi avaliar a presença de Candida em amostras biológicas coletadas de lesões e da superfície interna de PTS de idosos e jovens com EP e usuários de PTS não portadores da doença. Os resultados mostraram que espécies de Candida estavam presentes em 97,9\% das lesões e das PTS de pacientes com EP. C. albicans foi a espécie mais isolada tanto de lesão quanto de PTS dos pacientes, independente da faixa etária. Além disso, Candida tropicalis, Candida krusei e Candida dubliniensis foram identificadas em algumas amostras biológicas obtidas de pacientes com EP. Entre os indivíduos sem EP usuários de PTS, os idosos exibiram baixas taxas de positividade para C. albicans, C. tropicalis, C. krusei e C. dubliniensis. A positividade para $C$. albicans (70\% tanto no palato quanto na PTS) e para $C$. dubliniensis (20\% tanto no palato quanto na PTS) foram altas nos grupos de jovens sem EP.

Assim, os dados demonstraram que espécies de Candida são mais frequentemente isoladas do palato e da PTS de indivíduos com EP idosos e jovens. C. albicans foi a espécie mais detectada nas amostras de pacientes com EP. Os resultados indicam presença de $C$. dubliniensis que pode ter papel patogênico bem como comensal no microambiente oral humano. 



\section{INTRODUÇÃO}

Grande parte da população brasileira $(14,4 \%)$ apresenta edentulismo total (Disponível em http:// www.ibge.gov.br; acesso em jul/2005 e jun/2006). O uso de prótese total superior (PTS) é associado com um processo inflamatório na mucosa do palato denominado estomatite protética (EP) (FREITAS et al., 2008). Entre os brasileiros usuários de prótese total, 50\% apresentavam estomatite protética (PIRES et al., 2002), podendo ser considerada um problema de saúde bucal pública. A EP é descrita como uma doença local recorrente caracterizada por atingir a superfície mucosa subjacente ao material resinoso das próteses, popularmente conhecidas como dentaduras, especialmente PTS (BUDTZJORGENSEN; STENDERUP; GRABOWSKI, 1975; DAR-ODEH; SHEHABI, 2003). As lesões causadas pelo uso de próteses dentárias acrílicas removíveis têm recebido diferentes denominações com o passar dos anos, sendo atualmente denominadas como estomatite protética (SCALERCIO et al, 2007).

As superfícies internas das PTS comumente apresentam biofilmes microbianos aderidos, constituídos em grande parte por fungos do gênero Candida (FIGUEIRAL et al, 2007; PEREIRA-CENCI et al, 2008). Assim, a mucosa palatina, que suporta as PTS, pode apresentar a EP e espécies de Candida podem estar diretamente envolvidas com o estabelecimento da EP, clinicamente diagnosticada como pontos hiperêmicos (Tipo I) ou área eritematosa difusa (Tipo II) ou hiperplasia papilar (Tipo III) (BUDTZ-JORGENSEN, 1978; BUDTZ-JORGENSEN; BERTRAM， 1970; BUDTZ-JORGENSEN; STENDERUP; GRABOWSKI, 1975; ESPINOZA et al., 2003; NEWTON, 1962).

Muitos estudos têm discutido o envolvimento de Candida albicans (C. albicans) no estabelecimento e persistência da EP. Um dos principais fatores que apontam para esta hipótese seria a facilidade encontrada pelo microrganismo de aderir na superfície acrílica das dentaduras (MAKIHIRA et al., 2002; MOURA et al., 2006; RAMAGE et al., 2001; WEBB et al., 1998). Além disso, outros fatores locais como trauma relacionado com o uso de PT e xerostomia característica nos idosos constituem fatores facilitadores da aderência das leveduras Candida (BUDTZ-JORGENSEN, 1978; BUDTZ-JORGENSEN; BERTRAM, 1970; BUDTZ-JORGENSEN; STENDERUP; GRABOWSKI, 1975; KULAK-OZKAN; KAZAZOGLU; ARIKAN, 2002). Candida albicans (C. albicans) é o fungo mais comumente 
isolado da cavidade bucal de humanos, tanto em casos de ausência (BUDTZ-JORGENSEN; STENDERUP; GRABOWSKI, 1975) como de presença de candidose oral (BERDICEVSKY et al., 1980; BUDTZ-JORGENSEN; STENDERUP; GRABOWSKI, 1975; VITKOV et al., 2002. Nos usuários de prótese total superior, isolados de C. albicans são encontradas em $60 \%$ a 100\% dos casos (BERDICEVSKY et al, 1980). Outras espécies de Candida também são verificadas em lesões de EP (FIGUEIRAL et al., 2007). Da mesma maneira, outras espécies de Candida são isoladas como comensais em humanos saudáveis (QI; HU; ZHOU, 2005).

Além das alterações locais que podem predispor à EP, as alterações sistêmicas, como diabetes mellitus, quimioterapia, o uso de tabaco ou de medicamentos e ainda a idade avançada, podem também colaborar com a patogênese desta doença, por resultarem em ou representarem estados de imunossupressão, prejudicando assim os mecanismos de defesa do hospedeiro (MCELROY, 1984; OLIVER; SHILLITOE, 1984; VITKOV et al., 2003). A EP tem sido descrita como a lesão oral mais comum em pessoas idosas (BUDTZ-JORGENSEN; STENDERUP; GRABOWSKI, 1975; ESPINOZA et al., 2003; PIRES et al., 2002).

CHROMAgar Candida é um meio de cultura para identificação de espécies de Candida pelo crescimento de colônias de leveduras exibindo cores e morfologias diferentes (PFALLER; HOUSTON; COFFMANN, 1996; WILLINGER et al., 2001). Colônias de $C$. albicans em CHROMAgar Candida exibem cor verde de tonalidades clara ou escura. Há em torno de uma década tem sido descrita uma espécie - $C$. dubliniensis - que exibe diversas caracteristicas semelhantes à espécie $C$. albicans, inclusive colônias de coloração verde no meio CHROMAgar Candida (SAHAND et al., 2005; MARTINEZ et al., 2002; SULLIVAN, D.; COLEMAN, 1998). Inicialmente, C. dubliniensis foi isolada de lesões de candidose orofaríngea em pacientes contaminados com o vírus da imunodeficiência humana (HIV). $C$. dubliniensis já foi isolada da cavidade oral de humanos HIV negativos (MORAN et al., 1997). Recentemente, esta espécie foi isolada de lesões de EP em indivíduo imunocompetente (MOSCA et al., 2005).

Por todo o exposto, este trabalho teve o objetivo de analisar a detecção de espécies de Candida em amostras coletadas de lesão de EP ou de palato saudável, bem como da superfície interna das PTS de indivíduos idosos e jovens apresentando ou não EP. 


\section{MATERIAL E MÉTODOS}

\section{1 - CARACTERIZAÇÃO DOS GRUPOS DE ESTUDO}

Os indivíduos foram avaliados e selecionados nas clínicas de graduação e pósgraduação da Disciplina de Prótese do Departamento de Prótese da Faculdade de Odontologia de Bauru da Universidade de São Paulo (FOB - USP). A avaliação clínica dos indivíduos foi realizada sob a supervisão direta do Prof. Dr. Vinícius Carvalho Porto, do Departamento de Prótese (FOB - USP). Inicialmente, os voluntários que aceitaram participar da pesquisa responderam a uma anamnese direcionada (ANEXO I), onde foram registrados dados sobre tempo de uso da prótese total dentária e dados clínicos sobre a cavidade bucal e seus tecidos e, na presença de estomatite protética, sua aparência clínica detalhada e sintomatologia.

Os voluntários foram informados detalhadamente sobre a pesquisa e seus objetivos, sobre a coleta de amostras biológicas e de dados sobre sua história médica e sobre a prótese total superior. As coletas de material biológico e de dados foram realizadas após a concordância do paciente e documentadas com a assinatura do termo de consentimento livre e esclarecido, conforme prevê a resolução 196/96 do Conselho Nacional de Saúde. Este projeto de pesquisa foi aprovado pelo Comitê de Ética em Pesquisa, da FOB - USP, desde 30 de novembro de 2005 (ANEXO II).

Para a realização deste projeto de pesquisa foram excluídos os indivíduos 1 portadores de doença infecciosa sistêmica, de qualquer natureza, aguda ou crônica, com ou sem manifestação bucal; 2 - sofrendo de neoplasias malignas, de natureza bucal ou não; 3 sob qualquer tipo de tratamento quimioterápico ou radioterápico; 4 - portadores de alterações endócrinas (diabetes, gravidez, hipotireoidismo, hipertireoidismo); 5 - sob tratamento prolongado com antibioticoterapia de amplo espectro ou antifúngico; 6 -portadores de doenças hematológicas de qualquer natureza; 7 - fumantes; 8 - sob tratamento com antipsicóticos, metais pesados, anticonvulsivantes e cardiotônicos; 9 - portadores de doenças que envolvam o sistema imunológico com ou sem manifestação bucal.

Os indivíduos selecionados foram divididos em quatro grupos, cada grupo com 1020 pacientes, assim constituídos: 
- Indivíduos com idade acima de 60 anos (idosos) usuários de prótese total superior por, no mínimo, dois anos: apresentando estomatite protética (EP) ou sem qualquer lesão bucal induzida por microrganismo (S/ EP);

- Indivíduos com idade abaixo de 50 anos (jovens) usuários de prótese total superior por, no mínimo, dois anos: apresentando estomatite protética (EP) ou sem qualquer lesão bucal induzida por microrganismo (S/ EP).

As lesões de estomatite protética foram diagnosticadas clinicamente e por meio de confirmação microbiológica. Os pacientes com estomatite protética obrigatoriamente não apresentavam outra lesão bucal induzida por microrganismo ou de característica auto-imune.

\section{DIAGNÓSTICO MICROBIOLÓGICO (ISOLAMENTO DE CANDIDA)}

Nos pacientes com diagnóstico clínico de estomatite protética foram coletadas amostras de material biológico adicional da lesão utilizando-se cotonete de algodão estéril umedecido em solução salina, o qual foi passado sobre o palato e na superfície interna da prótese total superior. Depois o material foi transferido para tubos de ensaio contendo caldo Sabouraud (acrescido de cloranfenicol, $50 \mathrm{mg} / \mathrm{L}$ ). Em seguida, as amostras foram mantidas a $24^{\circ} \mathrm{C}$ por 7 dias, e então foi realizada a semeadura por esgotamento em Ágar Sabouraud (Difco) por 48 horas a $37^{\circ} \mathrm{C}$. Em seguida, as amostras positivas foram semeadas em placas de CHROMagar Candida (Difco), preparadas segundo instruções do fabricante, para a identificação das espécies de Candida (PFALLER; HOUSTON; COFFMANN, 1996). As colônias verdes foram submetidas à análise por PCR para confirmação de espécie albicans ou dubliniensis. As amostras de material biológico dos indivíduos que não apresentavam estomatite protética foram semelhantemente coletadas e analisadas do palato subjacente a prótese total superior e da superfície interna da prótese total superior. 


\section{EXTRAÇÃO DE DNA}

As amostras que apresentaram coloração verde nos testes de CHROMAgar Candida foram submetidas a análise de diferenciação entre Candida albicans e Candida dubliniensis. Para a extração de DNA das amostras foi utilizada técnica descrita previamente por (ROMEO; RACCO; CRISEO, 2006), com algumas modificações. Primeiramente, as colônias verdes foram obtidas, homogeneizadas em solução salina estéril, semeadas em Agar Sabouraud dextrose e mantidas a temperatura ambiente até o momento da purificação do DNA. As células de Candida foram lavadas três vezes a 10.000 x $g$ por 5 minutos a $4^{\circ} \mathrm{C}$. O precipitado foi suspenso em 0,1 mL de água livre de DNAse e RNAse contendo $0,1 \mathrm{~mL}$ de Instagene (Instagene Matrix; Bio-Rad Laboratories) e incubados por 30 minutos a $56^{\circ} \mathrm{C}$. As amostras foram fervidas por 10 minutos e novamente centrifugadas $10.000 \mathrm{x} g$ por 5 minutos a $4^{\circ} \mathrm{C}$ como descrito previamente por SAKAI et al, 2007. Os sobrenadantes das amostras foram obtidos e analisados quanto ao DNA de C. albicans e C. dubliniensis.

\section{AMPLIFICAÇÃO DE DNA DE C. ALBICANS E C. DUBLINIENSIS PELA REAÇÃO EM CADEIA DA POLIMERASE (PCR).}

As amostras foram amplificadas sob condições padronizadas usando um grupo de primers específicos para o gene HWP 1 (hyphal wall protein 1 gene, CRR forward primer 5'GTTTTTGCAACTTCTCTTTGTA-3', CRR reverse primer 5'ACAGTTGTATCATGTTCAGT-3'). A mistura para PCR (volume total $25 \mu \mathrm{L}$ ) continha 3 $\mu \mathrm{L}$ de DNA genômico, 0,2 $\mathrm{mM}$ de trifosfato denucleosídeo (IDT primer), 0,4 $\mu \mathrm{M}$ de cada primer, 2,5 U de GoTaq polimerase (Promega) e 1,5 mM de $\mathrm{MgCL}_{2}$. A amplificação foi feita após a desnaturação a $95^{\circ} \mathrm{C}$ por 5 minutos, seguido por 34 ciclos de desnaturação a $94^{\circ} \mathrm{C}$ por 45 segundos, anelamento de primer a $50^{\circ} \mathrm{C}$ por 60 segundos e extensão a $72^{\circ} \mathrm{C}$ por 90 segundos, seguido por uma extensão final a $72^{\circ} \mathrm{C}$ por 10 minutos em termociclador (Progene, Techne).

Os produtos da PCR foram separados em gel de agarose 1,5\% (p/v), corado com brometo de etídio $(0,5 \mu \mathrm{g} / \mathrm{mL})$ e comparado com o marcador de tamanho de DNA (100 Base- 
Pair Ladder, Amersham Biosciences) usando um transiluminador (Sigma T2202). Dois diferentes amplicons foram verificados: 1180 pares de base para $C$. albicans e 930 para $C$. dubliniensis.

\section{ANÁLISE ESTATÍSTICA.}

Os dados foram analisados através do teste Qui-quadrado com correção de Yates e o teste exato de Fisher, para verificação de possíveis diferenças entre as espécies ou entre os grupos analisados e adotou-se o nível de significância igual a 5\%. 


\section{RESULTADOS}

\section{Dados demográficos dos indivíduos com estomatite protética}

Os indivíduos idosos e jovens analisados neste trabalho não diferiram de maneira significante entre os grupos com e sem EP quanto ao gênero ou faixa etária incluída na amostra (Tabela 1). Embora a maioria das lesões de EP nos idosos foi do tipo I, três indivíduos apresentavam lesão do tipo II e apenas um indivíduo tinha lesão do tipo III. Os jovens com EPC analisados apresentavam apenas lesão de EP do tipo I.

TABELA 1. Dados demográficos dos indivíduos com estomatite protética (EP) e usuários de prótese total superior sem estomatite EP.

\begin{tabular}{ccccc}
\hline Grupos & $\begin{array}{c}\text { Masculino } \\
\mathbf{n}(\%)\end{array}$ & $\begin{array}{c}\text { Feminino } \\
\mathbf{n}(/ \%)\end{array}$ & $\begin{array}{c}\text { Idade } \\
\text { Mínimo - Máximo } \\
(\text { média } \pm \text { EPM })\end{array}$ & $\begin{array}{c}\text { Tipos de lesão } \\
\mathbf{n}(\mathbf{\%})\end{array}$ \\
\hline $\begin{array}{c}\text { Idosos com EP } \\
(\mathbf{n = 2 5})\end{array}$ & $10(40)$ & $15(60)$ & $60-85(69,4 \pm 3)$ & $\begin{array}{c}\text { Tipo I- 21 (84) } \\
\text { Tipo II- } 3(12) \\
\text { Tipo III- } 1(4)\end{array}$ \\
$\begin{array}{c}\text { Idosos sem EP } \\
(\mathbf{n = 2 0})\end{array}$ & $10(50)$ & $10(50)$ & $60-87(68,2 \pm 5,5)$ & \\
$\begin{array}{c}\text { Jovens com EP } \\
(\mathbf{n = 1 5})\end{array}$ & $8(53,3)$ & $7(46,7)$ & $35-50(43,8 \pm 1,5)$ & Tipo I - 15 (100\%) \\
$\begin{array}{c}\text { Jovens sem EP } \\
(\mathbf{n = 1 2})\end{array}$ & $7(58,3)$ & $5(41,7)$ & $38-50(47,4 \pm 1,7)$ & \\
\hline
\end{tabular}




\section{Espécies de Candida obtidas de lesão ou palato e prótese total superior de idosos e jovens com Estomatite Protética (EP).}

A análise do material biológico mostrou que uma porcentagem significantemente mais alta de positividade (97,9\%, Figura 1A) para Candida foi isolada das lesões de indivíduos com EP em comparação com aquela obtida do palato $(35,4 \%)$ de usuários de prótese total superior (PTS) saudáveis $(P<0,001)$. Do mesmo modo, as próteses totais dos pacientes com EP apresentavam maior positividade para Candida do que as dos usuários controles saudáveis S/ $\mathrm{EP}(97,9 \%$ e $35,4 \%$, respectivamente).

A espécie de Candida mais isolada das lesões de estomatite protética e das próteses totais destes pacientes foi $C$. albicans (Figura 1B-C). Os idosos com EP apresentaram alta positividade para $C$. albicans tanto na lesão (88\%) quanto na superfície interna da PTS (92\%). Os idosos usuários de PTS S/ EP tinham porcentagens semelhantes de positividade para $C$. albicans e $C$. tropicalis no palato (15\% em ambos, Figura 1B). Também não foram verificadas diferenças na taxa de positividade de C. albicans (17,5\%), C. tropicalis (15\%) e C. krusei (12\%) nas amostras de PTS dos usuários controles idosos (Figura 1B). C. tropicalis e C. krusei também foram identificadas nas lesões $(31 \%$ e $34,5 \%$, respectivamente) e na PTS $(24,1 \%$ de ambas as espécies) de idosos com EP.

Diferentemente dos resultados relacionados com o grupo de idosos sem EP (Figuras 1B-1C), C. albicans foi o fungo mais isolado de amostras de palato e PTS (70\% em ambos) de indivíduos jovens que não apresentavam a EP (Figura 1C). Outra diferença detectada quando comparamos os dados de ambos os grupos sem EP foi a ausência de detecção de $C$. tropicalis no palato e na PTS dos jovens sem EP (Figura 1C). C. krusei foi identificada a partir das amostras obtidas da lesão ou palato, e superfície interna das PTS dos indivíduos jovens com e sem EP (Figura 1C). 

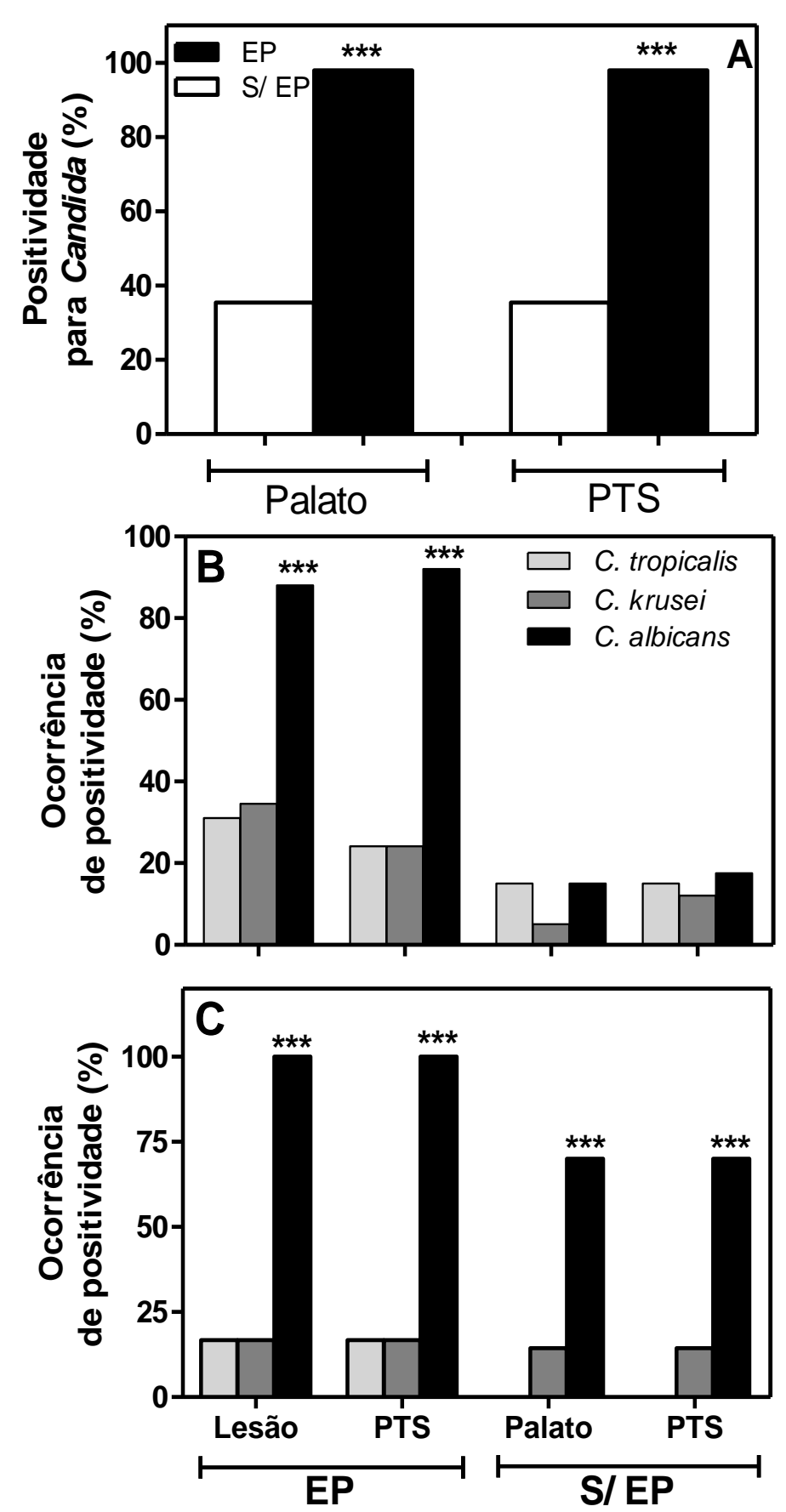

Figura 1. Ocorrência de espécies de Candida em lesão ou palato e prótese total superior na estomatite protética. Material biológico foi coletado de palato e prótese total superior de pacientes usuários de PTS sofrendo (EP, $n=40)$ ou não de estomatite protética (S/ EP, $n=32)$ e semeados em Agar Sabouraud e analisado em 2 dias. (A) Positividade para Candida em amostras totais coletadas.

Espécies de Candida obtidas do palato e da PT de idosos (B) com $(n=25)$ e sem EP $(n=20)$ e jovens $(\mathbf{C})$ com $(n=15)$ e sem EP $(n=12)$ foram determinadas através de CHROMAgar Candida. Os gráficos representam porcentagem de positividade para as espécies de Candida indicadas nas figuras. $* * * P<0,0001$ quando comparadas espécies de Candida dentro do mesmo grupo. $\mathrm{PTS}=$ Prótese total superior 
3. Positividade para Candida dubliniensis em amostras de lesão ou palato e prótese total superior de idosos e jovens com Estomatite Protética (EP).

As amostras coletadas analisadas por PCR, para pesquisa da presença de Candida dubliniensis, evidenciaram que indivíduos jovens bem como idosos, com e sem EP, apresentaram $C$. dubliniensis na superfície interna da PTS e na lesão ou palato. No entanto, porcentagem significantemente maior de pacientes idosos com EP (16\% em ambas as lesões e PTS, Figura 2A) era positiva para $C$. dubliniensis quando comparada com aquela de idosos sem EP $(2,5 \%$ em lesão e PTS, $P<0,001)$. Entre os grupos de jovens com e sem EP, nenhuma diferença foi verificada quando comparadas as positividades em lesão ou palato (25\% e 16\%, respectivamente) e em PTS (22\% - EP e 20\% - S/ EP, Figura 2B). Os resultados demonstraram que todas as amostras positivas para $C$. dubliniensis, a presença de $C$. albicans também foi detectada (dados não mostrados). 

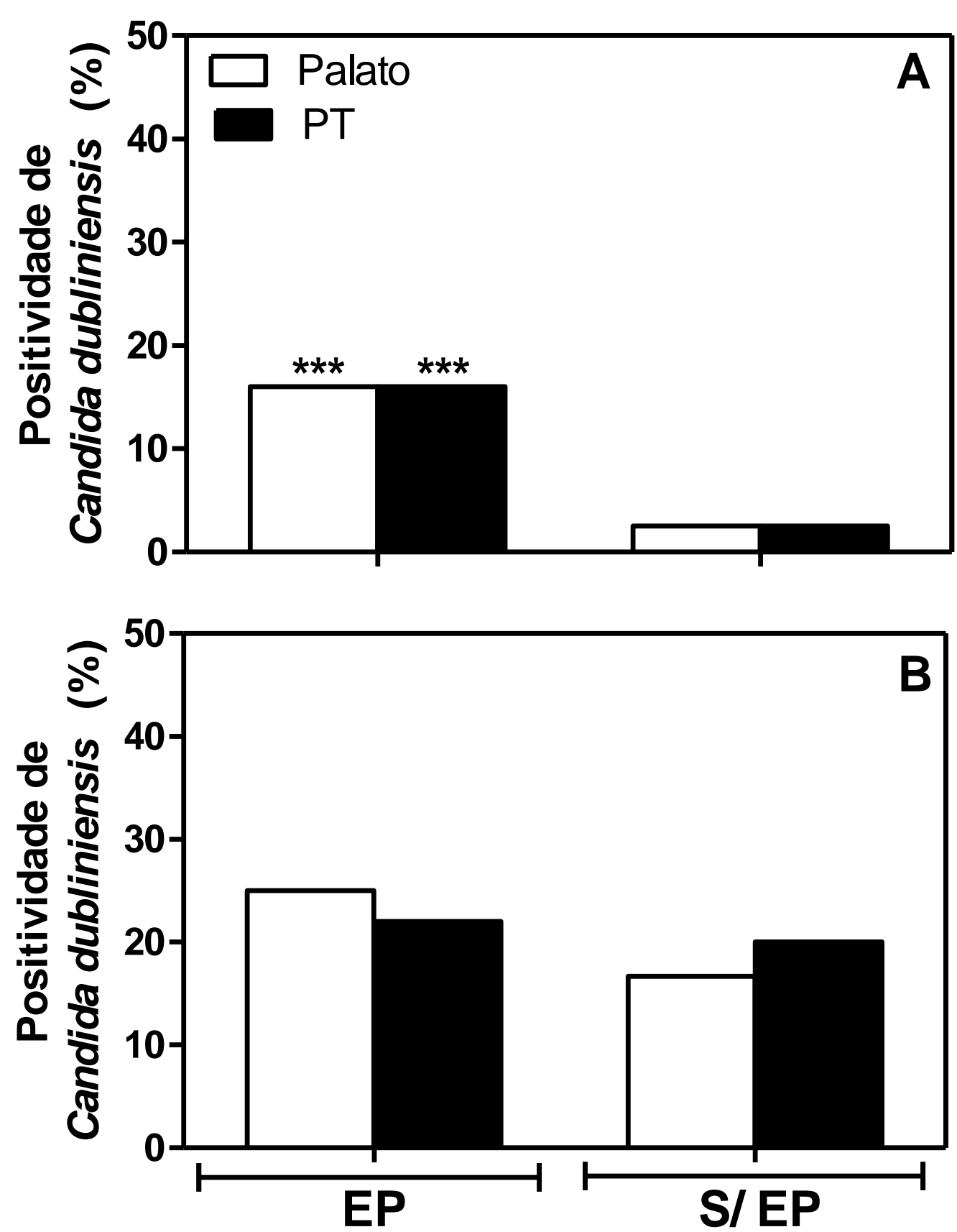

Figura 2. Ocorrência de Candida dubliniensis na estomatite protética. Amostras biológicas foram coletadas da lesão ou palato e prótese total superior de pacientes idosos e jovens usuários de PTS sofrendo (EP, idosos $n=25$ e jovens $n=15$ ) ou não de estomatite protética (S/ EP, idosos $n=20$ e jovens $n=12$ ), semeadas em CHROMAgar Candida e analisadas em 2 dias. As colônias de coloração verde foram obtidas, purificadas e submetidas à reação em cadeia da polimerase. Os gráficos representam porcentagem de positividade para Candida dubliniensis em amostras coletadas de lesão ou palato (colunas abertas) e PTS (colunas fechadas) de (A) idosos e $(\mathbf{B})$ e jovens. $* * * P<0,0001$.quando comparados indivíduos com e sem EP. PTS= Prótese total superior 


\section{DISCUSSÃO}

Muitos estudos relacionam a presença de espécies de Candida nas lesões e/ou na prótese dentária com o estabelecimento e persistência desta doença. A análise das espécies de Candida obtidas das amostras de palato e superfície interna da prótese total superior (PTS) mostrou que $C$. albicans é o microrganismo mais isolado tanto das lesões de estomatite protética (EP) quanto da PTS destes pacientes. Este resultado está de acordo com estudos anteriores (DOREY et al., 1985; FIGUEIRAL et al., 2007; FOUCHE; SLABBERT; COOGAN, 1986; GOLECKA et al., 2006; WEBB et al., 1998). Interessantemente, menor positividade para $C$. albicans foi encontrada nas amostras de indivíduos idosos sem EP do que nos indivíduos jovens do mesmo grupo. Uma possível explicação para este resultado poderia ser o fato de que idosos apresentam declínio nos mecanismos de defesa contra infecções e, no caso de haver presença de $C$. albicans nas próteses, este grupo já desenvolva a doença local (SHANLEY et al., 2009). Esta diferença ainda não havia sido descrita, provavelmente porque os estudos sobre estomatite protética não dividam os pacientes e controles usuários de PTS por faixa etária (BUDTZ-JORGENSEN; STENDERUP; GRABOWSKI, 1975; DOREY et al., 1985; FIGUEIRAL et al., 2007; FOUCHE; SLABBERT; COOGAN, 1986; GOLECKA et al., 2006; MARCOS-ARIAS et al., 2009; WEBB et al., 1998).

C. krusei e C. tropicalis foram detectadas nas amostras de pacientes com EP em amostras obtidas de lesões e de PTS. Diferentes espécies de Candida são detectadas em lesões de EP, associadas ou não com C. albicans, inclusive em casos de recidiva da doença (CROSS et al., 2004; FIGUEIRAL et al., 2007; MARCOS-ARIAS et al., 2009). A associação de diferentes espécies de Candida nas lesões de EP, bem como em PTS, foram verificadas neste estudo (dados não mostrados). Este dado também foi verificado em PTS e palato de indivíduos sem EP (dados não mostrados) no presente trabalho e em estudos anteriores (FIGUEIRAL et al., 2007). Outras espécies de Candida não albicans são isoladas como comensais em humanos saudáveis (FIGUEIRAL et al., 2007; QI; HU; ZHOU, 2005). Estes fatos podem estar relacionados com a habilidade destas espécies de Candida em formar biofilme em superfícies acrílicas, facilitando o contato prolongado com superfícies mucosas subjacentes (HASAN et al., 2009; THEIN; SAMARANAYAKE; SAMARANAYAKE, 2007a, 2007b). Além disso, C. tropicalis pode estar envolvida com infecções orais em 
indivíduos saudáveis visto que esta espécie apresenta atividade enzimática relacionada com virulência (DA COSTA et al., 2009).

A presença de Candida dubliniensis foi constatada em amostras de pacientes com EP e de usuários sem qualquer infecção oral aparente. A presença de C. dubliniensis como constituinte normal da microbiota humana já foi descrita (PONTON et al., 2000) em taxas tão baixas quanto àquelas verificadas nos idosos usuários de PTS sem EP no presente estudo. Apenas entre os grupos de indivíduos idosos houve diferença significante relacionada com a presença da EP. Além de diferenças relacionadas com o avanço da idade, esta diferença pode também estar relacionada com a menor prevalência de $C$. albicans na cavidade oral dos idosos sem estomatite, já que em todos os casos nos quais $C$. dubliniensis foi isolada, ambas as espécies estavam presentes nas amostras (dados não mostrados). Talvez, a oferta de nutrientes e as condições ideais de microambiente necessárias para o metabolismo de ambas as espécies estabeleçam esta associação encontrada neste trabalho (SULLIVAN, D.; COLEMAN, 1997, 1998; SULLIVAN, D.J. et al., 1995).

Entretanto, a relevância de $C$. dubliniensis nas infecções fúngicas orais não pode ser descartada visto que este patógeno é capaz de aderir e formar biofilmes na superfície de materiais acrílicos e de poliestireno como $C$. albicans (RAMAGE et al., 2001). Além disso, a presença de saliva ou películas de soro sanguíneo pode aumentar a aderência inicial de leveduras de $C$. dubliniensis aos biomateriais e subsequente formação de biofilme. Adicionalmente, o tratamento de pacientes com algumas medicações antifúngicas pode gerar a substituição de $C$. albicans por $C$. dubliniensis o que indica resistência deste patógeno a tratamentos convencionais (MARTINEZ et al., 2002). Apesar disso, C. dubliniensis é descrita como sendo muito mais vulnerável a destruição por neutrófilos, células comumente encontrada na saliva de humanos, do que $C$. albicans (VILELA et al., 2002). Assim, a resposta imune local pode controlar mais eficazmente a proliferação deste microrganismo impedindo que se estabeleça quadro infeccioso causado exclusivamente por ele em indivíduos imunocompetentes. 


\section{CONCLUSÃO}

Espécies de Candida estão presentes nas lesões de estomatite protética e na superfície interna de próteses totais superiores em, praticamente, a totalidade dos casos desta doença. $C$. albicans é a espécie mais comum deste fungo, porém outras espécies de Candida podem estar envolvidas no estabelecimento e persistência das lesões. 



\section{REFERÊNCIAS}

Berdicevsky I, Ben-Aryeh H, Szargel R, Gutman D. Oral Candida of asymptomatic denture wearers. Int J Oral Surg. 1980;9(2):113-5.

Budtz-Jorgensen E. Clinical aspects of Candida infection in denture wearers. J Am Dent Assoc. 1978;96(3):474-9.

Budtz-Jorgensen E, Bertram U. Denture stomatitis. I. The etiology in relation to trauma and infection. Acta Odontol Scand. 1970;28(1):71-92.

Budtz-Jorgensen E, Stenderup A, Grabowski M. An epidemiologic study of yeasts in elderly denture wearers. Community Dent Oral Epidemiol. 1975;3(3):115-9.

Cross LJ, Williams DW, Sweeney CP, Jackson MS, Lewis MA, Bagg J. Evaluation of the recurrence of denture stomatitis and Candida colonization in a small group of patients who received itraconazole. Oral Surg Oral Med Oral Pathol Oral Radiol Endod. 2004;97(3):351-8.

da Costa KR, Ferreira JC, Komesu MC, Candido RC. Candida albicans and Candida tropicalis in oral candidosis: quantitative analysis, exoenzyme activity, and antifungal drug sensitivity. Mycopathologia. 2009;167(2):73-9.

Dar-Odeh NS, Shehabi AA. Oral candidosis in patients with removable dentures. Mycoses. 2003;46(5-6):187-91.

Dorey JL, Blasberg B, MacEntee MI, Conklin RJ. Oral mucosal disorders in denture wearers. J Prosthet Dent. 1985;53(2):210-3.

Espinoza I, Rojas R, Aranda W, Gamonal J. Prevalence of oral mucosal lesions in elderly people in Santiago, Chile. J Oral Pathol Med. 2003;32(10):571-5.

Figueiral MH, Azul A, Pinto E, Fonseca PA, Branco FM, Scully C. Denture-related stomatitis: identification of aetiological and predisposing factors - a large cohort. J Oral Rehabil. 2007;34(6):448-55.

Fouche MH, Slabbert JC, Coogan MM. Microorganisms isolated from patients with denture stomatitis. J Dent Assoc S Afr. 1986;41(6):313-6. 
Freitas J, Gomez R, Abreu MD, Ferreira E. Relationship between the use of full dentures and mucosal alterations among elderly Brazilians. J Oral Rehabil. 2008;35(5):370-4.

Golecka M, Oldakowska-Jedynak U, Mierzwinska-Nastalska E, Adamczyk-Sosinska E. Candida-associated denture stomatitis in patients after immunosuppression therapy. Transplant Proc. 2006;38(1):155-6.

Hasan F, Xess I, Wang X, Jain N, Fries BC. Biofilm formation in clinical Candida isolates and its association with virulence. Microbes Infect. 2009;11(8-9):753-61.

Kulak-Ozkan Y, Kazazoglu E, Arikan A. Oral hygiene habits, denture cleanliness, presence of yeasts and stomatitis in elderly people. J Oral Rehabil. 2002;29(3):300-4.

Makihira S, Nikawa H, Nishimura M, Egusa H, Sadamori S, Rahayu RP, et al. Impact of components of denture acrylic resin on gingival cell growth and sensitivity to Candida albicans adhesion. Mycoses. 2002;45(8):300-5.

Marcos-Arias C, Vicente JL, Sahand IH, Eguia A, De-Juan A, Madariaga L, et al. Isolation of Candida dubliniensis in denture stomatitis. Arch Oral Biol. 2009;54(2):127-31.

Martinez M, Lopez-Ribot JL, Kirkpatrick WR, Coco BJ, Bachmann SP, Patterson TF. Replacement of Candida albicans with $C$. dubliniensis in human immunodeficiency virusinfected patients with oropharyngeal candidiasis treated with fluconazole. J Clin Microbiol. 2002;40(9):3135-9.

McElroy TH. Infection in the patient receiving chemotherapy for cancer: oral considerations. J Am Dent Assoc. 1984;109(3):454-6.

Moran GP, Sullivan DJ, Henman MC, McCreary CE, Harrington BJ, Shanley DB, et al. Antifungal drug susceptibilities of oral Candida dubliniensis isolates from human immunodeficiency virus (HIV)-infected and non-HIV-infected subjects and generation of stable fluconazole-resistant derivatives in vitro. Antimicrob Agents Chemother. 1997;41(3):617-23.

Mosca CO, Moragues MD, Brena S, Rosa AC, Ponton J. Isolation of Candida dubliniensis in a teenager with denture stomatitis. Med Oral Patol Oral Cir Bucal. 2005;10(1):28-31; 25-8.

Moura JS, da Silva WJ, Pereira T, Del Bel Cury AA, Rodrigues Garcia RC. Influence of acrylic resin polymerization methods and saliva on the adherence of four Candida species. $\mathrm{J}$ Prosthet Dent. 2006;96(3):205-11. 
Newton A. Denture sore mouth: a possible aetiology. Brit Dent J. 1962;1(112):357-60.

Oliver DE, Shillitoe EJ. Effects of smoking on the prevalence and intraoral distribution of Candida albicans. J Oral Pathol. 1984;13(3):265-70.

Pfaller MA, Houston A, Coffmann S. Application of CHROMagar Candida for rapid screening of clinical specimens for Candida albicans, Candida tropicalis, Candida krusei, and Candida (Torulopsis) glabrata. J Clin Microbiol. 1996;34(1):58-61.

Pereira-Cenci T, Del Bel Cury AA, Crielaard W, Ten Cate JM. Development of Candidaassociated denture stomatitis: new insights.J Appl Oral Sci. 2008 Apr;16(2):86-94. Review.

Pires FR, Santos EB, Bonan PR, De Almeida OP, Lopes MA. Denture stomatitis and salivary Candida in Brazilian edentulous patients. J Oral Rehabil. 2002;29(11):1115-9.

Ponton J, Ruchel R, Clemons KV, Coleman DC, Grillot R, Guarro J, et al. Emerging pathogens. Med Mycol. 2000;38 Suppl 1:225-36.

Qi QG, Hu T, Zhou XD. Frequency, species and molecular characterization of oral Candida in hosts of different age in China. J Oral Pathol Med. 2005;34(6):352-6.

Ramage G, Vande Walle K, Wickes BL, Lopez-Ribot JL. Biofilm formation by Candida dubliniensis. J Clin Microbiol. 2001;39(9):3234-40.

Romeo O, Racco C, Criseo G. Amplification of the hyphal wall protein 1 gene to distinguish Candida albicans from Candida dubliniensis. J Clin Microbiol. 2006;44(7):2590-2.

Sakai VT, Campos MR., Machado MAAM, Lauris JR. P, Greene AS, Santos, CF. Prevalence of four putative periodontopathic bacteria in saliva of a group of Brazilian children with mixed dentition: 1-year longitudinal study. Int J Paediatr Dent 2007; 17, 192-9.

Sahand IH, Moragues MD, Eraso E, Villar-Vidal M, Quindos G, Ponton J. Supplementation of CHROMagar Candida medium with Pal's medium for rapid identification of Candida dubliniensis. J Clin Microbiol. 2005;43(11):5768-70.

Scalercio M, Valente T, Israel MS, Ramos ME. Estomatite protética versus candidíase: diagnóstico e tratamento. RGO. 2007; 55(4): 395-8.

Shanley DP, Aw D, Manley NR, Palmer DB. An evolutionary perspective on the mechanisms of immunosenescence. Trends Immunol. 2009;30(7):374-81. 
Sullivan D, Coleman D. Candida dubliniensis: an emerging opportunistic pathogen. Curr Top Med Mycol. 1997;8(1-2):15-25.

Sullivan D, Coleman D. Candida dubliniensis: characteristics and identification. J Clin Microbiol. 1998;36(2):329-34.

Sullivan DJ, Westerneng TJ, Haynes KA, Bennett DE, Coleman DC. Candida dubliniensis sp. nov.: phenotypic and molecular characterization of a novel species associated with oral candidosis in HIV-infected individuals. Microbiology. 1995;141 ( PTS 7):1507-21.

Thein ZM, Samaranayake YH, Samaranayake LP. Characteristics of dual species Candida biofilms on denture acrylic surfaces. Arch Oral Biol. 2007a;52(12):1200-8.

Thein ZM, Samaranayake YH, Samaranayake LP. In vitro biofilm formation of Candida albicans and non-albicans Candida species under dynamic and anaerobic conditions. Arch Oral Biol. 2007b;52(8):761-7.

Vilela MM, Kamei K, Sano A, Tanaka R, Uno J, Takahashi I, et al. Pathogenicity and virulence of Candida dubliniensis: comparison with $C$. albicans. Med Mycol. 2002;40(3):249-57.

Vitkov L, Krautgartner WD, Hannig M, Weitgasser R, Stoiber W. Candida attachment to oral epithelium. Oral Microbiol Immunol. 2002;17(1):60-4.

Vitkov L, Weitgasser R, Hannig M, Fuchs K, Krautgartner WD. Candida-induced stomatopyrosis and its relation to diabetes mellitus. J Oral Pathol Med. 2003;32(1):46-50.

Webb BC, Thomas CJ, Willcox MD, Harty DW, Knox KW. Candida-associated denture stomatitis. Aetiology and management: a review. Part 2. Oral diseases caused by Candida species. Aust Dent J. 1998;43(3):160-6.

Willinger B, Hillowoth C, Selitsch B, Manafi M. Performance of candida ID, a new chromogenic medium for presumptive identification of Candida species, in comparison to CHROMagar Candida. J Clin Microbiol. 2001;39(10):3793-5. 


\section{CAPÍTULO - II}

\section{Imunossenescência e estomatite protética}

associada à Candida: fenótipo e função de neutrófilos sanguíneos 



\section{RESUMO}

Os neutrófilos são as primeiras células a migrar para sítios de infecção, e desempenham importante papel na defesa contra vários patógenos, especialmente Candida albicans. A função dos neutrófilos envolve fagocitose e destruição de leveduras e formas filamentosas do fungo, além de produção de citocinas e quimiocinas, capazes de ativar outras células relacionadas com a eliminação de C. albicans. Recentemente, tem sido mostrado que estas células apresentam prejuízos com o avanço da idade e estes fenômenos fazem parte de uma área da Imunologia conhecida como Imunossenescência. A estomatite protética é a lesão oral mais verificada em idosos, e a sua persistência é diretamente relacionada com a presença de espécies de Candida, principalmente $C$. albicans, nas lesões ou na superfície interna de próteses, especialmente totais superiores. Com o objetivo de avaliar possíveis alterações sistêmicas em idosos envolvendo neutrófilos sanguíneos que pudessem predispor usuários de prótese total superior à estomatite protética, amostras de sangue de pacientes idosos e jovens com estomatite protética associada à Candida (EPC), bem como de indivíduos controles, foram obtidas; fenótipo, função fagocítica e produção de citocinas e quimiocinas foram analisadas após desafio com C. albicans. Neutrófilos de idosos (com e sem EPC) e jovens com EPC tinham baixa expressão de CD11b, CXCR1 e CD62L, função fagocítica e fungicida diminuída. Além disso, o estudo mostrou que baixa porcentagem de neutrófilos de idosos expressava TLR2. Estas células de idosos secretavam níveis diminuídos de CXCL8 e GMCSF quando estimuladas com $C$. albicans. Neutrófilos de indivíduos com EPC secretaram altos níveis de IL-4 e IL-10 e baixos níveis de GM-CSF quando desafiados com C. albicans, independentemente da idade. Portanto, indivíduos com EPC têm alterações nos neutrófilos e com o avanço da idade, estas alterações são mais intensas, o que pode tornar os idosos mais suscetíveis ou doenças associadas a $C$. albicans. Neutrófilos de pacientes com EPC tendem a responder à $C$. albicans com a produção de citocinas do padrão Th2, o que pode favorecer a instalação e persistência da doença. 



\section{INTRODUÇÃO}

Os neutrófilos são células com alta motilidade que constituem a primeira linha de defesa do sistema imune contra agentes invasores. Estas células foram descritas pela primeira vez na década de 1880, por Elie Metchnikoff, como sendo as primeiras a chegar ao local de infecção (HAMPTON; KETTLE; WINTERBOURN, 1998; SEGAL, 2005). Os neutrófilos são granulócitos produzidos na medula óssea, onde duram até catorze dias e possuem como citocinas ativadoras fator de necrose tumoral (TNF) (sozinho ou combinado a interferon gama (IFN- $\gamma$ ), interleucina 6 (IL-6), fator de crescimento de colônias de granulócitos (GCSF) e o fator estimulador de colônia de macrófagos e granulócitos GM-CSF (VON VIETINGHOFF; LEY, 2008), tendo esta última ação inibitória de morte apoptótica ao lado de TNF-alfa e interleucina 8 (CXCL8 em humanos e CXCL1 em camundongos) (QUENTMEIER et al., 2003). Estas células são rapidamente recrutadas do sangue periférico para os sítios de infecção, onde são capazes de destruir os patógenos pela fagocitose, produção de espécies reativas de oxigênio, ação de peptídeos antimicrobianos e através de armadilhas extracelulares compostas por seu material genético (BRINKMANN; ZYCHLINSKY, 2007; DALE; BOXER; LILES, 2008; NATHAN, 2006).

Os neutrófilos possuem um sistema de enzimas presentes na membrana plasmática e na membrana de seus grânulos conhecido como sistema NADPH-oxidase que direciona um evento da morte por fagocitose conhecido como "burst respiratório" (explosão de consumo de oxigênio), o que representa a geração de intermediários reativos de oxigênio (ROS), entre eles anion superóxido $\left(\mathrm{O}^{-}\right)$, peróxido de hidrogênio $\left(\mathrm{H}_{2} \mathrm{O}_{2}\right)$ e radicais hidroxilas $\left(\mathrm{OH}^{*}\right)$. $\mathrm{ROS}$ são de grande importância na destruição de microrganismos e vão atuar danificando membranas celulares dos patógenos pela peroxidação lipídica, DNA e proteínas. Na fagocitose associada ao "burst respiratório", o oxigênio é convertido em superóxido e peróxido de hidrogênio, e quando há a ação da mieloperoxidase (abundante nos grânulos azurofílicos ou primários), esta enzima catalisa a peroxidação do íon cloro $\left(\mathrm{Cl}^{-}\right)$para formar o ácido hipocloroso. Este ácido pode reagir com aminas primárias ou outros componentes contendo nitrogênio para produzir derivados contendo ligação entre cloro e nitrogênio, e estes compostos são altamente tóxicos para patógenos (NATHAN, 2006; NAUSEEF, 2007). 
A chegada de neutrófilos para o microambiente infeccioso é guiada pela presença de fatores quimioatraentes presentes no local atacado, como restos de tecido celular do hospedeiro, níveis significantes de citocinas e quimiocinas como CXCL8, IL-1 e TNF- $\alpha$ e produtos de microrganismos (HADDAD, 2002; NATHAN, 2006). Ao chegar ao ambiente invadido, os neutrófilos irão desempenhar papel fundamental na defesa contra uma grande gama de microrganismos, prevenindo infecções disseminadas (BRINKMANN; ZYCHLINSKY, 2007; DALE; BOXER; LILES, 2008; NATHAN, 2006; SEGAL, 2005).

Nas últimas décadas, tem sido verificado que estes fagócitos têm a capacidade de produzir quimiocinas e citocinas, indicando uma função imunomodulatória no início da instalação de um quadro infeccioso (CASSATELLA, 1995; CASSATELLA et al., 1992; CASSATELLA; GASPERINI; RUSSO, 1997; CASSATELLA et al., 1995; ETHUIN et al., 2004). Apesar dos neutrófilos constituírem células de vida curta, incapazes de se proliferar, o padrão de citocinas no microambiente onde estas se encontram pode aumentar ou deprimir a sua função e secreção de outras citocinas (BLISS et al., 1999; CASSATELLA, 1995). Estas células são as maiores responsáveis pela produção inicial de citocinas e quimiocinas após a invasão tecidual por patógenos. Assim, neutrófilos produzem citocinas e quimiocinas após o contato com C. albicans, as quais podem atrair e ativar vários tipos celulares e, ultimamente, cooperar na determinação do padrão de resposta imune desempenhado pelos linfócitos $\mathrm{T}$ na resposta imune tardia, relacionadas com proteção ou suscetibilidade a candidoses, entre elas a IL-10 e a IL-12 (MENCACCI et al., 1996; NATHAN, 2006; ROMANI et al., 1996; SCHALLER et al., 2004) (NETEA et al., 2008).

Os neutrófilos são considerados fundamentais na proteção contra infecções fúngicas. Eles são responsáveis pelos principais mecanismos de defesa do hospedeiro contra a candidose disseminada e invasiva (SAUNUS; KAZOULLIS; FARAH, 2008) (KULLBERG et al., 1999). Seu papel em infecções por Candida é evidente, visto que a neutropenia é associada com o estabelecimento de candidose sistêmica, com graves prejuízos ao hospedeiro (KOH et al., 2008; PELTROCHE-LLACSAHUANGA et al., 2003; SHOHAM; LEVITZ, 2005). Além disso, os neutrófilos estão envolvidos diretamente com a defesa contra infecções localizadas causadas por Candida (KOH et al., 2008; SAUNUS; KAZOULLIS; FARAH, 2008; SCHALLER et al., 2004).

Entre as ações antifúngicas dos neutrófilos está a capacidade de matar as pseudo-hifas e hifas, que são as formas invasivas de $C$. albicans, através de mecanismos oxidativos e não 
oxidativos, além de matar blastoconídias de C. albicans intracelularmente, dentro de seus fagolisossomos (URBAN; LOURIDO; ZYCHLINSKY, 2006; URBAN et al., 2006). A habilidade para $C$. albicans estabelecer uma infecção disseminada envolve neutropenia e depressão da imunidade celular adaptativa do hospedeiro, além de persistência no tecido infectado. Estes fatos apontam para a importância tanto da imunidade celular adaptativa quanto à imunidade celular inata no controle das infecções por C. albicans (ROMANI, 2004).

C. albicans é um microrganismo oportunista que coloniza superfícies mucosas de humanos sem causar infecções. A ocorrência de candidose, indicando que o microrganismo passou do estado de comensalismo para o estado patogênico, depende de fatores predisponentes ambientais tais como diabetes, antibioticoterapia e imunodepressão (LEIGH et al., 2001; NIEWERTH; KORTING, 2002). Os mecanismos que compõe a resposta imune são os principais responsáveis pelo controle do estabelecimento de infecção por Candida nas mucosas, inclusive oral (LEIGH et al., 2002). ROS podem também atuar modificando o pH do ambiente e, no caso da Candida, levar a sua morte pela ação conjunta com um pH ácido (BIASOLI et al., 1999; MIMS et al., 1998). A presença de atividade da catalase e da superóxido dismutase em $C$. albicans aponta para um de seus mecanismos de resistência à destruição pelo sistema imune inato (URBAN et al., 2006), justamente evitando a sua eliminação pela atividade da mieloperoxidase, liberada a partir de grânulos primários de neutrófilos.

Os idosos sofrem taxas muito maiores de morbidez e mortalidade causadas por doenças infecciosas do que os adultos jovens (GOMEZ; BOEHMER; KOVACS, 2005). A lesão oral mais comum em pessoas idosas é a estomatite protética (MUJICA; RIVERA; CARRERO, 2008; SHULMAN; RIVERA-HIDALGO; BEACH， 2005) (SAMSON; STRAND; HAUGEJORDEN, 2008), que é uma condição inflamatória que afeta os usuários de próteses removíveis, principalmente totais superiores. Tal condição está associada com a presença de Candida, especialmente $C$. albicans (BARBEAU et al., 2003; FIGUEIRAL et al., 2007).

O envelhecimento é caracterizado por mudanças drásticas no sistema imunológico e o conjunto destas alterações é denominado imunossenescência (GINALDI et al., 2001; LICASTRO et al., 2005). Nesta fase, as células envolvidas com a resposta imune apresentam 
deterioração, facilitando o estabelecimento e exacerbação de infecções e tumores (HAYNES; MAUE, 2009).

Além disso, considerando-se as alterações observadas na imunossenescencia, os neutrófilos tornam-se funcionalmente danificados, principalmente quando desafiados por agentes infecciosos (AW; SILVA; PALMER, 2007; FULOP, T., JR. et al., 1997; PLACKETT et al., 2004; WENISCH et al., 2000). Os neutrófilos de indivíduos idosos apresentam capacidade microbicida diminuída contra $C$. albicans e, também, diminuição significante na produção de ROS (FULOP, T.; FORIS; LEOVEY, 1984; FULOP, T., JR. et al., 1997).

Considerando este contexto, prejuízo em relação ao número ou função dos neutrófilos, nos idosos, poderia resultar em maior suscetibilidade a estomatite protética associada a Candida. O número, fenótipo, função fagocítica e a produção de citocinas e quimiocinas por neutrófilos de indivíduos idosos e jovens, apresentando ou não estomatite protética, foram avaliados após estímulo com C. albicans. 


\section{MATERIAL E MÉTODOS}

\section{CARACTERIZAÇÃO DOS GRUPOS DE ESTUDO}

Os indivíduos foram avaliados e selecionados nas clínicas de graduação e pósgraduação da Disciplina de Prótese do Departamento de Prótese da Faculdade de Odontologia de Bauru da Universidade de São Paulo (FOB - USP). A avaliação clínica dos indivíduos teve a supervisão direta do Prof. Dr. Vinícius Carvalho Porto, do Departamento de Prótese (FOB - USP). Inicialmente, os pacientes e voluntários que participaram da pesquisa responderam uma anamnese direcionada, onde foram registrados dados clínicos sobre a cavidade bucal e seus tecidos e, na presença de estomatite protética, sua aparência clínica detalhada e sintomatologia.

Os voluntários foram informados detalhadamente sobre a pesquisa e seus objetivos, enfatizando a necessidade de coleta de amostras de sangue e de dados sobre sua história médica e sobre a prótese total superior, quando for usuário. As coletas de material biológico e de dados foram realizadas após a concordância do paciente, documentada com a assinatura do termo de consentimento livre e esclarecido, conforme prevê a resolução 196/96 do Conselho Nacional de Saúde. Este projeto de pesquisa foi aprovado pelo Comitê de Ética em Pesquisa, da FOB - USP, desde 30 de novembro de 2005 (ANEXO II).

Os critérios de inclusão e exclusão dos indivíduos foram os mesmos adotados para a análise de espécies de Candida, citados no Capítulo I (página 6).

Os indivíduos selecionados foram divididos em seis grupos, cada grupo com 10 a 20 pacientes, assim constituídos:

- Indivíduos com idade igual ou acima de 60 anos usuários de prótese total superior por no mínimo dois anos: apresentando estomatite protética relacionada à Candida (EPC) ou sem qualquer lesão bucal induzida por microrganismo (S/ EPC); 
- Indivíduos com idade igual ou inferior a 50 anos usuários de prótese total superior por no mínimo dois anos: apresentando estomatite protética relacionada à Candida (EPC) ou sem qualquer lesão bucal induzida por microrganismo (S/ EPC);

- Indivíduos não usuários de próteses totais superiores e sem qualquer lesão bucal induzida por microrganismo (Controle): com idade igual ou acima de 60 anos (Idosos Controles) ou com idade igual ou inferior a 50 anos (Jovens Controles).

As lesões de estomatite protética associadas à Candida foram diagnosticadas clinicamente e por meio de confirmação microbiológica da presença de Candida. Os pacientes com estomatite protética obrigatoriamente não apresentavam outra lesão bucal induzida por microrganismo ou de característica autoimune. Os limites de idade dos voluntários foram estabelecidos baseados nas primeiras alterações de função dos neutrófilos relacionadas a imunossenescência em humanos (WENISCH et al., 2000).

\section{MANIPULAÇÃO DE C. albicans ATCC 10231}

Para as culturas de neutrófilos sanguíneos e os ensaios de fagocitose dos neutrófilos sanguíneos o estímulo foi feito com leveduras de C. albicans ATCC 10231. Duas alçadas deste fungo foram transferidas para um frasco Enlermeyer contendo $10 \mathrm{~mL}$ de caldo Sabouraud Dextrose, mantido a $24^{\circ} \mathrm{C}$ por 24 a 48 horas. Em seguida, o material foi homogeneizado, transferido para um tubo de ensaio e centrifugado a $450 \mathrm{xg} / 6$ minutos $/ 4^{\circ} \mathrm{C}$. O sobrenadante foi dispensado e, no precipitado, será acrescentado $10 \mathrm{~mL}$ de PBS estéril. Após a homogeneização da suspensão, esta foi novamente centrifugada $450 \mathrm{xg} / 6$ minutos $/ 4^{\circ} \mathrm{C}$. O procedimento foi repetido duas vezes. Na última lavagem, o sobrenadante foi desprezado e foi colocado $1 \mathrm{~mL}$ de PBS no tubo. As leveduras foram contadas em Câmara de Neubauer. Foram feitas diluições do fungo em meio de cultura RPMI 1640 nas diferentes concentrações correspondentes a cada ensaio, conforme especificado nos itens subseqüentes. 


\section{COLETA DO SANGUE E SEPARAÇÃO DOS NEUTRÓFILOS}

$10 \mathrm{~mL}$ de sangue venoso de cada indivíduo de todos os grupos mencionados anteriormente foram obtidos com o auxílio de seringa descartável heparinizada estéril. O sangue foi aplicado sobre os gradientes Histopaque 1119 e 1083 (Sigma Aldrich) e centrifugados $460 \mathrm{xg} / 25$ minutos $/ 24^{\circ} \mathrm{C}$. A interface contendo os neutrófilos (segunda banda) foi coletada e lavada duas vezes em meio RPMI 1640 contendo $10 \%$ de soro fetal bovino (SFB). O precipitado foi ressuspenso em meio RPMI 10\% SFB e o número de neutrófilos contado com o auxílio de Câmara de Neubauer. A viabilidade celular foi determinada pela exclusão por marcação com iodeto de propídeo e a concentração ajustada para $1 \times 10^{6}$ células viáveis por $\mathrm{mL}$ de meio de cultura.

\section{FENOTIPAGEM PELA ANÁLISE DA EXPRESSÃO DE MOLÉCULAS DE SUPERFÍCIE}

Os neutrófilos $\left(1 \times 10^{6}\right.$ células $\left./ \mathrm{mL}\right)$ obtidos do sangue dos indivíduos foram lavados duas vezes com PBS e incubados em $100 \mu \mathrm{L}$ de PBS acrescido de $20 \%$ de soro normal de coelho, para bloquear ligações inespecíficas. A seguir, foram acrescentados anticorpos monoclonais contra moléculas humanas anti-CXCR1 (receptor de CXCL8), anti-CD66b (molécula relacionada à sobrevivência de neutrófilos), anti receptor do tipo Toll 2 (TLR2), anti-CD62L (L-selectina), anti-CD64 (receptor de alta afinidade para Fc $\gamma$ ), anti-CD69 (marcador de ativação leucocitária), anti- CD11b (MAC-1) e anti-CD206 (receptor de manose), conjugados a fluorocromos fluoresceína isoticianato (FITC) e ficoeritrina (PE) que emitem luz em diferentes comprimentos de onda (FL1 e FL2, respectivamente). Anticorpos controles (de mesmo isotipo) anti-TNPs, conjugados aos mesmos fluorocromos, foram utilizados para que fossem descontadas as fluorescências emitidas inespecificamente. Após incubação em geladeira, as amostras foram lavadas em PBS-BSA, acrescidas de $300 \mu \mathrm{L}$ de PBS-BSA e analisadas em citômetro de fluxo, utilizando-se o programa "CellQuest". 


\section{ENSAIO DE FAGOCITOSE}

Os neutrófilos sanguíneos obtidos de todos os voluntários foram avaliados quanto à capacidade fagocítica. As células e as leveduras viáveis de C. albicans ATCC 10231 opsonizadas com soro anti-Candida humano foram acomodados na proporção de 1 célula:1 levedura, em microtubos e mantidos por 30 e 120 minutos em incubadora a $37^{\circ} \mathrm{C} / 5 \% \mathrm{CO}_{2}$. Em seguida, os microtubos foram centrifugados a $350 \mathrm{xg} / 10$ minutos e o precipitado foi ressuspenso em PBS ( $\mathrm{pH} 7,2)$ e distribuído em lamínulas de vidro para microscopia tratadas com poli-L-lisina. Os neutrófilos fagocitando ou não as leveduras de C. albicans foram analisados após coloração com laranja de acridina $(0,05 \mathrm{mg} / \mathrm{mL}$ de PBS) e visualizados através de luz ultravioleta em microscópio de fluorescência Axiostar plus HBO 50/AC (Zeiss, Germany). A viabilidade das leveduras dentro dos neutrófilos também foi analisada. A coloração verde das leveduras indicava DNA intacto e a cor laranja indicava DNA fragmentado. Os resultados da atividade fagocítica bem como a viabilidade das leveduras internalizadas foram expressos como a média de porcentagem de neutrófilos contendo ao menos uma levedura pela contagem de 10 campos aleatórios. Todos os ensaios foram preparados e analisados em duplicata.

\section{DOSAGEM DE PRODUÇÃO DE CITOCINAS IN VITRO POR NEUTRÓFILOS SANGUÍNEOS}

Os neutrófilos obtidos do sangue periférico de todos os voluntários foram cultivados para a avaliação da função imunomodulatória contra $C$. albicans. Os neutrófilos foram incubados a $37^{\circ} \mathrm{C}$ em estufa $5 \% \mathrm{CO}_{2}$ e desafiados ou não (controle negativo) in vitro com $C$. albicans ATCC 10231 viável em placas de 24 poços, a uma concentração de 1x10 neutrófilos/mL por poço. Nos poços correspondentes, foram colocados $100 \mu \mathrm{L}$ de suspensões de $1 \times 10^{4}$ leveduras viáveis. De forma semelhante, os neutrófilos foram desafiados com lipopolissacarídeo (LPS) de Escherichia coli $(10 \mathrm{ng} / \mathrm{mL})$ para controle positivo das reações. Após 1, 4 e 18 horas, o conteúdo de cada poço foi aspirado e depositado em microtubos, centrifugados a $450 \mathrm{xg} / 6$ minutos $/ 4^{\circ} \mathrm{C}$; os sobrenadantes serão coletados e congelados a - 
$80^{\circ} \mathrm{C}$ para dosagens de citocinas. A viabilidade das células dos precipitados foi determinada após 1, 4 e 18 horas, através da marcação com anexina V conjugada a FITC e iodeto de propídeo e visualizada por microscópio de fluorescência.

Os sobrenadantes removidos das culturas celulares foram submetidos ao "Enzyme Linked Immunosorbent Assay" (ELISA), sendo avaliadas as seguintes citocinas, com função imunomodulatória: IL-4, IL-10, IL-12, CXCL8, GM-CSF e TNF- $\alpha$. Placas de 96 poços foram sensibilizadas com anticorpo monoclonal primário (captura/ $100 \mu \mathrm{L}$ por poço) diluído em tampão de ligação carbonato/bicarbonato, de acordo com especificações do fabricante. No dia seguinte, as placas foram lavadas quatro vezes com PBS/Tween 20. Os bloqueios dos anticorpos para evitar ligação inespecífica foram feitos com PBS contendo 10\% SFB por 1 hora a temperatura ambiente (Kit OPTSEia, BD Biosciences). As placas foram novamente lavadas com PBS/Tween 20 e as citocinas recombinantes e as amostras obtidas das culturas de neutrófilos foram colocadas nos poços. Após 3 horas de incubação a $37^{\circ} \mathrm{C}$, as placas foram lavadas, os anticorpos secundários biotinilados e a estreptoavidina peroxidase foram diluídos em PBS 10\% SFB e colocados nos poços. Após novas lavagens, a reação foi revelada pela adição tetrametilbenzidina e $\mathrm{H}_{2} \mathrm{O}_{2}$. Após 40 minutos, a reação foi interrompida com $\mathrm{H}_{2} \mathrm{SO}_{4} 4 \mathrm{~N}$, e o resultado lido em leitor de ELISA, a 492nm.

\section{ANÁLISE ESTATÍSTICA.}

Todos os dados, exceto as dosagens de citocinas, foram analisados através do teste de ANOVA e Teste de Tukey. As dosagens de citocinas foram analisadas pelo teste de ANOVA de dois critérios e o teste de Bonferroni. Para verificação de possíveis diferenças entre os grupos analisados, adotou-se o nível de significância igual a 5\%. 



\section{RESULTADOS}

\section{Quantificação e função fagocítica de neutrófilos isolados do sangue.}

Para iniciar todos os experimentos envolvendo neutrófilos de sangue, o número destas células isoladas de cada amostra foi determinado. Os indivíduos com EPC apresentaram número significantemente maior de neutrófilos isolados do sangue periférico, independentemente do grupo etário (Figura 1A). Provavelmente, este resultado reflete a presença da doença local (EPC) nestes indivíduos.

Ao analisarmos a função destas células, demonstramos que neutrófilos sanguíneos de idosos (EPC- 43,4 $\pm 4,1 \%$, S/ EPC- 49,1 \pm 8,5\% e Controle- 49,7 $\pm 6,3 \%$ ) apresentaram menor capacidade fagocítica contra $C$. albicans após 30 minutos em comparação aos grupos correspondentes jovens (Fig. 1B). Após duas horas de ensaio, houve um discreto aumento na atividade fagocítica dos neutrófilos sanguíneos dos indivíduos de todos os grupos avaliados, com exceção dos idosos com $(37,1 \pm 5,1 \%)$ e S/ EPC (46,3 \pm 7,6\%, Figura 1B). Assim, os neutrófilos sanguíneos dos idosos não fagocitaram $C$. albicans com a mesma eficiência que os neutrófilos isolados de jovens, independente da presença de EPC (Figura 1B).

A partir dos ensaios de fagocitose, foi avaliada a viabilidade das leveduras de $C$. albicans ingeridas pelos neutrófilos, através da coloração com laranja de acridina (verde em leveduras com DNA intacto e laranja quando o DNA está fragmentado). Os resultados obtidos mostraram que, após 30 minutos de ensaio fagocítico, a maioria das leveduras ingeridas pelos neutrófilos sanguíneos de todos os indivíduos idosos com (EPC- 70,3 $\pm 3,8 \%$, Figura 1C) e sem estomatite protética (S/ EPC $-59,9 \pm 6,7 \%$ e Controle $-57,9 \pm 5,7 \%$ ) e dos jovens portadores de estomatite protética $(62,2 \pm 5,7 \%)$ permanecia viável (Figura 1C). Após duas horas de ensaio, a viabilidade das leveduras diminuiu consideravelmente em todos os grupos de idosos (Figuras 1C e 2C-2F). Porém, a viabilidade das leveduras foi significativamente menor, após fagocitose por neutrófilos de jovens controles, nos dois tempos avaliados; estes indivíduos tiveram os menores valores de leveduras fagocitadas

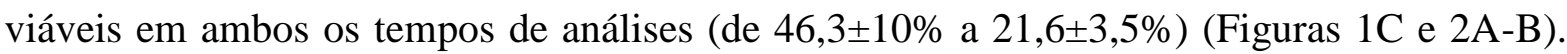
No grupo de jovens com EPC, $48 \pm 3 \%$ das leveduras permaneciam viáveis após duas horas do início do ensaio fagocítico. 

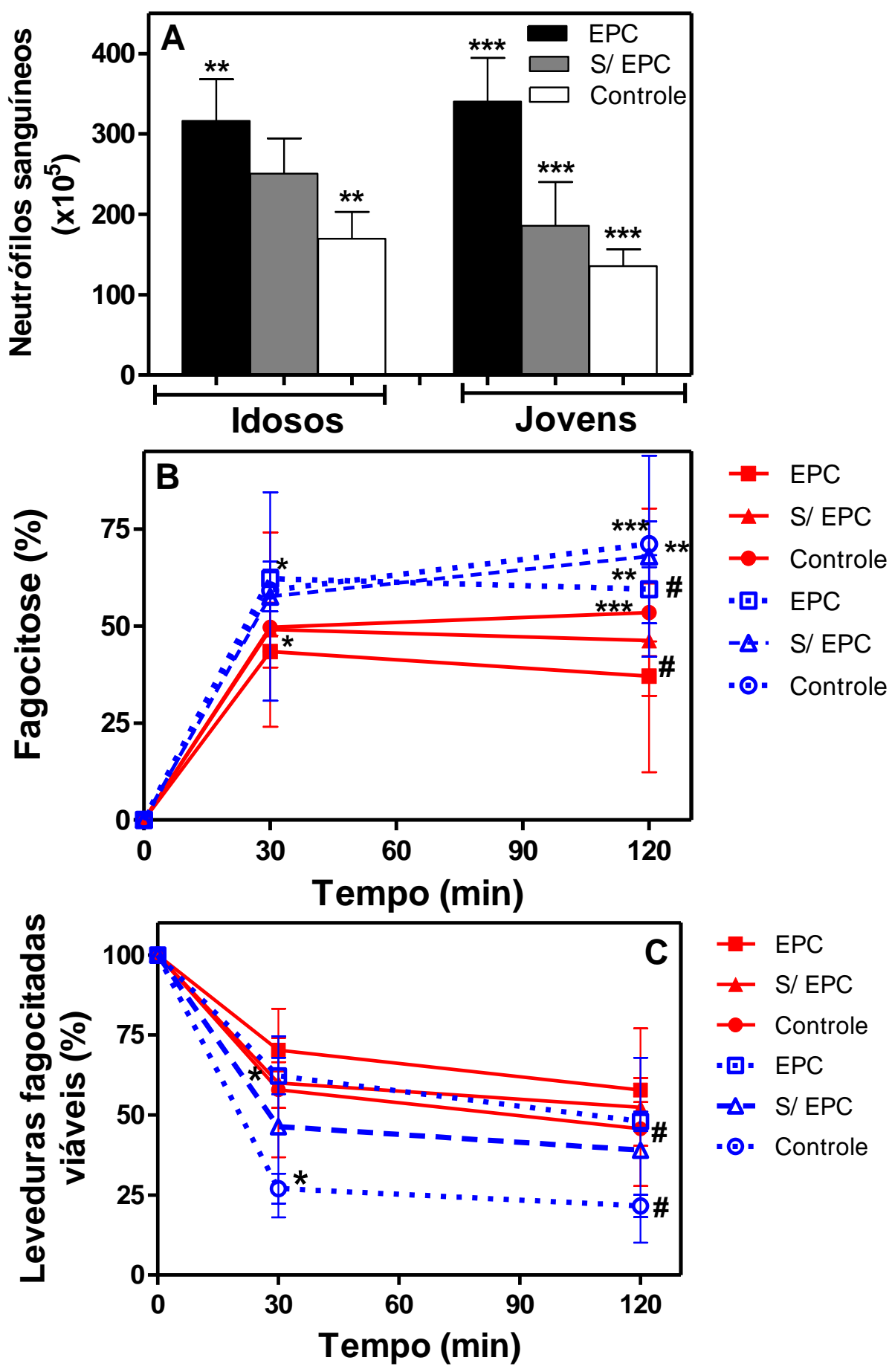

Figura 1. Número e função fagocítica de neutrófilos isolados do sangue periférico. $O$ sangue dos idosos com EPC $(\boldsymbol{\square}, n=25)$, idosos sem EPC e usuários de PTS $(\boldsymbol{\Delta}, n=20)$, idosos não usuários de prótese total $(\bullet, n=15)$, jovens com EPC $(\square, n=14)$, jovens sem DRS e usuários de PTS $(\Delta, n=8)$ e jovens não usuários de prótese total $(\circ, n=20)$ foram coletados e (A) o número absoluto de neutrófilos foi determinado. Neutrófilos viáveis foram incubados com leveduras opsonizadas de C. albicans (1:1) e (B) a fagocitose e (C) viabilidade de leveduras fagocitadas foram determinadas. Os resultados representam a média \pm EPM de indivíduos testados individualmente. Os dados foram analisados pelo teste de Tukey e símbolos iguais diferem estatisticamente, $*$ e \# $P<0,05$, ** e \# $P<0,01$, *** $P<0,001$. PTS $=$ Prótese total superior 


\section{Idosos}

\section{Jovens}

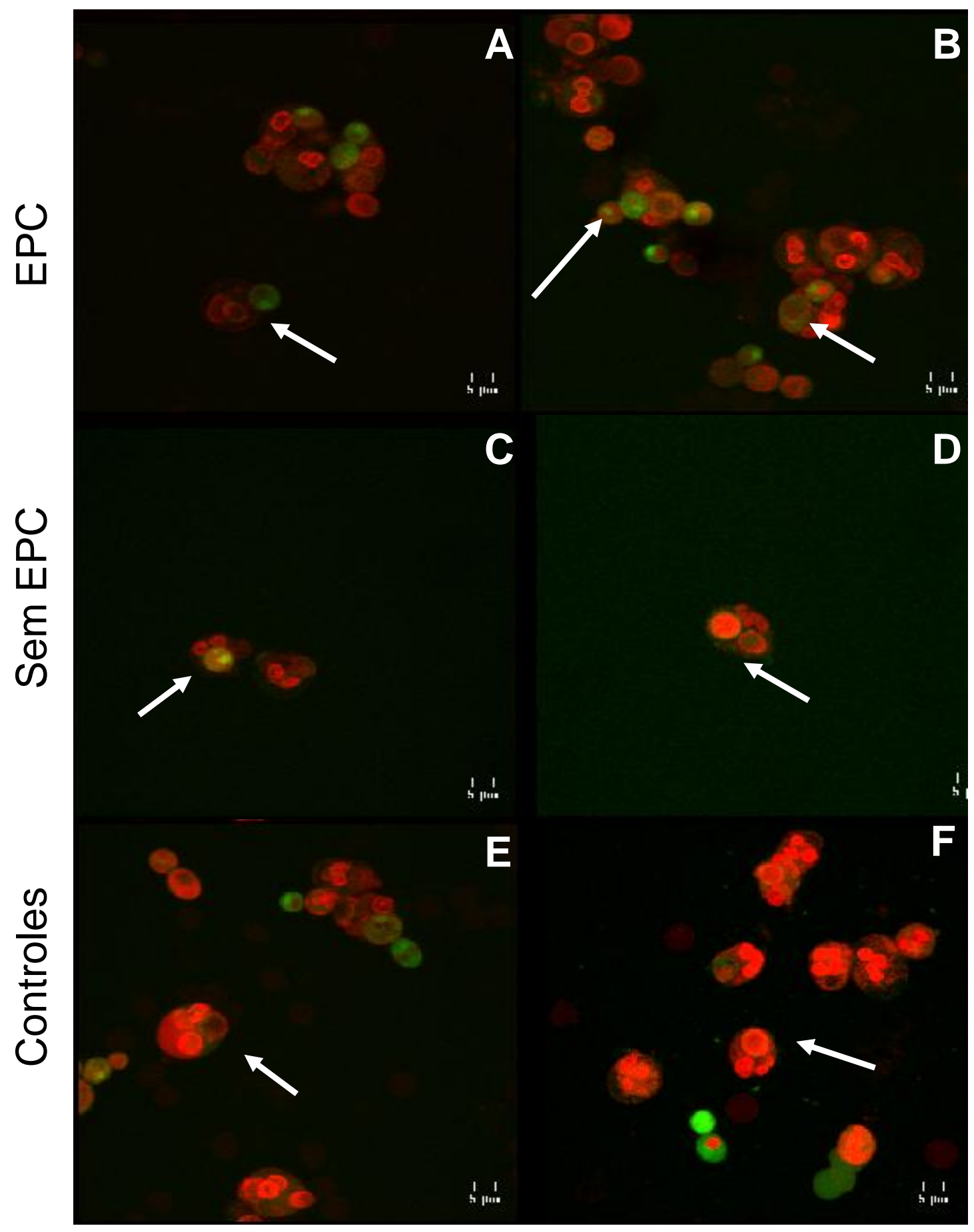

Figura 2. Função fagocítica de neutrófilos isolados do sangue periférico. Neutrófilos isolados do sangue de voluntários com EPC $(\mathrm{A}, n=25)$, idosos sem EPC e usuários de PTS $(\mathrm{C}, n=24)$, idosos não usuários de prótese total $(\mathrm{E}, n=14)$, jovens com $\mathrm{EPC}(\mathrm{B}, n=14)$, jovens sem EPC e usuários de PTS $(\mathrm{D}, n=8)$ e jovens não usuários de prótese total $(\mathrm{F}, n=20)$ foram coletados e (A - F) incubados com leveduras opsonizadas de $C$. albicans ATCC 10231 por 30 min e $2 \mathrm{~h}$. As setas indicam leveduras viáveis (verde) e mortas (laranja) dentro dos neutrófilos. PTS $=$ Prótese total superior 


\section{Expressão de moléculas por neutrófilos sanguíneos, envolvidas na resposta imune contra microrganismos.}

A porcentagem de expressão das moléculas CXCR1, CD62L, CD206, CD69, CD64, CD11b, CD66b e TLR2 em neutrófilos sanguíneos dos indivíduos com e sem EPC, além da análise da intensidade de expressão, foram determinadas.

Não houve qualquer diferença significante entre os grupos estudados quanto ao total de neutrófilos expressando CXCR1, CD206, CD69, CD64, CD11b e CD66b (Figuras 3A, $3 \mathrm{C}-\mathrm{G})$.

Menores porcentagens de neutrófilos expressando CD62L foram obtidas do sangue dos grupos idosos, independente da presença da EPC (Figura 3B). Essas diferenças foram estatisticamente significantes quando comparados idosos com e sem EPC e os grupos correspondentes jovens (Figura 3B). Ainda, os resultados mostraram que quantidades significantemente menores de neutrófilos expressavam TLR2 no sangue de idosos, independente da EPC (Figura 3H).

Quando a intensidade de expressão das moléculas foi analisada, os resultados mostraram que a expressão de CXCR1 estava significantemente diminuída em neutrófilos de todos os grupos de indivíduos idosos e nos jovens com EPC (Figura 4A). Além disso, os neutrófilos sanguíneos destes mesmos grupos de indivíduos também tinham expressão diminuída de CD62L e CD11b (Figuras 4B e 4G). Estes dados mostram que a expressão de CXCR1, CD62L e CD11b é menor nas células de idosos em comparação com jovens de grupos correspondentes. No entanto, a expressão diminuída destas moléculas foi identificada também nos grupos de jovens indivíduos com EPC (Figuras 4A-4B e 4G).

Maior expressão de CD206 e CD69 foi identificada em neutrófilos do sangue de idosos com EPC $(P<0,05)$ em comparação com os grupos de idosos sem a doença (Figuras 4C-4D). No entanto, esta diferença não foi estatisticamente significante.

Por outro lado, os resultados obtidos evidenciaram que a expressão de CD64 ocorreu em maior quantidade apenas no grupo de indivíduos jovens com EPC (Figura 4E). 
A análise de CD66b foi determinada e os resultados mostraram que não houve diferença significante na expressão desta molécula pelos neutrófilos do sangue entre todos os grupos avaliados (Figura 4F).

O receptor de padrões moleculares associados aos patógenos TLR2 foi avaliado. Nossos resultados demonstraram que a intensidade de expressão de TLR2 por neutrófilos do sangue foi semelhante em todos os grupos analisados (Figura $4 \mathrm{H}$ ). 

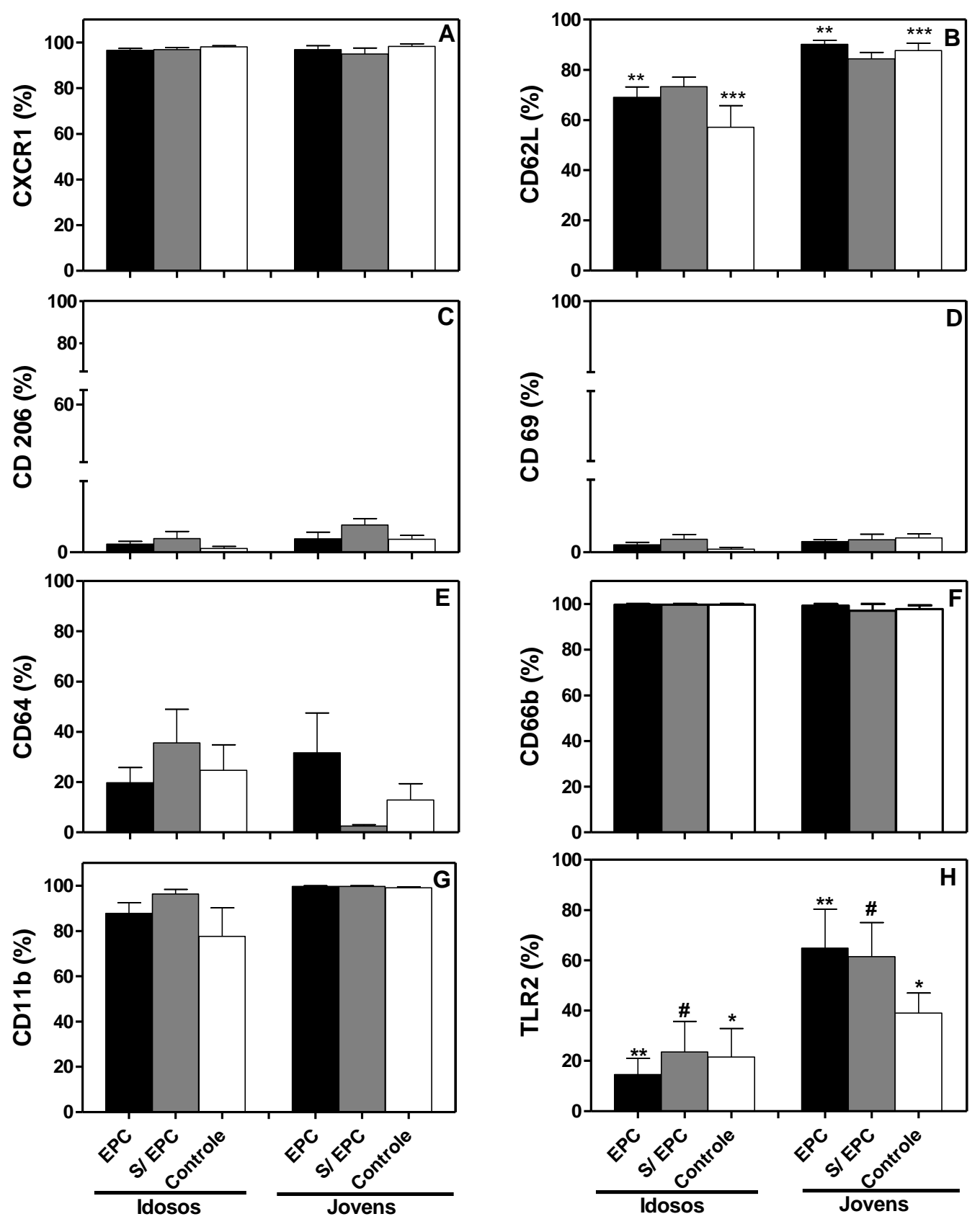

Figura 3. Análise do fenótipo de neutrófilos do sangue periférico. Leucócitos polimorfonucleares obtidos do sangue periférico de voluntários idosos com EPC $(n=10$, colunas fechadas), idosos usuários de PTS sem EPC $(n=10$, colunas cinza), idosos não usuários de PTS ( $n=10$, colunas abertas), jovens usuários com EPC ( $n=10$, colunas fechadas), jovens sem EPC e usuários de PTS ( $n=7$, colunas cinza) e jovens não usuários de prótese total ( $n=10$, colunas abertas) foram purificados e a porcentagem destas células expressando CXCR1 (A), CD62L (B), CD206 (C), CD69 (D), CD64 (E), CD11b (G) e TLR2 (H) foi determinada por citometria de fluxo (A- H). As barras representam os valores da média \pm EPM da porcentagem de neutrófilos positivos para cada molécula. Os dados foram analisados pelo teste ANOVA e Tukey e símbolos iguais diferem estatisticamente $\mathrm{e}^{*} \mathrm{e}$ \# $P<0,05, * * P<0,01, * * * P<0,001$. PTS= Prótese total superior 

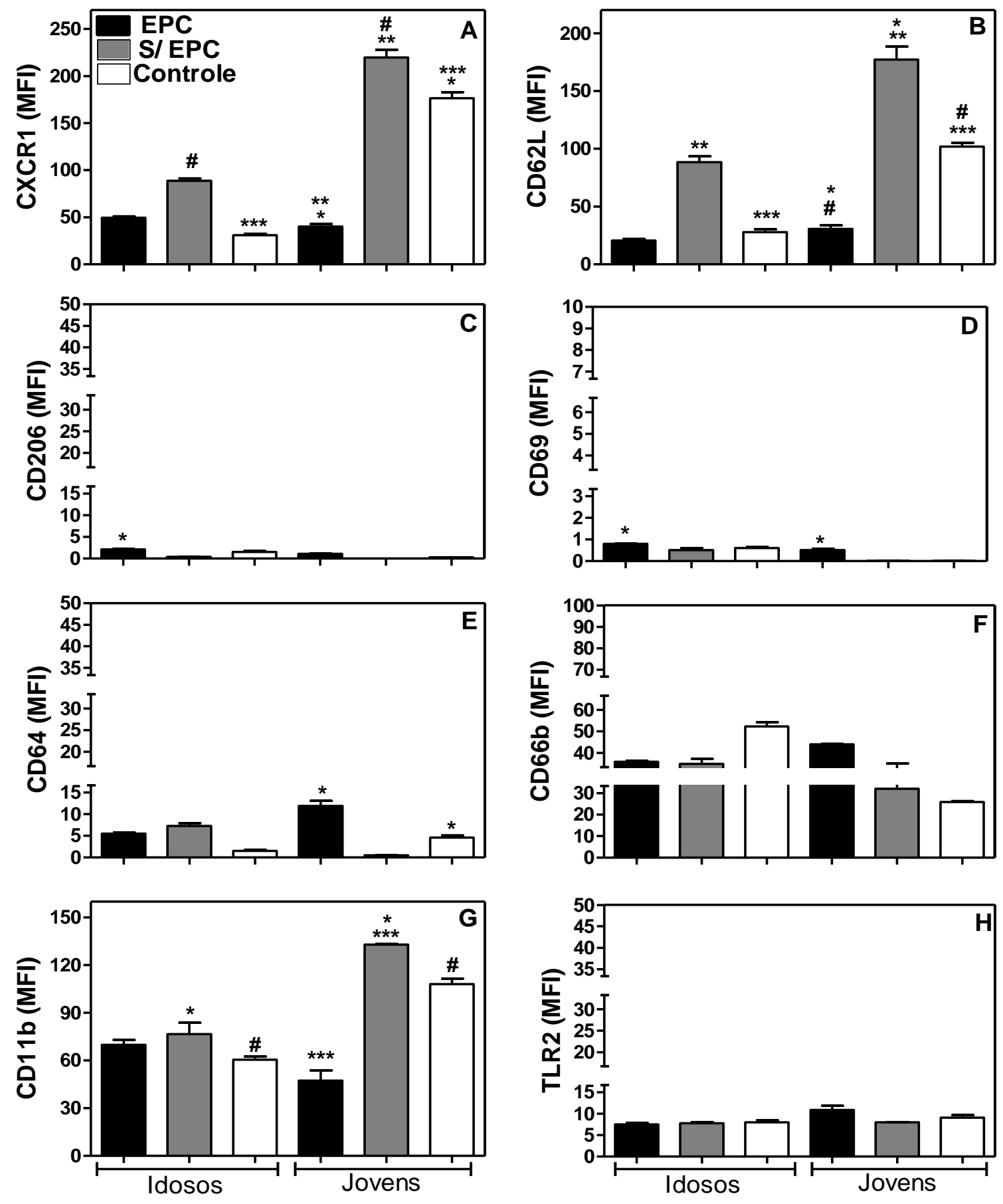

Figura 4. Análise da média de intensidade de fluorescência de receptores de membrana de neutrófilos do sangue periférico. Leucócitos polimorfonucleares obtidos do sangue periférico de voluntários idosos e jovens com EPC (colunas fechadas), idosos e jovens usuários de PTS sem EPC (colunas cinza), idosos e jovens não usuários de prótese total (colunas abertas), foram avaliados quanto a expressão de CXCR1, CD62L, CD206, CD69, CD64, CD11b e TLR2 por citometria de fluxo (A- H). As barras representam os valores da média \pm EPM da porcentagem de neutrófilos positivos para cada molécula. Os dados foram analisados pelo teste de Tukey e símbolos iguais diferem estatisticamente, * e \# $P<0,05$, $* * P<0,01, * * * P<0,001$. PTS $=$ Prótese total superior 


\section{Dosagem de citocinas IL4, IL-10, IL-12, TNF-alfa, CXCL8 e GM-CSF.}

\subsection{IL-4 e IL-10}

Os resultados obtidos demonstraram que, embora fossem verificadas diferenças após 1 hora de cultura, os neutrófilos de indivíduos de todos os grupos analisados secretaram níveis estatisticamente semelhantes de IL-4 (Figura 5A).

Após 4 horas de cultura a detecção de IL-4 nas culturas de neutrófilos desafiados com C. albicans diminuiu em todos os grupos de indivíduos sem EPC (Figura 5A). Estes valores se mantiveram baixos em 18 horas de cultura (Figura 5A).

Os neutrófilos de pacientes com EPC, tanto idosos quanto jovens, produziram níveis significantemente mais altos de IL-4, quando estimulados com C. albicans em 4 e 18 horas de cultura (Figura 5A). Entretanto, esta produção não era diferente entre os grupos na ausência de estímulo (Meio, Figura 5A), indicando que estas diferenças estavam relacionadas com o estímulo com o patógeno e não com produção espontânea de IL-4 pelos neutrófilos. Embora neutrófilos de jovens com EPC estimulados com LPS tenham secretado altos níveis desta citocina após 18 horas, a produção de IL-4 por neutrófilos dos pacientes com EPC geralmente foi mais elevada após o contato com C. albicans do que com LPS (Figura 5A).

A dosagem de IL-10 nas culturas de neutrófilos mostrou que idosos sem EPC, usuários ou não de PTS, produziram maiores níveis desta citocina do que as células dos grupos jovens correspondentes, quando desafiados com C. albicans por 1 hora (Figura 5B). Este dado também se repetiu quando se comparou o grupo de jovens com EPC com ambos os grupos controles jovens usuários ou não de PTS sem EPC.

Porém, os neutrófilos do sangue dos idosos produziam a mesma quantidade da citocina em 4 horas de estímulo com C. albicans, independentemente da EPC (Figura 5B). Estes níveis de IL-10 foram estatisticamente diferentes quando comparados com aqueles das culturas de neutrófilos de jovens sem EPC (Figura 5B). Porém, neutrófilos do grupo de jovens com EPC também secretaram mais IL-10 do que jovens sem EPC. Após 18 horas de contato com o fungo, os níveis de IL-10 eram mais elevados apenas nas culturas de 
neutrófilos estimulados de pacientes com EPC, independentemente da faixa etária dos pacientes analisados (Figura 5B). Quando as células de idosos e jovens com EPC foram estimuladas com LPS foi detectado aumento nos níveis de IL-10; porém, a resultante foi inferior a aquela verificada com estímulo por C. albicans (Figura 5B). 

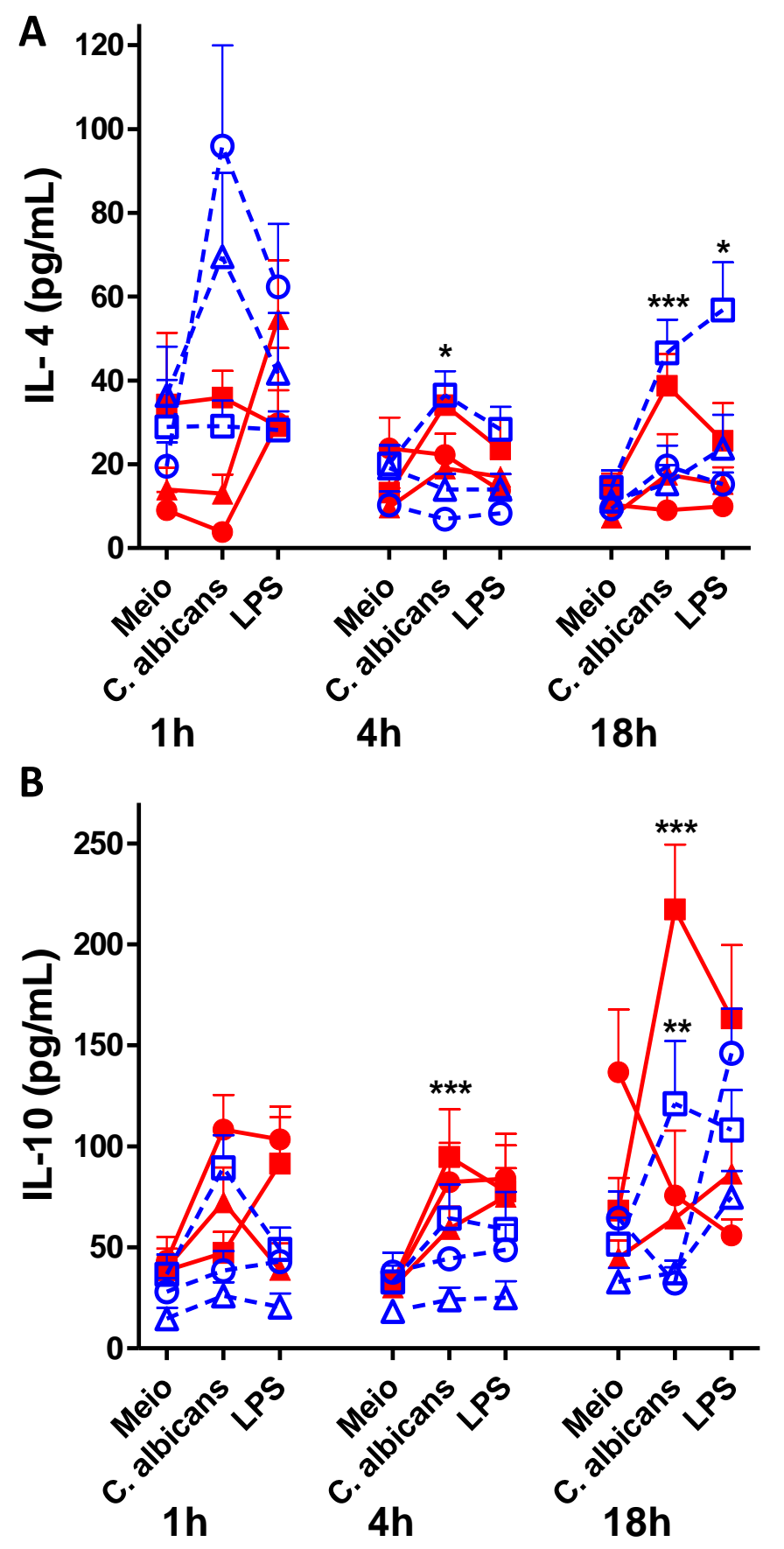

$$
\begin{aligned}
& - \text { Idosos EPC } \\
& - \text { Idosos S/ EPC } \\
& - \text { - Idosos Controles } \\
& -\square \cdot \text { Jovens EPC } \\
& -\triangle \cdot \text { Jovens S/ EPC } \\
& -\Theta \cdot \text { Jovens Controles }
\end{aligned}
$$

t- Idosos EPC

- Idosos S/ EPC

$\rightarrow$ Idosos Controles

-曰. Jovens EPC

$-\triangle$. Jovens S/ EPC

$\odot$. Jovens Controles

Figura 5. Dosagem de citocinas IL-4 e IL-10. Os neutrófilos do sangue periférico de idosos e jovens com EPC $(\boldsymbol{\square}, n=25$ e $\square, \mathrm{n}=14)$, idosos e jovens sem EPC usuários de PTS ( $\boldsymbol{\Delta} n=$ 24 e $\Delta, n=7)$, idosos e jovens não usuários de prótese total $(\bullet, n=15$ e $\circ, n=20)$, foram purificados e $1 \times 10^{6}$ desafiados in vitro ou não com leveduras de Candida albicans ATCC 10231 (100:1) ou LPS (10 ng/mL). Após $1 \mathrm{~h}, 4 \mathrm{~h}$ e $18 \mathrm{~h}$, o sobrenadante foi coletado e as dosagens de IL-4 (A) e IL-10 (B) foram avaliadas por ELISA. Os resultados representam a média da produção da citocina \pm EPM na ausência e presença de $C$. albicans testada individualmente em triplicata. Os dados foram analisados pelo teste ANOVA a dois critérios e teste de Bonferroni, $* P<0,05, * * P<0,01$ e $* * * P<0,001$, quando comparados grupos EPC e seus respectivos controles. $\mathrm{PTS}=$ Prótese total superior 


\subsection{IL-12 e TNF- $\alpha$}

A dosagem de IL-12 evidenciou maior produção pelos neutrófilos de jovens usuários de PTS sem EPC em comparação com seus correspondentes idosos e também com jovens com EPC após 1 hora de cultura com C. albicans (Figura 6A). Em 4 horas de estímulo com C. albicans, o nível de IL-12 foi mais alto apenas no grupo de idosos sem EPC usuários de PTS quando comparados aos seus correspondentes jovens e aos idosos com EPC (Figura 6A). Após 18 horas, os resultados mostram que neutrófilos de idosos com EPC secretaram mais IL-12 do que seus correspondentes jovens (Figura 6A). Porém, esta diferença foi significante apenas quando comparados os grupos de idosos sem EPC com idosos com EPC $(P<0,01)$.

A análise da produção de TNF- $\alpha$ mostra que nenhuma diferença foi detectada entre todos os grupos analisados em 1, 4 e 18 horas de cultura de neutrófilos estimulados ou não com C. albicans (Figura 6B). Embora os neutrófilos sistêmicos de todos os grupos não tenham produzido níveis significantes de TNF- $\alpha$ após contato com o fungo, o estímulo com LPS induziu secreção mais alta desta citocina, especialmente nas culturas de neutrófilos de jovens com e sem EPC no tempo de $18 \mathrm{~h}(P<0.01$, Figura 6B). 

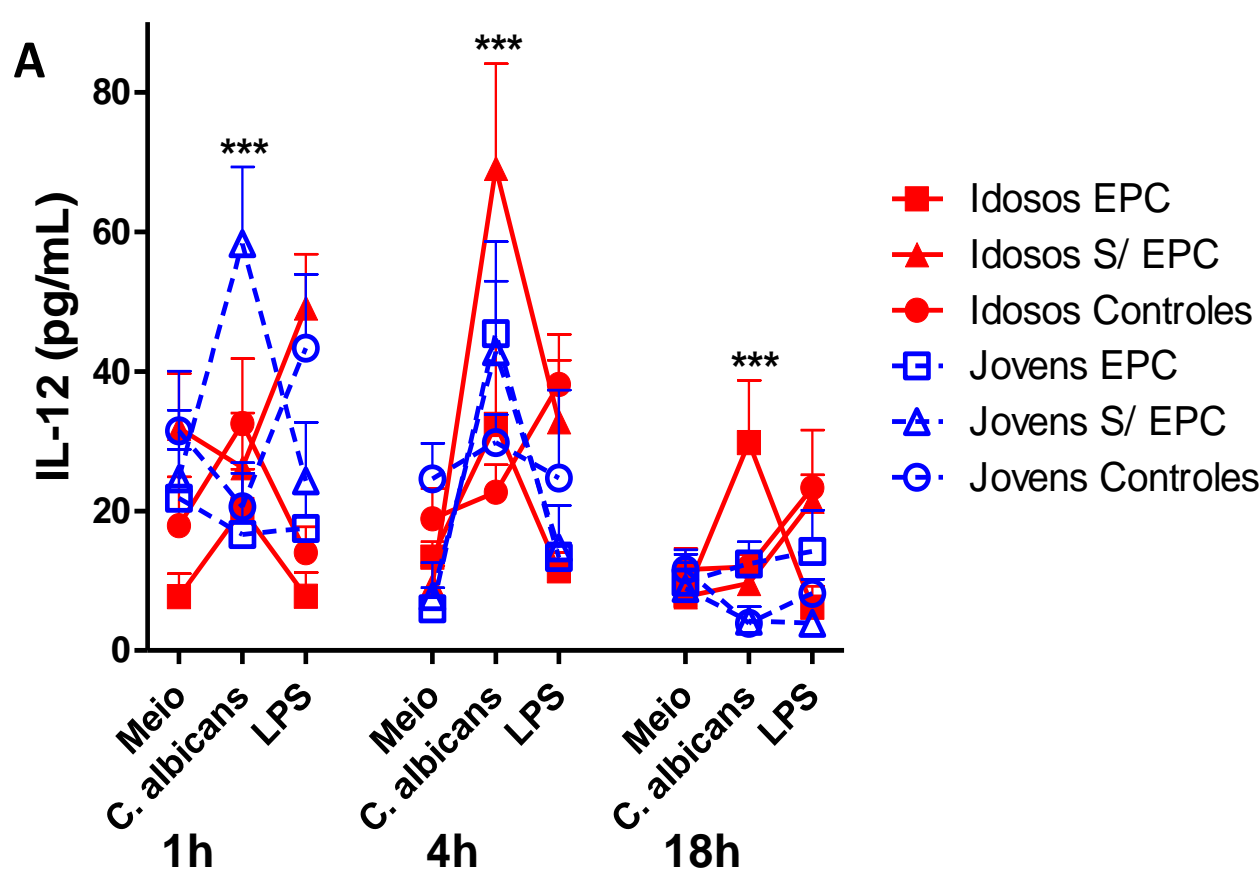

B

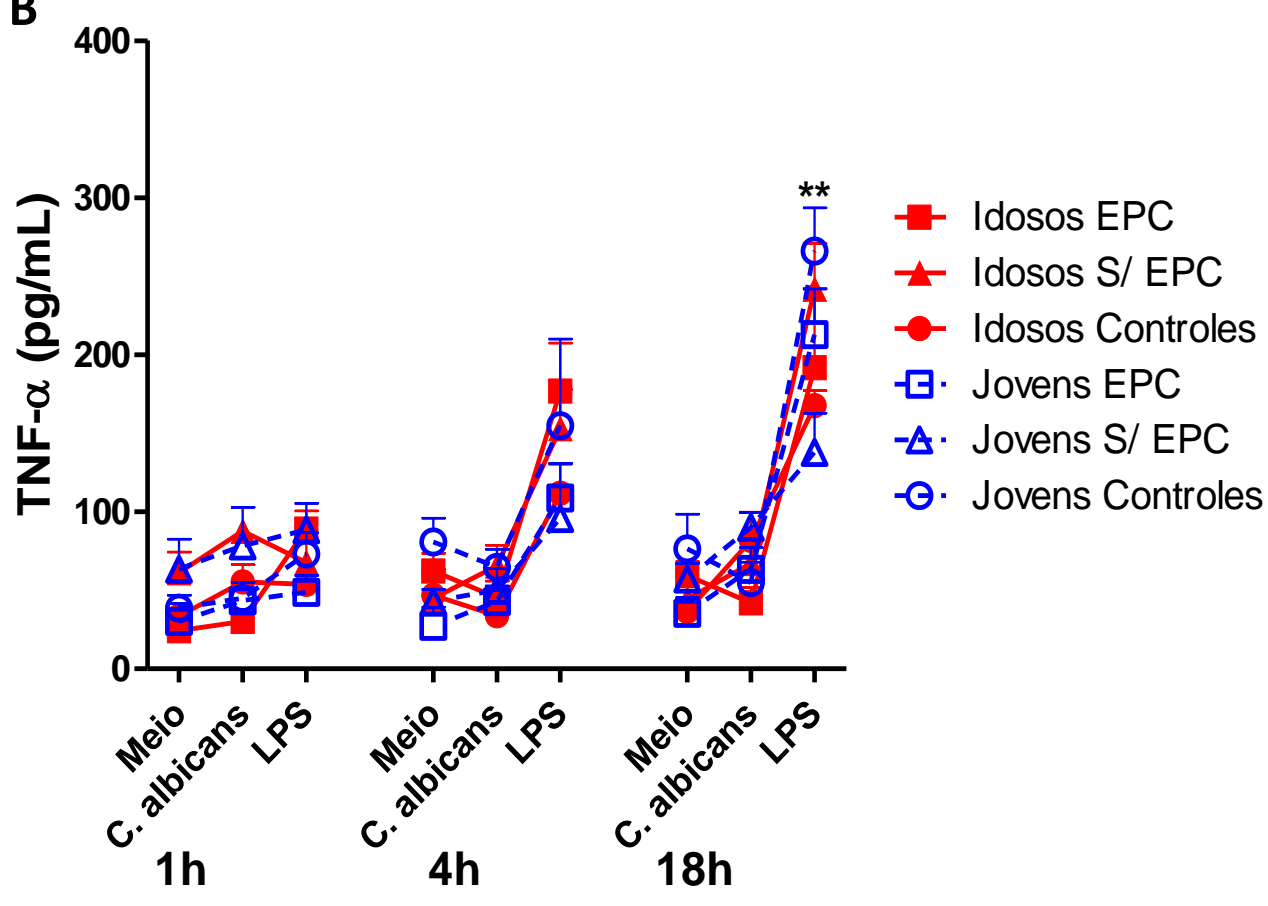

Figura 6. Dosagem de citocinas IL-12 e TNF- $\alpha$. Os neutrófilos do sangue periférico de idosos e jovens com EPC $(\boldsymbol{\square}, n=25$ e $\square, \mathrm{n}=14)$, idosos e jovens sem EPC usuários de PTS $(\boldsymbol{\Delta} n=24$ e $\Delta, n=7)$, idosos e jovens não usuários de prótese total $(\bullet, n=15$ e $\circ, n=20$ ), foram purificados e $1 \times 10^{6}$ desafiados in vitro ou não com leveduras de Candida albicans ATCC 10231 (100:1) ou LPS (10 ng/mL). Após 1h, 4 h e 18h, o sobrenadante foi coletado e a dosagem de IL-12 (A) e TNF- $\boldsymbol{\alpha}$ (B) foi avaliada por ELISA. Os resultados representam a média da produção da citocina \pm EPM na ausência e presença de $C$. albicans testada individualmente em triplicata. Os dados foram analisados pelo teste ANOVA a dois critérios e teste de Bonferroni e $* * P<0,01$ e $* * * P<0,001$ quando comparados grupos EPC e seus respectivos controles. $\mathrm{PTS}=$ Prótese total superior 


\subsection{CXCL8 e GM-CSF}

A produção de CXCL8 pelos neutrófilos, espontânea ou frente ao estímulo com $C$. albicans, aumentou em função do tempo em todos os grupos analisados (Figuras 7A).

Os níveis de CXCL8 foram mais baixos nas culturas de neutrófilos de pacientes com EPC tanto idosos quanto jovens após 4 horas de desafio com C. albicans (Figura 7A). É muito interessante observar que os neutrófilos dos pacientes com EPC mantiveram a mesma secreção de CXCL8 tanto na presença quanto na ausência de C. albicans (Figura 7A). Ao analisar o grupo de idosos usuários de PTS sem EPC foi verificado um aumento significante na produção de CXCL8 em 4 horas de estímulo com C. albicans ou com LPS. Estes valores se mantiveram semelhantes quando comparados com aqueles detectados após 18 horas de cultura com C. albicans ou com LPS (Figura 7A). Porém, em 18 horas de estímulo os níveis se elevaram, havendo aumento na detecção de CXCL8 na presença de C. albicans em todos os outros grupos (Figura 7A). Entretanto, este aumento detectado nas culturas de neutrófilos de idosos foi significantemente menor do que nos grupos jovens correspondentes.

A análise da produção de GM-CSF mostrou que os neutrófilos de jovens usuários ou não de PTS sem EPC secretaram significantemente maiores taxas deste fator de crescimento quando estimulados com $C$. albicans ou LPS por 1 e 4 horas, quando comparados com grupos correspondentes idosos ou com jovens com EPC (Figura 7B). Esta diferença significante ainda foi detectada entre jovens usuários de PTS sem EPC em 18 horas de cultura de neutrófilos com C. albicans ou LPS (Figura 7B).

De uma maneira geral, os neutrófilos do sangue periférico de indivíduos idosos de todos os grupos analisados produziram menor quantidade de GM-CSF, de maneira independente da EPC (Figura 7B). Além disso, os dados mostram que a produção deste fator de crescimento e sobrevivência de neutrófilos, na presença de ambos os tipos de estímulo, se mantinha semelhante à produção basal (Meio). Isto evidencia que mesmo ativadas, estas células de idosos não responderam produzindo GM-CSF, ao menos até 18 horas. 


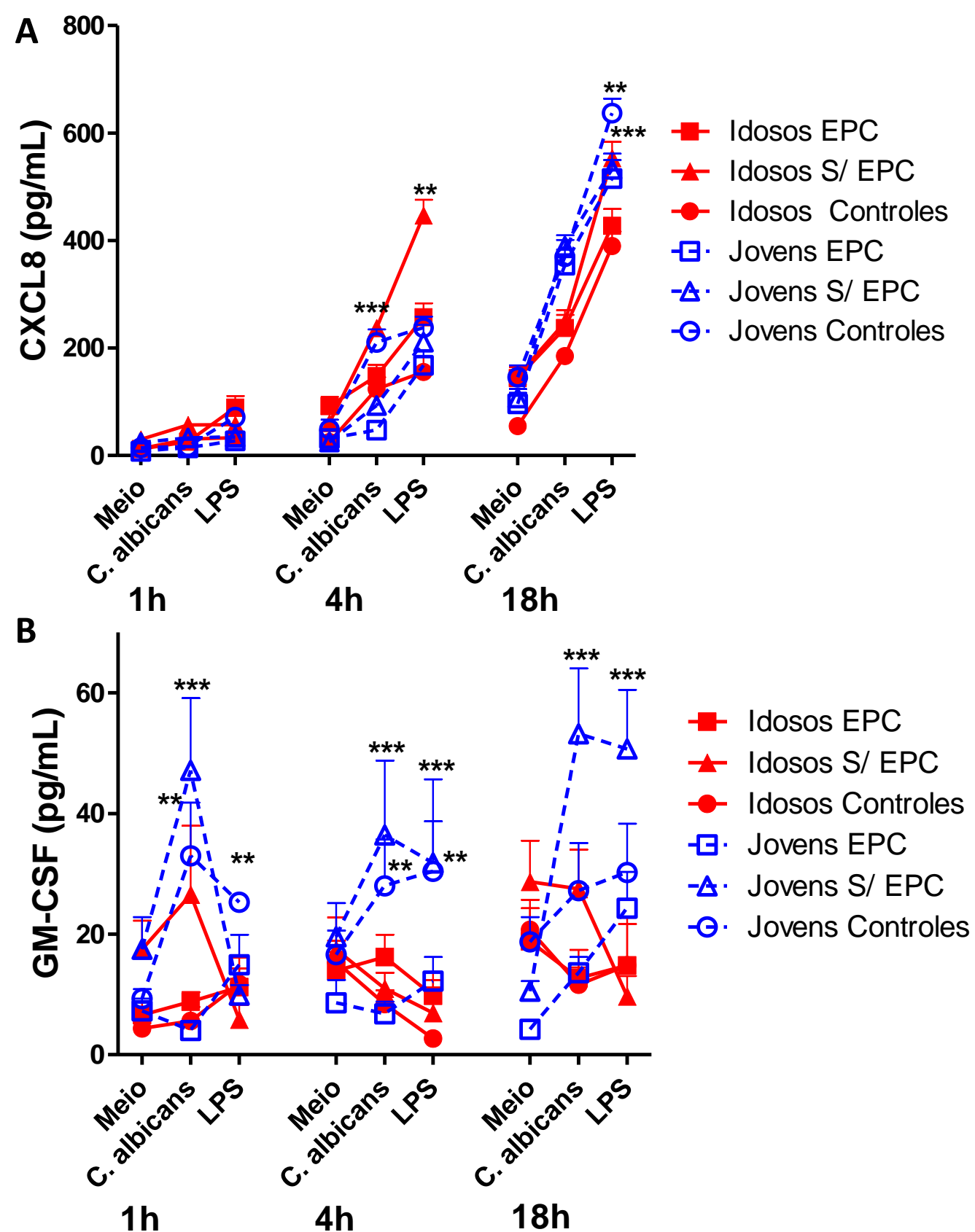

Figura 7. Dosagem de citocinas CXCL8 e GM-CSF. Os neutrófilos do sangue periférico de idosos e jovens com EPC $(\square, n=25$ e $\square, \mathrm{n}=14)$, idosos e jovens sem EPC usuários de PTS $(\boldsymbol{\Delta} n=24$ e $\Delta, n=7)$, idosos e jovens não usuários de prótese total $(\bullet, n=15 \mathrm{e} \circ, n=20)$, foram purificados e $1 \times 10^{6}$ desafiados in vitro ou não com leveduras de Candida albicans ATCC 10231 (100:1) ou LPS (10 ng/mL). Após 1h, 4 h e 18h, o sobrenadante foi coletado e a dosagem de CXCL8 (A) e GM-CSF (B) foi avaliada por ELISA. Os resultados representam a média da produção da citocina \pm EPM na ausência e presença de $C$. albicans testada individualmente em triplicata. Os dados foram analisados pelo teste ANOVA a dois critérios e teste de Bonferroni e $* * P<0,01 \mathrm{e}^{* * *} P<0,001$ quando comparados grupos EPC e seus respectivos controles ou idosos e jovens de grupos correspondentes. PTS= Prótese total superior 



\section{DISCUSSÃO}

Neste trabalho, objetivou-se avaliar o número e a função de neutrófilos do sangue periférico de indivíduos idosos e jovens apresentando ou não EPC. Embora na EPC não haja invasão tecidual profunda com disseminação fúngica em indivíduos imunocompetentes, os dados mostraram que os pacientes com EPC apresentavam número significantemente maior de neutrófilos na corrente sanguínea do que os grupos controles de idade correspondente. Entretanto, estas células tinham funções fagocítica e microbicida diminuídas frente à $C$. albicans. A capacidade fungicida atenuada foi verificada também nos neutrófilos sanguíneos dos indivíduos idosos sem EPC. Estes resultados demonstram que a defesa contra C. albicans pelos neutrófilos está afetada em indivíduos com EPC, e que o avanço da idade pode tornar estas células menos eficazes na eliminação de $C$. albicans, refletindo fenômenos conhecidos da Imunossenescência (PANDA et al., 2009; SHANLEY et al., 2009). Segundo alguns autores, o comprometimento da capacidade fagocítica pode ocorrer devido à interação ineficiente entre receptores de superfície dos neutrófilos e o patógeno (BUTCHER, S.; CHAHEL; LORD, 2000; BUTCHER, S.K. et al., 2001; WENISCH et al., 2000).

Assim, possíveis alterações na expressão de moléculas poderiam estar envolvidas com a diminuição de fagocitose e da ativação microbicida por neutrófilos do sangue dos pacientes com EPC. Por esta razão, o fenótipo destas células foi determinado por meio de citometria de fluxo. Os resultados mostraram que neutrófilos sanguíneos dos indivíduos dos grupos de idosos expressavam CD62L e TLR2 em menor porcentagem. Porém, esta alteração não foi observada nas células dos jovens com EPC, indicando uma característica de neutrófilos na imunossenescência, e não relacionada com a EPC. A regulação negativa de CD62L em neutrófilos isolados de indivíduos idosos já havia sido descrita previamente (DE MARTINIS; MODESTI; GINALDI, 2004). Este dado pode indicar um possível estado de ativação prévio destas células, visto que neutrófilos ativados expressam menores níveis de CD62L (BORREGAARD et al., 1994). CD62L ou L-selectina é altamente expressa em neutrófilos em repouso, sendo responsável por mediar interação entre neutrófilo e endotélio durante a diapedese. Esta molécula tem sua expressão diminuída durante a ativação e migração de neutrófilos para sítios extravasculares, podendo ser usada como marcador de ativação de neutrófilos (KISHIMOTO et al., 1989; LEE et al., 1992). A ativação via TLR2 regula importantes funções dos neutrófilos, incluindo adesão, geração de espécies reativas de 
oxigênio e liberação de quimiocinas, bem como ativação de vias de sinalização intracelulares como a via do fator nuclear de ativação B (NF-kB) (ROEDER et al., 2004; SABROE; DOWER; WHYTE, 2005; VILLAMON et al., 2004). Assim, a diminuição na quantidade de neutrófilos expressando TLR2 pode indicar células com menor capacidade de responder a estímulos antigênicos. De fato, os neutrófilos de pacientes com EPC, bem como de idosos controles, produziram menores níveis de CXCL8, quando estimulados por C. albicans durante 4 horas. Também, CXCL8 foi menos detectada em neutrófilos de idosos com ou sem EPC, em 18 horas de estímulo com C. albicans. Estes dados podem significar que neutrófilos sanguíneos de idosos, frente a $C$. albicans, têm baixa produção desta quimiocina e/ou consumo rápido da mesma, visto que estas células tinham maior sobrevivência in vitro do que aquelas dos jovens (dados não mostrados). Esta relação entre os neutrófilos sanguíneos de idosos e baixos níveis de CXCL8 parece ser característica do desafio frente à C. albicans, já que níveis altos desta quimiocina foram observados após desafio celular com LPS por 18 horas, mostrando que estas células foram mais bem estimuladas por componentes de bactérias do que de fungos. Da mesma forma, TNF- $\alpha$ foi mais intensamente secretado por neutrófilos estimulados com LPS do que com $C$. albicans. No entanto, níveis de TNF- $\alpha$ foram similares entre todos os grupos analisados e após ambos os tipos de estímulo. Pelo fato de menores porcentagens de neutrófilos obtidos de idosos expressarem TLR2 e produzirem níveis de TNF- $\alpha$ similares entre os grupos, acreditamos que outros receptores, que não o TLR2, podem estar ativando a produção de TNF- $\alpha$ por estas células, como o CD66b (Schröder et al, 2006; Drewniak et al, 2008), por meio de mecanismos compensatórios.

A análise da intensidade de expressão das moléculas nos neutrófilos sanguíneos mostrou que CXCR1, CD62L e CD11b eram significativamente menos expressas nas células de idosos (com e sem EPC) e de jovens com EPC. A molécula CXCR1, receptor de CXCL8, é expressa em todos os neutrófilos, funcionando como marcador molecular destes leucócitos (Lee et al, 1992). A redução de CXCR1 e CD62L pode prejudicar a função de CD11b nos mecanismos de diapedese por neutrófilos (BORREGAARD et al., 1994; KISHIMOTO et al., 1989). Estes dados indicam que o envelhecimento pode gerar redução na chegada de neutrófilos em resposta a eventos quimiotáticos. Além disso, alterações nos processos de migração dos neutrófilos podem ter predisposto estes indivíduos a EPC, já que ambos os grupos com EPC tinham menor expressão de CXCR1 e CD62L em neutrófilos sanguíneos. Torna-se de grande importância o estudo de polimorfismos genéticos envolvendo a expressão destes receptores. O CD11b é uma molécula com importante função fagocítica nestas células 
(ROSS 2000; BORREGAARD et al., 1994) É interessante observar que, apesar dos neutrófilos de todos os grupos de idosos e dos jovens com EPC apresentarem características de ativação, a diminuição de CD11b pode indicar o contrário. Provavelmente, embora estas células possuam estas diferenças fenotípicas, isso não signifique que estejam em estado de ativação funcional, evidenciada pela baixa expressão de outras moléculas relacionadas com ativação de leucócitos como CD206, CD69 e CD64 (ATZENI et al., 2004; ATZENI et al., 2002; KISHIMOTO et al., 1989; LEE et al., 1992; MCEVER; MOORE; CUMMINGS, 1995; NUUTILA et al., 2007; TAYLOR; GORDON; MARTINEZ-POMARES, 2005).

Os resultados revelaram ainda que os neutrófilos do sangue dos pacientes com EPC apresentaram aumento significante na produção de IL-4 e IL-10 quando desafiados com $C$. albicans, independentemente da idade do indivíduo. Estas citocinas estão relacionadas com suscetibilidade a candidose persistente, e este dado demonstra alterações nos neutrófilos destes indivíduos, que podem estar influenciando a resposta frente à $C$. albicans, resultando em predisponência sistêmica adicional, já que a EPC é uma condição multifatorial (CAMARGO et al., 2009; FIGUEIRAL et al., 2007; KOSONEN et al., 2006; MOLERO et al., 2005). Aparentemente, de acordo com nossos resultados, indivíduos com EPC têm neutrófilos sanguíneos com tendência a resposta Th2 (não protetora) (HADDAD; FAHLMAN, 2002) frente a C. albicans. Embora IL-12 tenha sido secretada por neutrófilos de indivíduos com EPC estimulados com C. albicans, os níveis eram menores do que os de IL-4 e IL-10 nas mesmas amostras. Talvez os neutrófilos tenham secretado IL-12 préformada, independentemente de cascatas de sinalização intracelular, visto que estas células possuem IL-12p70 estocada em sua membrana para liberação imediata após contato com patógenos (QUINONES et al., 2000).

A análise dos sobrenadantes das culturas de neutrófilos sanguíneos estimulados com C. albicans e LPS mostrou que indivíduos idosos produziram menores níveis de GM-CSF, independentemente da EPC. Neutrófilos obtidos do sangue de jovens com EPC também apresentarem baixa secreção de GM-CSF; este resultado ocorreu apenas quando estimulados com C. albicans, mas não com LPS, mostrando ativação insatisfatória frente a este estimulo específico. Estudos anteriores têm evidenciado esta alteração em idosos, relacionando com uma menor ativação de TLR2 (GASPAROTO et al., 2009; KLEIN et al., 2000; VAN PELT et al., 1996; WEI et al., 1996). 
Assim, os dados obtidos no presente trabalho demonstram que os neutrófilos do sangue dos pacientes apresentando EPC têm diferenças fenotípicas e funcionais em relação aos indivíduos sem EPC, que podem estar relacionadas com polimorfismos gênicos, facilitando a persistência da EPC. Além disso, estas células exibem produção de citocinas do padrão Th2. Também, nossos dados demonstraram que os neutrófilos de idosos possuem mudanças fenotípicas e funcionais, em especial a baixa produção de CXCL8 e GM-CSF após desafio com $C$. albicans, sugerindo maior vulnerabilidade à infecções e doenças associadas com C. albicans. 


\section{CONCLUSÕES}

Os indivíduos com estomatite protética associada a Candida apresentam danos na função de neutrófilos do sangue periférico. Modificações de fenótipo associadas com ativação e fagocitose podem estar relacionadas com uma resposta imune ineficaz, favorecendo a instalação e/ou persistência da doença. Os neutrófilos do sangue de pacientes com estomatite protética secretaram altos níveis de citocinas Th2, IL-4 e IL-10, e baixos níveis de GM-CSF e apresentaram baixa atividade fungicida após desafio com C. albicans, e menor expressão ex vivo de CXCR1, CD62L e CD11b, sugerindo uma predisposição individual à doença, envolvendo alterações nos mecanismos imunes dos neutrófilos, especialmente contra $C$. albicans. Além disso, o estudo evidenciou que neutrófilos sanguíneos de idosos exibem mudanças fenotípicas (porcentagem diminuída de células expressando TLR2 e CD62L, menor expressão de CD11b, CXCR1 e CD62L) e prejuízo na resposta contra $C$. albicans, com baixa taxa de fagocitose e de morte do patógeno, e menor produção de CXCL8 e GM-CSF. Estas alterações associadas com imunossenescência podem tornar os idosos mais suscetíveis a doenças associadas a C. albicans. 



\section{REFERÊNCIAS}

Atzeni F, Del Papa N, Sarzi-Puttini P, Bertolazzi F, Minonzio F, Capsoni F. CD69 expression on neutrophils from patients with rheumatoid arthritis. Clin Exp Rheumatol. 2004;22(3):331-4.

Atzeni F, Schena M, Ongari AM, Carrabba M, Bonara P, Minonzio F, et al. Induction of CD69 activation molecule on human neutrophils by GM-CSF, IFN-gamma, and IFN-alpha. Cell Immunol. 2002;220(1):20-9.

Aw D, Silva AB, Palmer DB. Immunosenescence: emerging challenges for an ageing population. Immunology. 2007;120(4):435-46.

Barbeau J, Seguin J, Goulet JP, de Koninck L, Avon SL, Lalonde B, et al. Reassessing the presence of Candida albicans in denture-related stomatitis. Oral Surg Oral Med Oral Pathol Oral Radiol Endod. 2003;95(1):51-9.

Biasoli MS, Tosello ME, Bottai H, Cuesta C, Magaró HM. Efecto de la temperatura y el pH em la adherencia de Candida albicans in vitro. Revista Iberoamericana de Micologia. 1999;16:46-9

Bliss SK, Marshall AJ, Zhang Y, Denkers EY. Human polymorphonuclear leukocytes produce IL-12, TNF-alpha, and the chemokines macrophage-inflammatory protein-1 alpha and -1 beta in response to Toxoplasma gondii antigens. J Immunol. 1999;162(12):7369-75.

Borregaard N, Kjeldsen L, Sengelov H, Diamond MS, Springer TA, Anderson HC, et al. Changes in subcellular localization and surface expression of L-selectin, alkaline phosphatase, and Mac-1 in human neutrophils during stimulation with inflammatory mediators. J Leukoc Biol. 1994;56(1):80-7.

Brinkmann V, Zychlinsky A. Beneficial suicide: why neutrophils die to make NETs. Nat Rev Microbiol. 2007;5(8):577-82.

Butcher S, Chahel H, Lord JM. Review article: ageing and the neutrophil: no appetite for killing? Immunology. 2000;100(4):411-6.

Butcher SK, Chahal H, Nayak L, Sinclair A, Henriquez NV, Sapey E, et al. Senescence in innate immune responses: reduced neutrophil phagocytic capacity and CD16 expression in elderly humans. J Leukoc Biol. 2001;70(6):881-6. 
Camargo MR, Venturini J, Vilani-Moreno FR, Arruda MS. Modulation of macrophage cytokine profiles during solid tumor progression: susceptibility to Candida albicans infection. BMC Infect Dis. 2009;9:98.

Cassatella MA. The production of cytokines by polymorphonuclear neutrophils. Immunol Today. 1995;16(1):21-6.

Cassatella MA, Bazzoni F, Ceska M, Ferro I, Baggiolini M, Berton G. IL-8 production by human polymorphonuclear leukocytes. The chemoattractant formyl-methionyl-leucylphenylalanine induces the gene expression and release of IL-8 through a pertussis toxinsensitive pathway. J Immunol. 1992;148(10):3216-20.

Cassatella MA, Gasperini S, Russo MP. Cytokine expression and release by neutrophils. Ann N Y Acad Sci. 1997;832:233-42.

Cassatella MA, Meda L, Gasperini S, D'Andrea A, Ma X, Trinchieri G. Interleukin-12 production by human polymorphonuclear leukocytes. Eur J Immunol. 1995;25(1):1-5.

Dale DC, Boxer L, Liles WC. The phagocytes: neutrophils and monocytes. Blood. 2008;112(4):935-45.

De Martinis M, Modesti M, Ginaldi L. Phenotypic and functional changes of circulating monocytes and polymorphonuclear leucocytes from elderly persons. Immunol Cell Biol. 2004;82(4):415-20.

Ethuin F, Gerard B, Benna JE, Boutten A, Gougereot-Pocidalo MA, Jacob L, et al. Human neutrophils produce interferon gamma upon stimulation by interleukin-12. Lab Invest. 2004;84(10):1363-71.

Figueiral MH, Azul A, Pinto E, Fonseca PA, Branco FM, Scully C. Denture-related stomatitis: identification of aetiological and predisposing factors - a large cohort. J Oral Rehabil. 2007;34(6):448-55.

Fulop T, Foris G, Leovey A. Age-related changes in cAMP and cGMP levels during phagocytosis in human polymorphonuclear leukocytes. Mech Ageing Dev. 1984;27(2):2337.

Fulop T, Jr., Fouquet C, Allaire P, Perrin N, Lacombe G, Stankova J, et al. Changes in apoptosis of human polymorphonuclear granulocytes with aging. Mech Ageing Dev. 1997;96(1-3):15-34. 
Gasparoto TH, Vieira NA, Porto VC, Campanelli AP, Lara VS. Ageing exacerbates damage of systemic and salivary neutrophils from patients presenting Candida-related denture stomatitis. Immun Ageing. 2009;6:3.

Ginaldi L, Loreto MF, Corsi MP, Modesti M, De Martinis M. Immunosenescence and infectious diseases. Microbes Infect. 2001;3(10):851-7.

Gomez CR, Boehmer ED, Kovacs EJ. The aging innate immune system. Curr Opin Immunol. 2005; 17(5):457-62.

Haddad JJ. Cytokines and related receptor-mediated signaling pathways. Biochem Biophys Res Commun. 2002;297(4):700-13.

Haddad JJ, Fahlman CS. Redox- and oxidant-mediated regulation of interleukin-10: an antiinflammatory, antioxidant cytokine? Biochem Biophys Res Commun. 2002;297(2):163-76.

Haynes L, Maue AC. Effects of aging on $\mathrm{T}$ cell function. Curr Opin Immunol. 2009;21(4):414-7.

Hampton MB, Kettle AJ, Winterbourn CC. Inside the neutrophil phagosome: oxidants, myeloperoxidase, and bacterial killing. Blood. 1998;92(9):3007-17.

Kishimoto TK, Jutila MA, Berg EL, Butcher EC. Neutrophil Mac-1 and MEL-14 adhesion proteins inversely regulated by chemotactic factors. Science. 1989;245(4923):1238-41.

Klein JB, Rane MJ, Scherzer JA, Coxon PY, Kettritz R, Mathiesen JM, et al. Granulocytemacrophage colony-stimulating factor delays neutrophil constitutive apoptosis through phosphoinositide 3-kinase and extracellular signal-regulated kinase pathways. J Immunol. 2000;164(8):4286-91.

Koh AY, Kohler JR, Coggshall KT, Van Rooijen N, Pier GB. Mucosal damage and neutropenia are required for Candida albicans dissemination. PLoS Pathog. 2008;4(2):e35.

Kosonen J, Rantala A, Little CH, Lintu P, Harjamaki PR, Georgiou GM, et al. Increased levels of Candida albicans mannan-specific T-cell-derived antigen binding molecules in patients with invasive candidiasis. Clin Vaccine Immunol. 2006;13(4):467-74. 
Kullberg BJ, Netea MG, Vonk AG, van der Meer JW. Modulation of neutrophil function in host defense against disseminated Candida albicans infection in mice. FEMS Immunol Med Microbiol. 1999;26(3-4):299-307.

Lee J, Horuk R, Rice GC, Bennett GL, Camerato T, Wood WI. Characterization of two high affinity human interleukin-8 receptors. J Biol Chem. 1992;267(23):16283-7.

Leigh JE, Barousse M, Swoboda RK, Myers T, Hager S, Wolf NA, et al. Candida-specific systemic cell-mediated immune reactivities in human immunodeficiency virus-positive persons with mucosal candidiasis. J Infect Dis. 2001;183(2):277-85.

Leigh JE, Steele C, Wormley F, Fidel PL, Jr. Salivary cytokine profiles in the immunocompetent individual with Candida-associated denture stomatitis. Oral Microbiol Immunol. 2002;17(5):311-4.

Licastro F, Candore G, Lio D, Porcellini E, Colonna-Romano G, Franceschi C, et al. Innate immunity and inflammation in ageing: a key for understanding age-related diseases. Immun Ageing. 2005;2:8.

McEver RP, Moore KL, Cummings RD. Leukocyte trafficking mediated by selectincarbohydrate interactions. J Biol Chem. 1995;270(19):11025-8.

Mencacci A, Cenci E, Spaccapelo R, Tonnetti L, del Sero G, d'Ostiani CF, et al. Neutrophils producing interleukin-10 antagonize the effect of interleukin-12 in mice with candidiasis. Ann N Y Acad Sci. 1996;795:394-6.

Mims C, Playfair J, Roitt I, Wakelin D, Williams R. Medical Microbiology. $2^{\mathrm{a}}$ edição ed; 1998.

Molero G, Guillen MV, Martinez-Solano L, Gil C, Pla J, Nombela C, et al. The importance of the phagocytes' innate response in resolution of the infection induced by a low virulent Candida albicans mutant. Scand J Immunol. 2005;62(3):224-33.

Mujica V, Rivera H, Carrero M. Prevalence of oral soft tissue lesions in an elderly venezuelan population. Med Oral Patol Oral Cir Bucal. 2008;13(5):E270-4.

Nathan C. Neutrophils and immunity: challenges and opportunities. Nat Rev Immunol. 2006;6(3):173-82. 
Nauseef WM. How human neutrophils kill and degrade microbes: an integrated view. Immunol Rev. 2007;219:88-102.

Netea MG, Brown GD, Kullberg BJ, Gow NA. An integrated model of the recognition of Candida albicans by the innate immune system. Nat Rev Microbiol. 2008;6(1):67-78.

Niewerth M, Korting HC. Candida albicans and the principle of opportunism. an essay. Mycoses. 2002;45(8):253-8.

Nuutila J, Hohenthal U, Laitinen I, Kotilainen P, Rajamaki A, Nikoskelainen J, et al. Simultaneous quantitative analysis of FcgammaRI (CD64) expression on neutrophils and monocytes: a new, improved way to detect infections. J Immunol Methods. 2007;328(12):189-200.

Panda A, Arjona A, Sapey E, Bai F, Fikrig E, Montgomery RR, et al. Human innate immunosenescence: causes and consequences for immunity in old age. Trends Immunol. 2009;30(7):325-33.

Peltroche-Llacsahuanga H, Schnitzler N, Jentsch S, Platz A, De Hoog S, Schweizer KG, et al. Analyses of phagocytosis, evoked oxidative burst, and killing of black yeasts by human neutrophils: a tool for estimating their pathogenicity? Med Mycol. 2003;41(1):7-14.

Plackett TP, Boehmer ED, Faunce DE, Kovacs EJ. Aging and innate immune cells. J Leukoc Biol. 2004;76(2):291-9.

Quentmeier H, Reinhardt J, Zaborski M, Drexler HG. Granulocyte-macrophage colonystimulating factor: inhibitor of tumor necrosis factor-induced apoptosis. Leuk Res. 2003;27(6):539-45.

Quinones M, Ahuja SK, Melby PC, Pate L, Reddick RL, Ahuja SS. Preformed membraneassociated stores of interleukin (IL)-12 are a previously unrecognized source of bioactive IL12 that is mobilized within minutes of contact with an intracellular parasite. J Exp Med. 2000;192(4):507-16.

Roeder A, Kirschning CJ, Rupec RA, Schaller M, Weindl G, Korting HC. Toll-like receptors as key mediators in innate antifungal immunity. Med Mycol. 2004;42(6):485-98.

Romani L. Immunity to fungal infections. Nat Rev Immunol. 2004;4(1):1-23. 
Romani L, Mencacci A, Cenci E, Puccetti P, Bistoni F. Neutrophils and the adaptive immune response to Candida albicans. Res Immunol. 1996;147(8-9):512-8.

Ross GD. Regulation of the adhesion versus cytotoxic functions of the Mac1/CR3/alphaMbeta2-integrin glycoprotein. Crit Rev Immunol. 2000;20(3):197-222.

Sabroe I, Dower SK, Whyte MK. The role of Toll-like receptors in the regulation of neutrophil migration, activation, and apoptosis. Clin Infect Dis. 2005;41 Suppl 7:S421-6.

Samson H, Strand G, Haugejorden O. Change in oral health status among the institutionalized Norwegian elderly over a period of 16 years. Acta Odontol Scand. 2008;66(6):368-73.

Saunus JM, Kazoullis A, Farah CS. Cellular and molecular mechanisms of resistance to oral Candida albicans infections. Front Biosci. 2008;13:5345-58.

Schaller M, Boeld U, Oberbauer S, Hamm G, Hube B, Korting HC. Polymorphonuclear leukocytes (PMNs) induce protective Th1-type cytokine epithelial responses in an in vitro model of oral candidosis. Microbiology. 2004;150(PTS 9):2807-13.

Segal AW. How neutrophils kill microbes. Annu Rev Immunol 2005;23:197-223. 2005;23:197-223.

Shanley DP, Aw D, Manley NR, Palmer DB. An evolutionary perspective on the mechanisms of immunosenescence. Trends Immunol. 2009;30(7):374-81.

Shoham S, Levitz SM. The immune response to fungal infections. Br J Haematol. 2005;129(5):569-82.

Shulman JD, Rivera-Hidalgo F, Beach MM. Risk factors associated with denture stomatitis in the United States. J Oral Pathol Med. 2005;34(6):340-6.

Taylor PR, Gordon S, Martinez-Pomares L. The mannose receptor: linking homeostasis and immunity through sugar recognition. Trends Immunol. 2005;26(2):104-10.

Urban CF, Lourido S, Zychlinsky A. How do microbes evade neutrophil killing? Cell Microbiol. 2006;8(11):1687-96.

Urban CF, Reichard U, Brinkmann V, Zychlinsky A. Neutrophil extracellular traps caPTSure and kill Candida albicans yeast and hyphal forms. Cell Microbiol. 2006;8(4):668-76. 
van Pelt LJ, Huisman MV, Weening RS, von dem Borne AE, Roos D, van Oers RH. A single dose of granulocyte-macrophage colony-stimulating factor induces systemic interleukin-8 release and neutrophil activation in healthy volunteers. Blood. 1996;87(12):5305-13.

Villamon E, Gozalbo D, Roig P, O'Connor JE, Fradelizi D, Gil ML. Toll-like receptor-2 is essential in murine defenses against Candida albicans infections. Microbes Infect. 2004;6(1):1-7.

von Vietinghoff S, Ley K. Homeostatic regulation of blood neutrophil counts. J Immunol. 2008;181(8):5183-8.

Wei S, Liu JH, Epling-Burnette PK, Gamero AM, Ussery D, Pearson EW, et al. Critical role of Lyn kinase in inhibition of neutrophil apoptosis by granulocyte-macrophage colonystimulating factor. J Immunol. 1996;157(11):5155-62.

Wenisch C, Patruta S, Daxbock F, Krause R, Horl W. Effect of age on human neutrophil function. J Leukoc Biol. 2000;67(1):40-5. 



\section{CAPÍTULO - III}

\section{Imunossenescência e estomatite protética}

associada a Candida: fenótipo e função dos neutrófilos salivares e perfil de citocinas salivares 



\section{RESUMO}

A saliva é composta por células e fatores solúveis que desempenham proteção contra a invasão de microrganismos. Os neutrófilos são os fagócitos mais abundantes na saliva e participam na defesa contra patógenos no local, evitando o desenvolvimento de infecções orais. Os indivíduos com estomatite protética associada a Candida (EPC) apresentam danos na função e fenótipo de neutrófilos do sangue. Assim, a análise destas células que migraram para o microambiente oral tornou-se necessária. Saliva de idosos e jovens com EPC foram coletadas e a função e fenótipo dos neutrófilos salivares foram avaliadas. Citocinas e quimiocinas na saliva que estão relacionadas com a resposta contra infecções por $C$. albicans foram determinadas. Os indivíduos com EPC apresentaram defeitos na função fagocítica e na destruição de $C$. albicans, independente da idade. Estes pacientes tinham altos níveis de IL-4 e IL-10 bem como baixos níveis de IL-12 na saliva. Ainda, observou-se menor porcentagem de neutrófilos salivares expressando TLR2 em jovens com EPC e em todos os idosos (com e sem EPC). Idosos com EPC possuíam menos neutrófilos expressando CD11b, CD66b e CD206 quando comparados dados deste grupo com jovens com EPC, além de altas concentrações de CXCL8 e TNF- $\alpha$. Concentrações baixas de IFN- $\gamma$ e menor porcentagem de neutrófilos expressando CD64 foram detectadas na saliva de todos os idosos, independentemente da EPC. Os resultados indicam diferenças nos neutrófilos salivares e componentes solúveis da saliva de pacientes com EPC. Também, mudanças associadas com a Imunossenescência podem tornar os idosos mais suscetíveis a candidose. 



\section{INTRODUÇÃO}

Durante o envelhecimento, ocorrem inúmeras alterações numéricas e fenotípicas nas células do sistema imune inato ou adaptativo (FULOP et al., 1997; HAYNES; MAUE, 2009; LICASTRO et al., 2005; PANDA et al., 2009; PLACKETT et al., 2004; SHANLEY et al., 2009; WENISCH et al., 2000). Os neutrófilos, por exemplo, são células que podem demonstrar diferenças quanto ao número, ativação e função, na senescência; embora os dados na literatura sejam contrastantes, necessitando um maior esclarecimento quanto à participação desta célula no contexto dos mecanismos de defesa do idoso contra os diferentes patógenos.

Os neutrófilos são as células encontradas em maior número na mucosa oral, contribuindo de forma efetiva para o controle da infecção (VAN DYKE; LEVINE; GENCO, 1985). A saliva desempenha importante papel na defesa oral, visto que muitas células leucocitárias são encontradas entre seus componentes, mesmo em casos de ausência de patologia oral ou cáries dentárias (SCULLY, 1982).

Os neutrófilos obtidos da saliva mostram diferenças morfológicas, fenotípicas e de função quando comparados aos neutrófilos do sangue periférico (TAKUBO et al., 1997). Também são verificadas diferenças na atividade imunológica dos neutrófilos salivares frente a diferentes patógenos bucais (LUKAC et al., 2003).

A presença de neutrófilos na cavidade bucal está envolvida diretamente com a proteção contra infecções. A infiltração de neutrófilos é a característica marcante nas lesões bucais por Candida albicans (C. albicans), e a sua ausência está relacionada ao agravamento da candidose oral (FARAH et al., 2001).

C. albicans é o fungo mais comumente isolado da cavidade bucal de humanos na ausência (BUDTZ-JORGENSEN; STENDERUP; GRABOWSKI, 1975) ou presença de candidose oral (VITKOV et al., 2002). A invasão da mucosa bucal, com o aparecimento de placas, surge como conseqüência de características inerentes ao fungo e ao hospedeiro (revisto por FOTOS; HELLSTEIN; VINCENT, 1991).

A doença bucal por Candida pode variar desde leve envolvimento de superfície mucosa até quadros graves de doença localizada, levando a uma infecção que acomete outras 
regiões mucosas do trato gastrintestinal. Estes casos graves podem ocorrer em indivíduos imunossuprimidos e em idosos (KULAK-OZKAN; KAZAZOGLU; ARIKAN, 2002; MCMULLAN-VOGEL et al., 1999).

A estomatite protética apresenta prevalência muito alta em usuários de prótese total. O local das lesões corresponde à área de mucosa coberta pela prótese (REEVE; VAN ROEKEL, 1987), e o agente etiológico mais identificado é C. albicans (BUDTZJORGENSEN; STENDERUP; GRABOWSKI, 1975; FIGUEIRAL et al., 2007). A ausência de elementos dentários parece contribuir para a menor presença de leucócitos na saliva, o que tornaria o paciente portador de prótese total naturalmente mais suscetível a afecções por $C$. albicans (WRIGHT, 1962).

Os macrófagos e neutrófilos são as células responsáveis pela fagocitose e destruição do fungo. O desvio no padrão de citocinas logo no início da resposta imune contra Candida, gerando maior produção de citocinas do tipo Th2, leva a uma resposta não protetora contra este fungo (FARAH et al., 2001; ROMANI; BISTONI; PUCCETTI, 1997). Assim, a resistência à infecção por $C$. albicans é determinada por mecanismos fagocíticos, atividade que é estimulada por citocinas produzidas, principalmente, por células T CD4+ do tipo auxiliar 1 (Th1) e inibida pelas citocinas do tipo auxiliar 2 (Th2). Isto se dá pelo fato de que as citocinas do padrão Th1 (IFN- $\gamma$, IL-12) ativam os fagócitos para um estado fungicida, enquanto aquelas produzidas por células Th2 (IL-4 e IL-10) exacerbam a doença por desativarem propriedades protetoras das células fagocíticas contra o fungo (ROMANI; BISTONI; PUCCETTI, 1997); revisto por (ROMANI, 2004). Entre as principais funções dos fagócitos que são estimuladas por IFN- $\gamma$ e IL-12 estão a produção de óxido nítrico (KAPOSZTA et al., 1998), peróxido de hidrogênio, IL-6, GM-CSF, IL-8 e TNF- $\alpha$. O TNF- $\alpha$ está envolvido com a proteção em candidose orofaríngea (FARAH et al., 2002).

O desenvolvimento da hipersensibilidade tipo tardia (HTT) e ausência de anticorpos correspondem com a remoção total da candidose palatal em animais experimentais e em humanos (BUDTZ-JORGENSEN, 1978), enquanto a doença envolve perfis de citocinas do padrão Th2, com alta produção de IL-4 e IL-10, altos títulos de anticorpos e baixa secreção de IFN- $\gamma$ (GASPAROTO et al., 2004; SLAVINSKY et al., 2002). No entanto, muitos pacientes com estomatite protética associada a Candida apresentam HTT satisfatória (BUDTZ-JORGENSEN, 1973). Isto demonstra que a doença não está relacionada especialmente com danos a resposta imune celular adaptativa, mas talvez com outros 
mecanismos de proteção, como resposta imune inata. A função de neutrófilos salivares contra patógenos orais, inclusive $C$. albicans, é bem descrita na literatura. Os neutrófilos influenciam no estabelecimento de doenças orais (LUKAC et al., 2003; MURRAY; PATTERS, 1980; SCULLY, 1982; WILTON; RENGGLI; LEHNER, 1977) e disfunções envolvendo estas células estão relacionadas com infecções orais bacterianas e fúngicas recorrentes (VAN DYKE; HOOP, 1990). Embora os neutrófilos participem, principalmente, da resposta imediata a agentes infecciosos em muitos tecidos, o influxo destas células para a cavidade oral ocorre o tempo todo. Estas células são atraídas por fatores presentes no microambiente oral como microrganismos, toxinas, quimiocinas e produtos de degradação celular. Alterações no número ou função dos neutrófilos são associadas com predisposição a doenças orais (ALBILIA et al., 2007; BAGDADE; NIELSON; BULGER, 1972; BEERTSEN et al., 2008; MANOUCHEHR-POUR et al., 1981a, 1981b; RYAN; CARNU; KAMER, 2003; VAN DYKE; HOOP, 1990).

Sabendo-se que os neutrófilos são as células mais importantes da resposta imune inata contra fungos patogênicos, desempenhando papel fundamental na proteção do hospedeiro contra C. albicans, e que indivíduos idosos apresentam uma alta suscetibilidade à instalação da estomatite protética associada a $C$. albicans, foram avaliados a função e o fenótipo de neutrófilos salivares de indivíduos idosos portadores desta doença.

Objetivando o entendimento dos mecanismos de defesa que podem influenciar no estabelecimento e persistência da estomatite protética associada a Candida em idosos, este estudo avaliou: o número total, a ocorrência de apoptose, a expressão de moléculas de superfície relacionadas à ativação e fagocitose, e a função fagocítica in vitro, dos neutrófilos obtidos da saliva. Além disso, níveis de citocinas envolvidas com proteção ou suscetibilidade a infecções por Candida foram quantificados na saliva dos voluntários. 


\section{MATERIAL E MÉTODOS}

\section{CARACTERIZAÇÃO DOS GRUPOS DE ESTUDO}

As amostras de saliva foram coletadas dos mesmos voluntários que doaram amostras de sangue periférico para isolamento de neutrófilos sistêmicos, conforme descrito no Capítulo II (páginas 7 e 8).

\section{MANIPULAÇÃO DE C. albicans ATCC 10231}

Para os ensaios de fagocitose dos neutrófilos salivares foi utilizado leveduras de $C$. albicans ATCC 10231. As leveduras de C. albicans foram cultivadas e manipuladas de acordo com o protocolo descrito no Capítulo II (página 50).

\section{ISOLAMENTO DE NEUTRÓFILOS SALIVARES}

Os neutrófilos salivares de todos os indivíduos dos grupos de estudo foram coletados de acordo com metodologia modificada de (ASHKENAZI; DENNISON, 1989; LUKAC et al., 2003). Os indivíduos bochecharam $10 \mathrm{~mL}$ de $\mathrm{NaCl} 1,5 \%$ estéril, por 2 minutos e expeliram a saliva + PBS em um frasco do tipo Becker estéril. Este procedimento foi repetido mais nove vezes. A solução coletada foi centrifugada $450 \mathrm{xg}$ por 10 minutos a $4^{\circ} \mathrm{C}$. Após este procedimento, o precipitado foi suspenso em meio RPMI suplementado com 10\% de soro fetal bovino (SFB) e filtrado seqüencialmente em membranas de nylon de $20 \mu \mathrm{M}$ e $10 \mu \mathrm{M}$ e centrifugado a $250 \mathrm{x} g$ por 10 minutos a $4^{\circ} \mathrm{C}$. O precipitado foi suspenso em $500 \mu \mathrm{L}$ de RPMI 10\% de SFB. Os neutrófilos salivares foram identificados através de coloração com solução de Türk. A viabilidade de neutrófilos salivares foi determinada pela positividade para Anexina V-FITC ou iodeto de propídio (Aposcreen Annexin V-FITC, R\&D Systems, 
Minneapolis, USA). As células foram analisadas por microscopia de fluorescência usando microscópio Axiostar plus HBO 50/AC (Zeiss, Germany) e as percentagens de células apoPTSóticas e/ou necróticas foram calculadas a partir da proporção de neutrófilos positivos (verdes e/ou vermelhos) em relação ao total de neutrófilos (GASPAROTO et al., 2004).

\section{FENOTIPAGEM DOS NEUTRÓFILOS PELA ANÁLISE DA EXPRESSÃO DE MOLÉCULAS DE SUPERFÍCIE POR IMUNOFLUORESCÊNCIA.}

Os neutrófilos obtidos da saliva dos indivíduos dos grupos experimentais e controles foram lavados duas vezes e, suspensos em meio RPMI 10\% SFB. Estas células foram acomodadas em lamínulas pré-tratadas com poli-L-lisina, incubadas para permitir a aderência por 30 minutos e fixadas com acetona 100\%. Posteriormente, as células foram lavadas em PBS (pH 7,2) e incubadas com os anticorpos monoclonais anti-CXCR1, CD11b, CD16, CD32, CD64, CD66b, CD69, CD206, TLR2 e TLR4 conjugados a fluorescência e diluídos em PBS (acrescido com 20\% de soro de coelho não imune), por 4 horas, em temperatura ambiente e ao abrigo da luz. Após a incubação as células foram lavadas com PBS e montadas em lâminas com meio de montagem contendo DAPI (Vector, Estados Unidos). As células foram analisadas por microscopia de fluorescência usando microscópio Axiostar plus HBO 50/AC (Zeiss, Germany) e as percentagens de células positivas para as moléculas de interesse foram calculadas pela relação entre neutrófilos positivos e número total de neutrófilos, em 10 campos das lâminas escolhidos aleatoriamente.

\section{ENSAIO DE FAGOCITOSE}

Os ensaios de fagocitose realizados com neutrófilos salivares foram conduzidos de acordo com o protocolo utilizado nos ensaios de fagocitose com os neutrófilos do sangue (páginas 52). 


\section{DOSAGEM DE CITOCINAS NA SALIVA}

Antes que qualquer procedimento fosse realizado, foi solicitado a cada voluntário que expectorasse (sem qualquer estímulo) em um tubo até que completasse 2-3 mL de saliva total. Nas amostras, foi acrescentado $10 \%$ de inibidor de proteinase; estas foram centrifugadas a $500 \mathrm{Xg}$ por 10 minutos a $4^{\circ} \mathrm{C}$. O sobrenadante de cada amostra foi obtido e então filtrado $(0,22 \mu \mathrm{M})$ e submetido ao "Enzyme Linked Immunosorbent Assay" (ELISA), sendo avaliadas as seguintes citocinas, com função imunomoduladora: IL-4, IL-10, IL-12, CXCL8, GM-CSF e TNF- $\alpha$. Placas de 96 poços foram sensibilizadas com anticorpo monoclonal primário (captura/ $100 \mu \mathrm{L}$ por poço) diluído em tampão de ligação carbonato/bicarbonato, de acordo com especificações do fabricante. No dia seguinte, as placas foram lavadas quatro vezes com PBS/Tween 20. Os bloqueios dos anticorpos para evitar ligação inespecífica foram feitos com PBS contendo 10\% SFB por 1 hora a temperatura ambiente (Kit OPTEia, BD Biosciences). As placas foram novamente lavadas com PBS/Tween 20 e as citocinas recombinantes e as amostras de saliva foram colocadas nos poços. Após 3 horas de incubação a $37^{\circ} \mathrm{C}$ as placas foram lavadas, os anticorpos secundários biotinilados e a estreptoavidina peroxidase foram diluídos em PBS 10\% SFB e colocados nos poços. Após novas lavagens, a reação foi revelada pela adição de tetrametilbenzidina e $\mathrm{H}_{2} \mathrm{O}_{2}$. Após 40 minutos, a reação foi interrompida com $\mathrm{H}_{2} \mathrm{SO}_{4} 4 \mathrm{~N}$, e o resultado lido em leitor de ELISA, a 492nm. 


\section{RESULTADOS}

\section{Quantificação e função fagocítica de neutrófilos isolados da saliva.}

Os grupos de idosos tinham número significativamente menor de neutrófilos salivares em comparação com os jovens correspondentes (Figura 1A). O número de neutrófilos salivares era ainda menor nos idosos usuários de prótese total superior; destes, os portadores de EPC apresentaram o menor número de neutrófilos isolados da saliva $(0,17 \pm$ $0,02 \times 10^{5}$ ). Os jovens portadores de EPC mostraram número absoluto significativamente menor de neutrófilos salivares $\left(0,5 \pm 0,05 \times 10^{5}\right)$ quando comparados com jovens sem EPC usuários ou não de PTS superior $\left(1,7 \pm 0,4 \times 10^{5}\right.$ e 3,9 $\pm 0,33 \times 10^{5}$, respectivamente, Figura 1A). Embora a presença de $C$. albicans pudesse diminuir o número de neutrófilos salivares por indução de apoptose, os dados mostram que a porcentagem de neutrófilos viáveis era menor nos grupos de idosos, mesmo na ausência de EPC, em comparação aos grupos jovens correspondentes (Figura 1B).

Os neutrófilos salivares de indivíduos idosos e jovens sem EPC fagocitaram mais eficientemente leveduras de $C$. albicans do que aqueles de pacientes idosos e jovens com EPC, em ambos os tempos analisados (Figura 1C). Os neutrófilos salivares de jovens com EPC apresentaram um aumento na atividade fagocítica em duas horas de ensaio (26 $\pm 6,2 \%$, Figura 1C), quando comparado com o tempo de 30 minutos $(15,4 \pm 3,5 \%, P<0,05)$. No entanto, as células de idosos com EPC mantiveram a baixa atividade fagocítica em ambos os tempos analisados $(18,2 \pm 2,6 \%$ em 30 minutos e 18,4 \pm 1,99\% em duas horas). Além de menor atividade fagocítica, neutrófilos salivares de pacientes com EPC tinham maior taxa de leveduras viáveis do que aquela dos indivíduos sem EPC (Figura 1D).

A capacidade fungicida dos neutrófilos foi avaliada através da determinação da taxa de leveduras que permaneciam viáveis após a ingestão. Maior porcentagem de neutrófilos salivares de idosos com EPC apresentava leveduras fagocitadas viáveis em ambos os tempos de análise em comparação com os grupos sem EPC idosos. Entretanto, a capacidade fungicida dos neutrófilos de saliva de todos os grupos de idosos foi inferior àquela dos grupos correspondentes jovens (Figura 1D). Estes dados reforçam o provável prejuízo dos 
neutrófilos nos pacientes com EPC, talvez pela presença de C. albicans na saliva, tornando os indivíduos mais predispostos à persistência da estomatite protética em função da diminuição na atividade fagocítica destas células. Este fator parece ser mais marcante nos neutrófilos de idosos com EPC. Também, os dados indicam que os neutrófilos salivares de idosos são menos eficientes na defesa contra $C$. albicans do que os neutrófilos salivares de indivíduos idosos. 

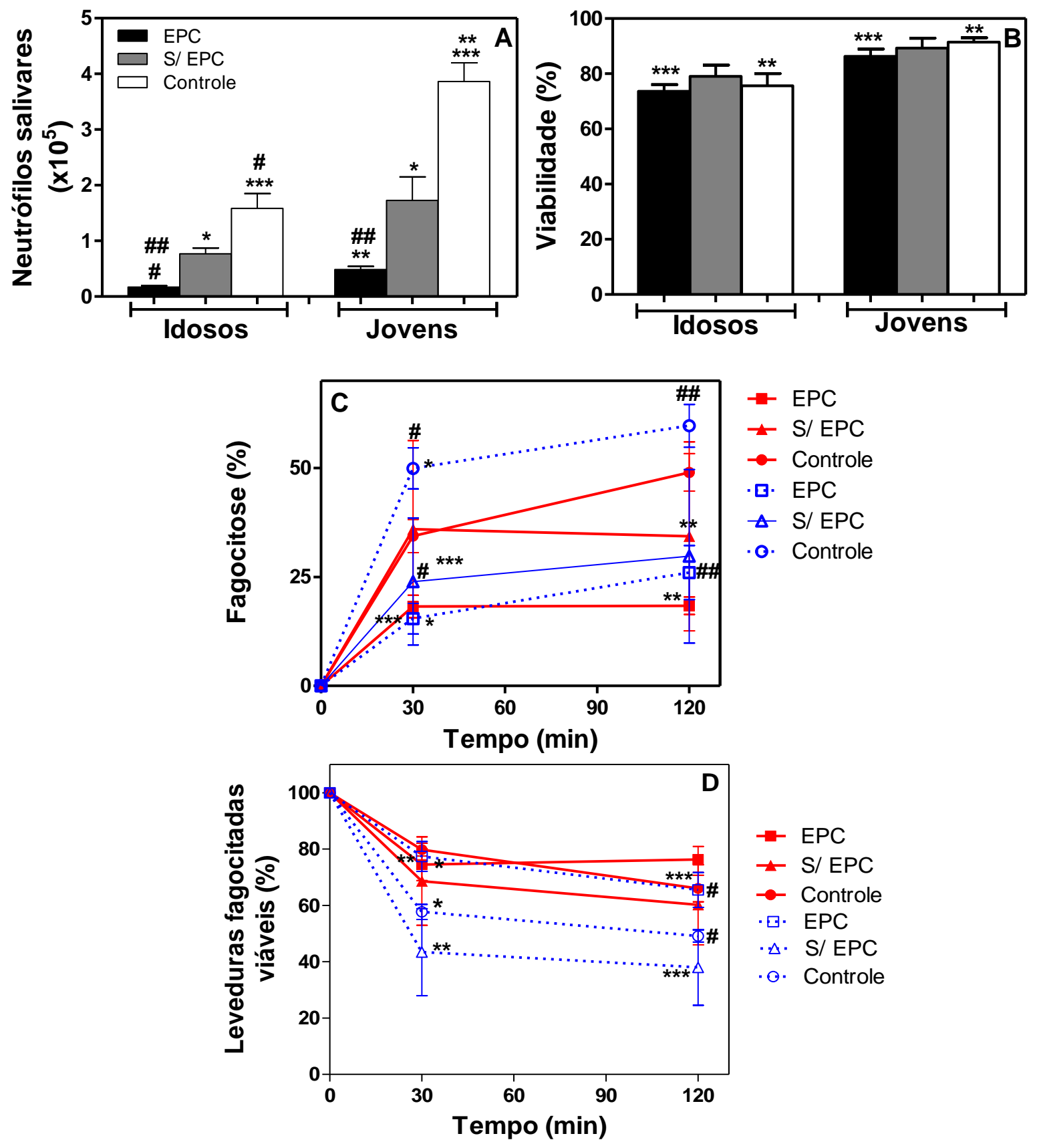

Figura 1. Número e função fagocítica de neutrófilos isolados da saliva. A saliva dos idosos com EPC $(\boldsymbol{\square}, n=25)$, idosos sem EPC e usuários de PTS superior $(\boldsymbol{\Lambda}, n=20)$, idosos não usuários de prótese total $(\bullet, n=15)$, jovens com EPC $(\square, n=15)$, jovens sem EPC e usuários de PTS superior $(\Delta, n=7)$ e jovens não usuários de prótese total $(n=20)$ foi obtida e (A) o número absoluto e (B) a viabilidade de neutrófilos foram determinadas. Neutrófilos viáveis (1:1) foram incubados com leveduras opsonizadas de $C$. albicans e a (C) fagocitose e (D) a viabilidade de leveduras fagocitadas foram quantificadas. Os resultados representam a média \pm EPM de indivíduos testados individualmente. Os dados foram analisados pelo teste de Tukey e símbolos iguais diferem estatisticamente, * e \# $P<0,05$, ** $P<0,01 \mathrm{e} * * * P<$ 0,001. PTS=Prótese total superior 
2. Análise das moléculas TLR2, TLR4, CD16, CD36, CD64, CD66b, CD69, CD206, CXCR1 e CD11b em neutrófilos salivares.

As expressões de moléculas envolvidas com a ativação e fagocitose de neutrófilos foram avaliadas por imunofluorescência, nas células obtidas da saliva dos indivíduos. Para tanto, as porcentagens de células expressando os marcadores de superfície foram determinadas. Menor porcentagem de neutrófilos salivares de indivíduos jovens com EPC expressava TLR2 em comparação com ambos os grupos de jovens sem EPC, usuários ou não de PTS (Figura 2A). Todos os grupos de idosos sem EPC tinham mais baixa porcentagem de neutrófilos expressando TLR2 (S/ EPC- 68,9 $\pm 8,3 \%$ e Controle- $71 \pm 6,1 \%$ ) do que os grupos correspondentes jovens (S/ EPC- $89 \pm 6,1 \%$ e Controle- 91,9 $\pm 3,4 \%$, Figura 2A). Também, os neutrófilos salivares dos indivíduos idosos sem EPC apresentaram reduzida expressão de CD64 do que as células dos jovens correspondentes. Igualmente, a porcentagem destas células positivas para CD64 era mais baixa em jovens com EPC (Figura 2E). Por outro lado, os neutrófilos salivares dos idosos e jovens com EPC expressaram CD69 (74,5 \pm 8,5\% e $67,5 \pm 9,5 \%$, respectivamente) em porcentagens mais altas do que os grupos controles correspondentes, indicando maior ativação destas células (Figura 2G).

Apenas os pacientes com EPC idosos tinham significantemente menores porcentagens de neutrófilos salivares expressando CD66b, CD206 e CD11b do que os idosos sem EPC (Figura 2F, 2H e 2I). Finalmente, apenas jovens com EPC apresentaram menor porcentagem de neutrófilos expressando CXCR1 (Figura 2J). As Figuras 3A-3F são fotomicrografias demonstrativas de neutrófilos salivares de pacientes com e sem EPC expressando ou não TLR4/TLR2, CD66b/CD206 e CD64/CD69. 

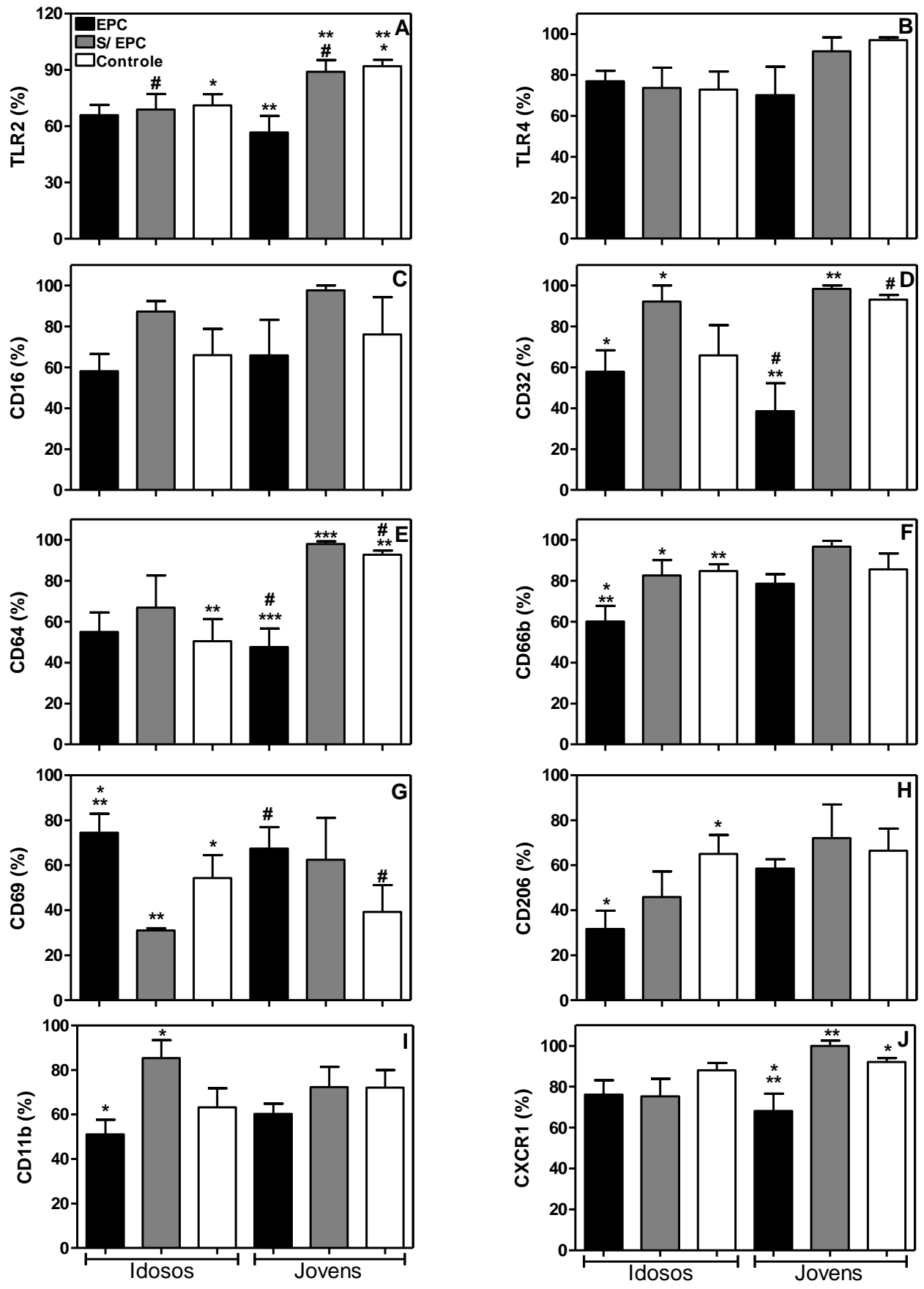

Figura 2. Análise do fenótipo de neutrófilos da saliva. Amostras de saliva foram obtidas de voluntários idosos com EPC ( $n=25$, colunas fechadas), idosos usuários de PTS sem EPC ( $n=20$, colunas cinza), idosos não usuários de prótese total ( $n=15$, colunas abertas), jovens usuários com EPC ( $n=14$, colunas fechadas), jovens usuários de PTS sem EPC $(n=8$, colunas cinza) e jovens não usuários de prótese total ( $n=20$, colunas abertas) e os neutrófilos foram purificados. A porcentagem destas células expressando TLR2, TLR4, CD16, CD32, CD64, CD66b, CD69, CD206, CD11b e CXCR1 foi determinada após marcação com anticorpos conjugados com FITC, PE e Alexa Fluor 647 e contagem em microscópio de fluorescência (A-J). As barras representam os valores da média \pm EPM da porcentagem de neutrófilos positivos para cada molécula. Os dados foram analisados pelo teste de Tukey e símbolos iguais diferem estatisticamente, $*$ e $\# P<0,05, * * P<0,01, * * * P<0,001$. PTS $=$ Prótese total superior 



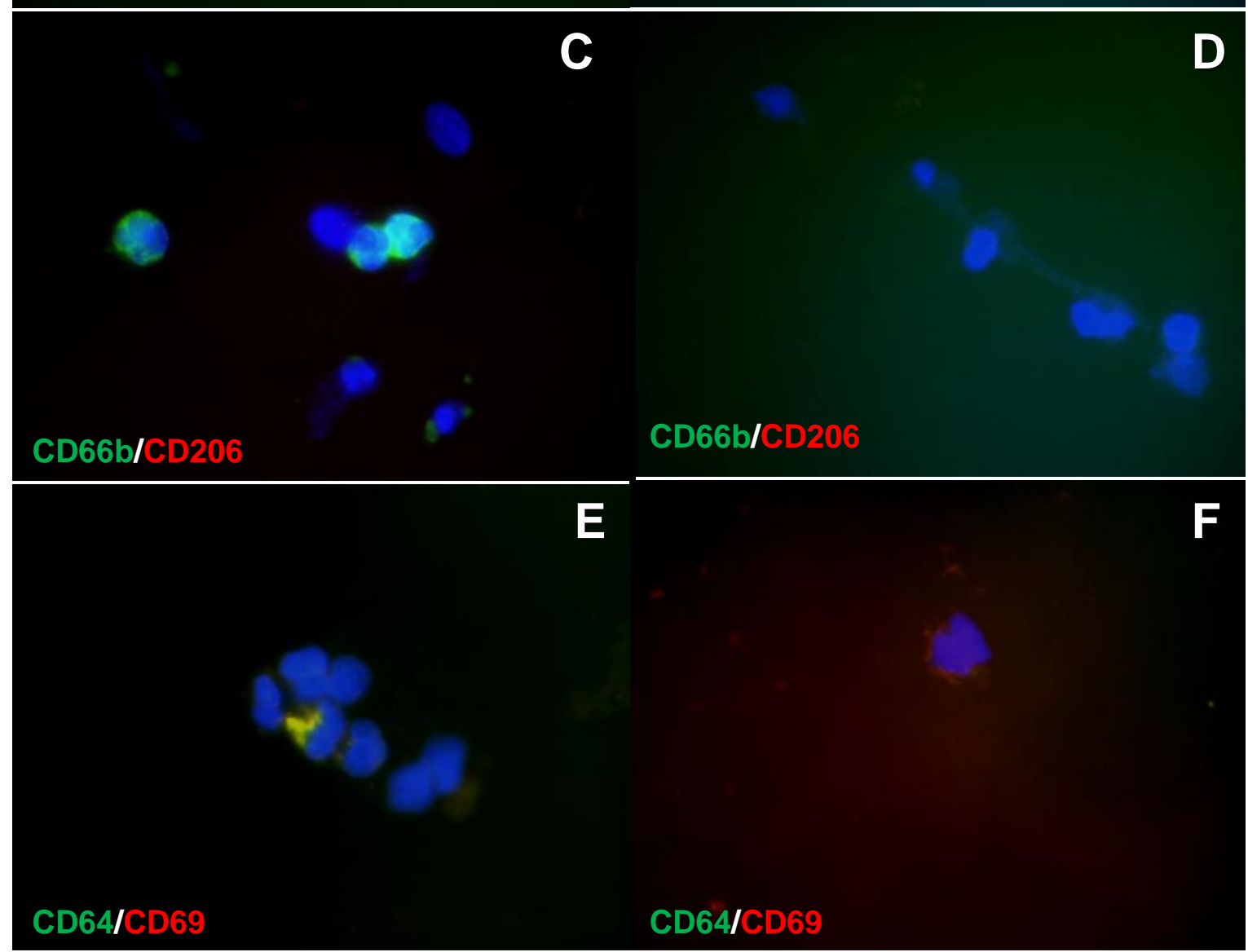

Figura 3. Análise do fenótipo de neutrófilos obtidos da saliva. Amostras de saliva foram obtidas de voluntários idosos e jovens com EPC ( $n=25$ e $n=14)$, idosos e jovens usuários de PTS sem EPC ( $n=20$ e $n=8)$, idosos e jovens não usuários de prótese total $(n=15$ e $n=20)$ e os neutrófilos foram purificados. A expressão de TLR2, TLR4, CD16, CD32, CD64, CD66b, CD69, CD206, CD11b e CXCR1 foi determinada após marcação com anticorpos conjugados com FITC, PE e Alexa Fluor 647 e contagem em microscópio de fluorescência. As fotomicrografias são representativas de neutrófilos obtidos de idosos controles sem EPC (A, C e E) e com EPC (B, D e F) expressando TLR4-FITC, TLR2-PE, CD66b-FITC, CD206-PE, CD64-FITC e CD69-PE. PTS= Prótese total superior 



\section{Análise das citocinas IL-4, IL-6, CXCL8, IL-10, IL-12, IFN- $\gamma$, TNF- $\alpha$ e GM-CSF na saliva.}

A análise de citocinas salivares mostra que pacientes idosos com EPC apresentaram níveis significantemente mais altos de IL-4 do que ambos os grupos de idosos, sem a EPC, usuários ou não de PTS ( $P<0,001$, Figura 4A). Além disso, estes pacientes tinham mais IL-4 na saliva do que os jovens com EPC ( $P<0,05$, Figura 4A). No entanto, quando comparados apenas os grupos de doadores jovens, observou-se que aqueles com EPC eram os que apresentaram maior nível de IL-4 do que os jovens sem EPC usuários de PTS $(P<0,05)$.

IL-6 foi mais detectada na saliva de indivíduos com EPC (Figura 4B). Entretanto, apenas os idosos com EPC tinham IL-6 salivar em concentração significantemente maior do que ambos os grupos idosos sem doença e jovens com EPC $(P<0,05)$. Por outro lado, os jovens com EPC apresentaram os maiores níveis de IL-10 na saliva do que todos os grupos analisados (Figura 4C). Todos os grupos de idosos tinham quantidades semelhantes de IL-10 na saliva (Figura 4C).

Indivíduos com EPC exibiram níveis significantemente menores de IL-12 na saliva do que os grupos sem EPC de faixa etária correspondente (Figura 4D). Porém, todos os grupos jovens tinham IFN- $\gamma$ em altas concentrações na saliva, independente da presença da EPC (Figura 4E). Estes resultados eram significantemente maiores quando comparados aos grupos correspondentes idosos com e sem EPC $(P<0,01$ e $P<0,001$, respectivamente). Curiosamente, idosos usuários de PTS sem EPC apresentaram concentração semelhante de IFN- $\gamma$ em comparação ao grupo correspondente jovem (Figura 4E).

TNF- $\alpha$ e CXCL8 estavam significantemente mais elevadas apenas na saliva dos indivíduos idosos com EPC $(P<0,001$, Figuras 4F e 4G). Embora os idosos com EPC apresentassem mais TNF- $\alpha$ na saliva do que os jovens com EPC, o inverso ocorreu quando comparados idosos e jovens sem EPC usuários ou não de PTS; maior detecção de TNF- $\alpha$ salivar dos jovens do que dos idosos (Figura 4F). No entanto, GM-CSF estava em concentrações mais altas na saliva dos jovens do que dos idosos com EPC (Figura 4H). Este aumento de GM-CSF e menor nível de CXCL8 na saliva de jovens foram detectados quando se comparou os jovens e idosos não usuários de PTS (Figuras 4G e 4H). Estas diferenças não foram verificadas nos grupos usuários de PTS não portadores de EPC (Figuras 4G e 4H). 

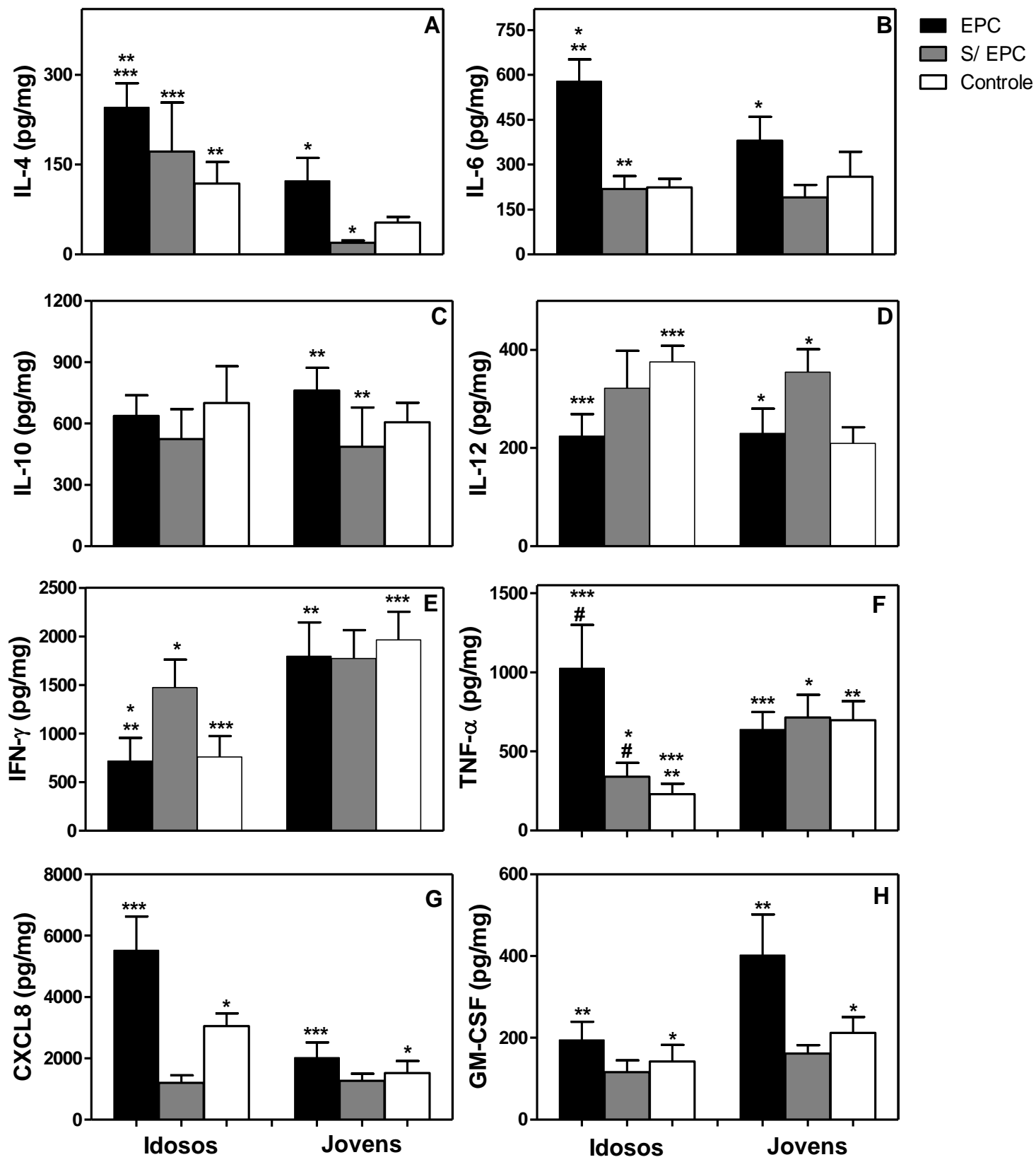

Figura 4. Dosagem de citocinas da saliva. Amostras de saliva foram obtidas de idosos e jovens com EPC ( $n=16$ e $n=14$, colunas fechadas), idosos e jovens sem EPC usuários de PTS ( $n=16$, e $n=8$, colunas cinza), idosos e jovens não usuários de prótese total $(n=15$, e $n=$ 20 colunas abertas), e os níveis de IL-4, IL-6, IL-10, IL-12, IFN- $\gamma$, TNF- $\alpha$, CXCL8 e GMCSF foram avaliados por ELISA e normalizados pela concentração de proteínas. Os resultados representam a média da produção da citocina \pm EPM testada individualmente em triplicata. Os dados foram analisados pelo teste ANOVA de Tukey e $* P<0,05, * * P<0,01$ e $* * * P<0,001$ quando comparados grupos EPC e seus respectivos controles ou grupos idosos e seus correspondentes jovens. Símbolos iguais indicam diferença estatística entre os grupos. PTS $=$ Prótese total superior 


\section{DISCUSSÃO}

O número de neutrófilos infiltrantes na saliva dos pacientes com EPC foi muito menor do que nos grupos controles de faixa etária semelhante. Além disso, o número destas células na saliva dos idosos foi sempre significantemente menor do que nos jovens dos grupos correspondentes, independentemente da presença de EPC. Apesar de ambos os grupos de idosos não apresentarem nenhum tipo de infecção oral ou periodontal, a saliva é sabidamente rica em agentes quimiotáticos para neutrófilos como microrganismos e restos de células (DODDS; JOHNSON; YEH, 2005).

Um possível efeito citotóxico de $C$. albicans na EPC no local poderia estar influenciando a sobrevivência de neutrófilos salivares, assim reduzindo o número destas células na saliva dos doadores (GASPAROTO et al., 2004; KAMINISHI et al., 1995; PANAGIO et al., 2002), visto que as taxas de apoptose dos neutrófilos salivares mostraram que estas células eram tão viáveis quanto àqueles dos seus respectivos controles. Além disso, os idosos apresentaram menores porcentagens de neutrófilos salivares viáveis do que os jovens, independente da EPC. Este dado pode estar relacionado com o menor número de neutrófilos na saliva dos idosos. Assim, os estímulos antigênicos salivares podem influenciar a viabilidade dos neutrófilos de maneiras diferentes de acordo com a idade do indivíduo. Outros autores têm descrito este aumento na taxa de apoptose de neutrófilos em função do avanço da idade (FULOP et al., 1997; SCHRODER; RINK, 2003). Apesar da ausência de dentes nos usuários de prótese total poder ser um fator determinante na diminuição dos neutrófilos salivares, pois, por meio dos sulcos gengivais, ocorre a entrada de neutrófilos para a cavidade bucal (SCULLY, 1982), os indivíduos com EPC tinham menor número de neutrófilos salivares do que aqueles sem a doença. Além disso, estas células tiveram menor atividade fagocítica e maiores taxas de leveduras ingeridas viáveis. Possíveis alterações na expressão de receptores relacionados com a fagocitose das leveduras de C. albicans opsonizadas (CD16, CD32, CD64 e CD11b) ou não (CD206), além de moléculas envolvidas na ativação de neutrófilos, poderiam estar envolvidas com danos na resposta destas células às infecções. Os resultados indicaram que menor porcentagem de neutrófilos salivares dos grupos de idosos, com e sem EPC, expressavam TLR2. Este resultado está de acordo com aquele verificado nos neutrófilos do sangue dos mesmos indivíduos (ver Capítulo II). Além disso, jovens com EPC exibiram menos neutrófilos salivares positivos para TLR2. Embora as taxas de expressão de TLR4 em neutrófilos salivares também tenham sido mais baixas nos grupos de idosos e nos pacientes jovens com EPC, estas diferenças não foram 
estatisticamente significantes. O reconhecimento de patógenos via receptores do tipo Toll coordenam as respostas imunes inatas através da indução de produção de citocinas e quimiocinas que induzem o recrutamento de mais neutrófilos e a morte de agentes microbianos invasores (inclusive $C$. albicans), especialmente pela indução da fagocitose (GODALY et al., 2001; REAVES; CHIN; PARKOS, 2005; TAKEDA; KAISHO; AKIRA, 2003; TESSAROLLI et al., 2009). Assim, a diminuição de neutrófilos expressando TLR2 pode ser mais um fator envolvido com o menor número destas células na saliva de idosos com e sem EPC e de jovens com EPC.

A porcentagem de neutrófilos salivares expressando CD32 foi significantemente menor nos grupos de pacientes com EPC, tanto idosos quanto jovens, quando comparados aos respectivos controles sem EPC. Este receptor, ao lado dos outros receptores para IgG (CD16 e CD64), tem papel relevante na defesa contra $C$. albicans por neutrófilos (MONARI et al., 1999). Além disso, a ativação de neutrófilos via CD32 está diretamente relacionada com o aumento na expressão de CD11b e a liberação de elastase por estas células (VAN MIRRE et al., 2006). De fato, a expressão de CD11b estava diminuída nos grupos de pacientes com EPC, porém esta diferença foi estatisticamente significante apenas quando comparados idosos com e sem EPC usuários de PTS. CD11b está associada com a ativação de neutrófilos e macrófagos por componentes fúngicos, inclusive $C$. albicans (NUUTILA et al., 2006).

Embora a molécula CD64 seja o receptor de IgG mais expresso em neutrófilos em situações de infecção (NUUTILA et al., 2007), nenhuma diferença foi detectada na porcentagem destas células da saliva expressando esta molécula entre os grupos de idosos com e sem EPC. Entretanto, pacientes jovens com EPC e idosos sem EPC tinham taxa significantemente menor de neutrófilos expressando CD64 em comparação com ambos os grupos de jovens sem EPC. Esta molécula, ao lado da Fc $\gamma$ RIII, é endocitada após a ligação e fagocitose de patógenos (DAERON, 1997), e talvez este resultado elucide a maior carga de Candida na boca dos pacientes com EPC e de idosos com e sem EPC (ver Capítulo I). Também, esta diminuição na expressão de CD64 pode gerar prejuízos na resposta fagocítica dos neutrófilos salivares desses indivíduos, facilitando o estabelecimento da infecção local.

Os resultados mostraram que neutrófilos salivares expressando CD206 e CD66b estavam em menor quantidade nos indivíduos idosos com EPC. O CD206 ou receptor de manose é um dos receptores para reconhecimento e ingestão de C. albicans por fagócitos. É 
expresso em baixa quantidade na membrana de fagócitos em situações de homeostasia (TAYLOR; GORDON; MARTINEZ-POMARES, 2005). CD66b é mais expresso em neutrófilos ativados através da mobilização de grânulos, inclusive em resposta às leveduras (HAJKOVA et al., 2009; TIROUVANZIAM et al., 2008).

Ainda que os neutrófilos salivares dos idosos com EPC apresentassem menor expressão de CD66b do que todos os outros grupos analisados, este resultado pode não indicar menor ativação destas células. Isto porque as taxas de neutrófilos salivares destes indivíduos e dos jovens com EPC expressando CD69 eram mais altas do que nos grupos controles. A molécula de CD69 tem sido envolvida em doenças inflamatórias e o aumento na expressão de CD69 em neutrófilos ocorre após horas de estímulo com citocinas próinflamatórias ((ATZENI et al., 2004; ATZENI et al., 2002). De fato, este dado correlacionase com os níveis de algumas citocinas que estavam aumentados na saliva de pacientes com EPC, como GM-CSF e IFN (ATZENI et al., 2002). Apesar de os idosos com EPC terem apresentado mais neutrófilos expressando CD69 e níveis significantemente menores de GMCSF e IFN, estes pacientes tinham os mais altos níveis de TNF- $\alpha$ na saliva e esta citocina poderia estar ativando as células e induzindo a expressão de CD69 (MCLEISH et al., 1998).

Os neutrófilos salivares de jovens com EPC também apresentaram menor expressão de CXCR1 do que seus controles correspondentes sem EPC. Este resultado confirma o fenótipo de ativação destas células nestes pacientes (LEE et al., 1992).

Os dados obtidos demonstraram que os indivíduos idosos que tinham níveis mais baixos de GM-CSF, independente da EPC, apresentaram maior taxa de neutrófilos apoptóticos na saliva. De fato, níveis mais altos de GM-CSF na saliva de indivíduos jovens com EPC e idosos usuários de PTS sem EPC poderiam estar protegendo os neutrófilos salivares de sofrer apoptose induzida por $C$. albicans. Baixos níveis de GM-CSF, combinados com altos níveis de IL-10, no microambiente oral, podem ser importantes fatores predispondo idosos ao estabelecimento de infecções neste local, dado o fato de que enquanto GM-CSF desempenha um papel fundamental na sobrevivência e ativação de neutrófilos, IL10 tem papel supressor de respostas imunes contra agentes infecciosos de qualquer natureza (BLANCHARD et al., 1991; DEROUET et al., 2004; KLEIN et al., 2000; KURT-JONES et al., 2002; O'GARRA; MURPHY, 2009). Entretanto, embora GM-CSF tenha participação na indução de expressão de TLR2 em neutrófilos, jovens com EPC tinham baixa porcentagem de neutrófilos salivares TLR2 ${ }^{+}$(FLO et al., 2001). Este dado pode estar relacionado com 
outros fatores associados com a ativação dos neutrófilos, como a presença de IL-10 (FLO et al., 2001). Os idosos com EPC, porém, tinham altas concentrações de CXCL8 e TNF- $\alpha$ na saliva. Provavelmente, os altos níveis destas citocinas/quimiocinas ajudem a evitar que ocorra uma infecção invasiva por $C$. albicans, pois ambas CXCL8 e TNF- $\alpha$ têm importante papel na resistência inata contra infecções mucosas por Candida ((BALISH et al., 1999; CROSS; MOOTS; EDWARDS, 2008; FARAH et al., 2006). Diferenças detectadas na presença de CXCL8 e TNF- $\alpha$ em indivíduos com EPC poderiam estar tanto relacionadas com fenótipo do fungo presente nas lesões quanto com fatores relacionados com a faixa etária do paciente, visto que a maior produção destas citocinas em idosos com infecções tem sido extensivamente descrita na literatura (SCHRODER; RINK, 2003; VILLAR et al., 2005).

Pacientes idosos com EPC apresentaram níveis de citocinas relacionadas com resposta imune de suscetibilidade a $C$. albicans, como aumentos de IL-4 e IL-6 combinados com diminuição de IL-12 e IFN- $\gamma$ (LEIGH et al., 2001; LEIGH et al., 1998; ROMANI, 2004; SAUNUS; KAZOULLIS; FARAH, 2008). Apesar de os pacientes jovens com EPC terem níveis altos de IFN- $\gamma$ na saliva, houve queda em IL-12 e aumento de IL-4 e IL-10, fatores que poderiam estar favorecendo a persistência da estomatite protética associada a Candida. Além de afetar negativamente a resposta imune tardia contra $C$. albicans, IL-4 e IL-10 podem diminuir a expressão de TLR2 em células humanas (neutrófilos e monócitos) de uma maneira tempo dependente (FLO et al., 2001). 


\section{CONCLUSÃO}

Os indivíduos com estomatite protética associada a Candida apresentam danos na função de neutrófilos salivares. Modificações de fenótipo associadas com ativação e fagocitose podem estar relacionadas com uma resposta imune ineficaz, favorecendo a persistência da doença nos pacientes com EPC, independente da idade. A saliva de pacientes com estomatite protética apresentou altos níveis de citocinas relacionadas com padrão de suscetibilidade a candidose, como IL-4 e IL-10 e baixos níveis de citocinas protetoras, como IL-12. No entanto, a análise da saliva dos idosos com EPC determinou diferenças quando comparados com jovens com EPC, como menos neutrófilos expressando CD11b, CD66b e CD206, além de altas concentrações de CXCL8 e TNF- $\alpha$. Baixas concentrações de IFN- $\gamma$, ao lado de menor porcentagem de neutrófilos expressando CD64 e TLR2, foram detectadas na saliva de todos os idosos, independentemente da EPC. Assim, os resultados indicam diferenças nos neutrófilos salivares e componentes solúveis da saliva de pacientes com EPC. Também, alterações nos neutrófilos salivares associadas com a imunossenescência podem tornar os idosos mais suscetíveis a infecções por Candida e doenças associadas com a presença deste fungo. 



\section{REFERÊNCIAS}

Albilia JB, Lam DK, Clokie CM, Sandor GK. Systemic lupus erythematosus: a review for dentists. J Can Dent Assoc. 2007;73(9):823-8.

Ashkenazi M, Dennison DK. A new method for isolation of salivary neutrophils and determination of their functional activity. J Dent Res. 1989;68(8):1256-61.

Atzeni F, Del Papa N, Sarzi-Puttini P, Bertolazzi F, Minonzio F, Capsoni F. CD69 expression on neutrophils from patients with rheumatoid arthritis. Clin Exp Rheumatol. 2004;22(3):331-4.

Atzeni F, Schena M, Ongari AM, Carrabba M, Bonara P, Minonzio F, et al. Induction of CD69 activation molecule on human neutrophils by GM-CSF, IFN-gamma, and IFN-alpha. Cell Immunol. 2002;220(1):20-9.

Bagdade JD, Nielson KL, Bulger RJ. Reversible abnormalities in phagocytic function in poorly controlled diabetic patients. Am J Med Sci. 1972;263(6):451-6.

Balish E, Wagner RD, Vazquez-Torres A, Jones-Carson J, Pierson C, Warner T. Mucosal and systemic candidiasis in IL-8Rh-/- BALB/c mice. J Leukoc Biol. 1999;66(1):144-50.

Beertsen W, Willenborg M, Everts V, Zirogianni A, Podschun R, Schroder B, et al. Impaired phagosomal maturation in neutrophils leads to periodontitis in lysosomal-associated membrane protein-2 knockout mice. J Immunol. 2008;180(1):475-82.

Blanchard DK, Michelini-Norris MB, Pearson CA, McMillen S, Djeu JY. Production of granulocyte-macrophage colony-stimulating factor (GM-CSF) by monocytes and large granular lymphocytes stimulated with Mycobacterium avium-M. intracellulare: activation of bactericidal activity by GM-CSF. Infect Immun. 1991;59(7):2396-402.

Budtz-Jorgensen E. Cellular immunity in acquired candidiasis of the palate. Scand J Dent Res. 1973;81(5):372-82.

Budtz-Jorgensen E. Clinical aspects of Candida infection in denture wearers. J Am Dent Assoc. 1978;96(3):474-9.

Budtz-Jorgensen E, Stenderup A, Grabowski M. An epidemiologic study of yeasts in elderly denture wearers. Community Dent Oral Epidemiol. 1975;3(3):115-9. 
[Digite texto]

Cross A, Moots RJ, Edwards SW. The dual effects of TNFalpha on neutrophil apoptosis are mediated via differential effects on expression of Mcl-1 and Bfl-1. Blood. 2008;111(2):87884.

Daeron M. Fc receptor biology. Annu Rev Immunol. 1997;15:203-34.

Derouet M, Thomas L, Cross A, Moots RJ, Edwards SW. Granulocyte macrophage colonystimulating factor signaling and proteasome inhibition delay neutrophil apoPTSosis by increasing the stability of Mcl-1. J Biol Chem. 2004;279(26):26915-21.

Dodds MW, Johnson DA, Yeh CK. Health benefits of saliva: a review. J Dent. 2005;33(3):223-33.

Farah CS, Elahi S, Pang G, Gotjamanos T, Seymour GJ, Clancy RL, et al. T cells augment monocyte and neutrophil function in host resistance against oropharyngeal candidiasis. Infect Immun. 2001;69(10):6110-8.

Farah CS, Gotjamanos T, Seymour GJ, Ashman RB. Cytokines in the oral mucosa of mice infected with Candida albicans. Oral Microbiol Immunol. 2002;17(6):375-8.

Farah CS, Hu Y, Riminton S, Ashman RB. Distinct roles for interleukin-12p40 and tumour necrosis factor in resistance to oral candidiasis defined by gene-targeting. Oral Microbiol Immunol. 2006;21(4):252-5.

Figueiral MH, Azul A, Pinto E, Fonseca PA, Branco FM, Scully C. Denture-related stomatitis: identification of aetiological and predisposing factors - a large cohort. J Oral Rehabil. 2007;34(6):448-55.

Flo TH, Halaas O, Torp S, Ryan L, Lien E, Dybdahl B, et al. Differential expression of Tolllike receptor 2 in human cells. J Leukoc Biol. 2001;69(3):474-81.

Fotos PG, Hellstein JW, Vincent SD. Oral candidosis revisited. Gen Dent. 1991;39(6):42230.

Fulop T, Jr., Fouquet C, Allaire P, Perrin N, Lacombe G, Stankova J, et al. Changes in apoptosis of human polymorphonuclear granulocytes with aging. Mech Ageing Dev. 1997;96(1-3):15-34. 
Gasparoto TH, Gaziri LC, Burger E, de Almeida RS, Felipe I. Apoptosis of phagocytic cells induced by Candida albicans and production of IL-10. FEMS Immunol Med Microbiol. 2004;42(2):219-24.

Godaly G, Bergsten G, Hang L, Fischer H, Frendeus B, Lundstedt AC, et al. Neutrophil recruitment, chemokine receptors, and resistance to mucosal infection. J Leukoc Biol. 2001;69(6):899-906.

Hajkova V, Svobodova A, Krejcova D, Ciz M, Velebny V, Lojek A, et al. Soluble glucomannan isolated from Candida utilis primes blood phagocytes. Carbohydr Res. 2009;344(15):2036-41.

Haynes L, Maue AC. Effects of aging on $\mathrm{T}$ cell function. Curr Opin Immunol. 2009;21(4):414-7.

Kaminishi H, Miyaguchi H, Tamaki T, Suenaga N, Hisamatsu M, Mihashi I, et al. Degradation of humoral host defense by Candida albicans proteinase. Infect Immun. 1995;63(3):984-8.

Kaposzta R, Tree P, Marodi L, Gordon S. Characteristics of invasive candidiasis in gamma interferon- and interleukin-4-deficient mice: role of macrophages in host defense against Candida albicans. Infect Immun. 1998;66(4):1708-17.

Klein JB, Rane MJ, Scherzer JA, Coxon PY, Kettritz R, Mathiesen JM, et al. Granulocytemacrophage colony-stimulating factor delays neutrophil constitutive apoptosis through phosphoinositide 3-kinase and extracellular signal-regulated kinase pathways. J Immunol. 2000;164(8):4286-91.

Kulak-Ozkan Y, Kazazoglu E, Arikan A. Oral hygiene habits, denture cleanliness, presence of yeasts and stomatitis in elderly people. J Oral Rehabil. 2002;29(3):300-4.

Kurt-Jones EA, Mandell L, Whitney C, Padgett A, Gosselin K, Newburger PE, et al. Role of toll-like receptor 2 (TLR2) in neutrophil activation: GM-CSF enhances TLR2 expression and TLR2-mediated interleukin 8 responses in neutrophils. Blood. 2002;100(5):1860-8.

Lee J, Horuk R, Rice GC, Bennett GL, Camerato T, Wood WI. Characterization of two high affinity human interleukin-8 receptors. J Biol Chem. 1992;267(23):16283-7. 
[Digite texto]

Leigh JE, Barousse M, Swoboda RK, Myers T, Hager S, Wolf NA, et al. Candida-specific systemic cell-mediated immune reactivities in human immunodeficiency virus-positive persons with mucosal candidiasis. J Infect Dis. 2001;183(2):277-85.

Leigh JE, Steele C, Wormley FL, Jr., Luo W, Clark RA, Gallaher W, et al. Th1/Th2 cytokine expression in saliva of HIV-positive and HIV-negative individuals: a pilot study in HIVpositive individuals with oropharyngeal candidiasis. J Acquir Immune Defic Syndr Hum Retrovirol. 1998;19(4):373-80.

Licastro F, Candore G, Lio D, Porcellini E, Colonna-Romano G, Franceschi C, et al. Innate immunity and inflammation in ageing: a key for understanding age-related diseases. Immun Ageing. 2005;2:8.

Lukac J, Mravak-Stipetic M, Knezevic M, Vrcek J, Sistig S, Ledinsky M, et al. Phagocytic functions of salivary neutrophils in oral mucous membrane diseases. J Oral Pathol Med. 2003;32(5):271-4.

Manouchehr-Pour M, Spagnuolo PJ, Rodman HM, Bissada NF. Comparison of neutrophil chemotactic response in diabetic patients with mild and severe periodontal disease. J Periodontol. 1981a;52(8):410-5.

Manouchehr-Pour M, Spagnuolo PJ, Rodman HM, Bissada NF. Impaired neutrophil chemotaxis in diabetic patients with severe periodontitis. J Dent Res. 1981b;60(3):729-30.

McLeish KR, Knall C, Ward RA, Gerwins P, Coxon PY, Klein JB, et al. Activation of mitogen-activated protein kinase cascades during priming of human neutrophils by TNFalpha and GM-CSF. J Leukoc Biol. 1998;64(4):537-45.

McMullan-Vogel CG, Jude HD, Ollert MW, Vogel CW. Serotype distribution and secretory acid proteinase activity of Candida albicans isolated from the oral mucosa of patients with denture stomatitis. Oral Microbiol Immunol. 1999;14(3):183-9.

Monari C, Casadevall A, Pietrella D, Bistoni F, Vecchiarelli A. Neutrophils from patients with advanced human immunodeficiency virus infection have impaired complement receptor function and preserved Fcgamma receptor function. J Infect Dis. 1999;180(5):1542-9.

Murray PA, Patters MR. Gingival crevice neutrophil function in periodontal lesions. J Periodontal Res. 1980;15(5):463-9. 
Nuutila J, Hohenthal U, Laitinen I, Kotilainen P, Rajamaki A, Nikoskelainen J, et al. Quantitative analysis of complement receptors, CR1 (CD35) and CR3 (CD11b), on neutrophils improves distinction between bacterial and viral infections in febrile patients: comparison with standard clinical laboratory data. J Immunol Methods. 2006;315(1-2):191201.

Nuutila J, Hohenthal U, Laitinen I, Kotilainen P, Rajamaki A, Nikoskelainen J, et al. Simultaneous quantitative analysis of FcgammaRI (CD64) expression on neutrophils and monocytes: a new, improved way to detect infections. J Immunol Methods. 2007;328(12):189-200.

O'Garra A, Murphy KM. From IL-10 to IL-12: how pathogens and their products stimulate APCs to induce T(H)1 development. Nat Immunol. 2009;10(9):929-32.

Panagio LA, Felipe I, Vidotto MC, Gaziri LC. Early membrane exposure of phosphatidylserine followed by late necrosis in murine macrophages induced by Candida albicans from an HIV-infected individual. J Med Microbiol. 2002;51(11):929-36.

Panda A, Arjona A, Sapey E, Bai F, Fikrig E, Montgomery RR, et al. Human innate immunosenescence: causes and consequences for immunity in old age. Trends Immunol. 2009;30(7):325-33.

Plackett TP, Boehmer ED, Faunce DE, Kovacs EJ. Aging and innate immune cells. J Leukoc Biol. 2004;76(2):291-9.

Reaves TA, Chin AC, Parkos CA. Neutrophil transepithelial migration: role of toll-like receptors in mucosal inflammation. Mem Inst Oswaldo Cruz. 2005;100 Suppl 1:191-8.

Reeve CM, Van Roekel NB. Denture sore mouth. Dermatol Clin. 1987;5(4):681-6.

Romani L. Immunity to fungal infections. Nat Rev Immunol. 2004;4(1):1-23.

Romani L, Bistoni F, Puccetti P. Initiation of T-helper cell immunity to Candida albicans by IL-12: the role of neutrophils. Chem Immunol. 1997;68:110-35.

Ryan ME, Carnu O, Kamer A. The influence of diabetes on the periodontal tissues. J Am Dent Assoc. 2003;134 Spec No:34S-40S. 
[Digite texto]

Saunus JM, Kazoullis A, Farah CS. Cellular and molecular mechanisms of resistance to oral Candida albicans infections. Front Biosci. 2008;13:5345-58.

Schroder AK, Rink L. Neutrophil immunity of the elderly. Mech Ageing Dev. 2003;124(4):419-25.

Scully C. Phagocytic and killing activity of human blood, gingival crevicular, and salivary polymorphonuclear leukocytes for oral streptococci. J Dent Res. 1982;61(5):636-9.

Shanley DP, Aw D, Manley NR, Palmer DB. An evolutionary perspective on the mechanisms of immunosenescence. Trends Immunol. 2009;30(7):374-81.

Slavinsky J, 3rd, Myers T, Swoboda RK, Leigh JE, Hager S, Fidel PL, Jr. Th1/Th2 cytokine profiles in saliva of HIV-positive smokers with oropharyngeal candidiasis. Oral Microbiol Immunol. 2002;17(1):38-43.

Takeda K, Kaisho T, Akira S. Toll-like receptors. Annu Rev Immunol. 2003;21:335-76.

Takubo T, Yamane T, Tsuda I, Tagawa S, Tatsumi N. Polymorphonuclear neutrophils in saliva and blood: a comparative study of morphology, function and phenotype. Br J Biomed Sci. 1997;54(4):260-6.

Taylor PR, Gordon S, Martinez-Pomares L. The mannose receptor: linking homeostasis and immunity through sugar recognition. Trends Immunol. 2005;26(2):104-10.

Tessarolli V, Gasparoto TH, Lima HR, Figueira EA, Garlet TP, Torres SA, et al. Absence of TLR2 influences survival of neutrophils after infection with Candida albicans. Med Mycol. 2009:1-12.

Tirouvanziam R, Gernez Y, Conrad CK, Moss RB, Schrijver I, Dunn CE, et al. Profound functional and signaling changes in viable inflammatory neutrophils homing to cystic fibrosis airways. Proc Natl Acad Sci U S A. 2008;105(11):4335-9.

Van Dyke TE, Hoop GA. Neutrophil function and oral disease. Crit Rev Oral Biol Med. 1990;1(2):117-33.

Van Dyke TE, Levine MJ, Genco RJ. Neutrophil function and oral disease. J Oral Pathol. 1985;14(2):95-120. 
van Mirre E, Breunis WB, Geissler J, Hack CE, de Boer M, Roos D, et al. Neutrophil responsiveness to $\mathrm{IgG}$, as determined by fixed ratios of mRNA levels for activating and inhibitory FcgammaRII (CD32), is stable over time and unaffected by cytokines. Blood. 2006;108(2):584-90.

Villar CC, Kashleva H, Mitchell AP, Dongari-Bagtzoglou A. Invasive phenotype of Candida albicans affects the host proinflammatory response to infection. Infect Immun. 2005;73(8):4588-95.

Vitkov L, Krautgartner WD, Hannig M, Weitgasser R, Stoiber W. Candida attachment to oral epithelium. Oral Microbiol Immunol. 2002;17(1):60-4.

Wenisch C, Patruta S, Daxbock F, Krause R, Horl W. Effect of age on human neutrophil function. J Leukoc Biol. 2000;67(1):40-5.

Wilton JM, Renggli HH, Lehner T. A functional comparison of blood and gingival inflammatory polymorphonuclear leucocytes in man. Clin Exp Immunol. 1977;27(1):152-8.

Wright DE. Leucocytes in the saliva of edentulous and caries-free subjects. Arch Oral Biol. 1962;7:581-5. 
. 

6 Conclusões

[Digite texto] 



\section{CONCLUSÕES}

As conclusões baseadas nos resultados obtidos neste trabalho estão descritas detalhadamente em cada capítulo.

De uma maneira geral, com base nos resultados obtidos pode-se concluir que:

As espécies de Candida estão presentes nas lesões de estomatite protética e na superfície interna de próteses totais superiores em, praticamente, a totalidade dos casos desta doença. C. albicans é a espécie mais comum deste fungo, porém outras espécies de Candida podem estar envolvidas no estabelecimento e persistência das lesões. Os indivíduos com estomatite protética associada a Candida apresentam danos na função de neutrófilos do sangue periférico e da saliva. Alterações associadas com imunossenescência podem tornar os idosos mais suscetíveis a doenças associadas a presença deste fungo. 

7 Referências

Bibliográficas 



\section{REFERÊNCIAS BIBLIOGRÁFICAS}

Brinkmann V, Zychlinsky A. Beneficial suicide: why neutrophils die to make NETs. Nat Rev Microbiol. 2007;5(8):577-82.

Budtz-Jorgensen E, Stenderup A, Grabowski M. An epidemiologic study of yeasts in elderly denture wearers. Community Dent Oral Epidemiol. 1975;3(3):115-9.

Dale DC, Boxer L, Liles WC. The phagocytes: neutrophils and monocytes. Blood. 2008;112(4):935-45.

Dar-Odeh NS, Shehabi AA. Oral candidosis in patients with removable dentures. Mycoses. 2003;46(5-6):187-91.

Farah CS, Elahi S, Pang G, Gotjamanos T, Seymour GJ, Clancy RL, et al. T cells augment monocyte and neutrophil function in host resistance against oropharyngeal candidiasis. Infect Immun. 2001;69(10):6110-8.

Freitas J, Gomez R, Abreu MD, Ferreira E. Relationship between the use of full dentures and mucosal alterations among elderly Brazilians. J Oral Rehabil. 2008;35(5):370-4.

Fulop T, Jr., Fouquet C, Allaire P, Perrin N, Lacombe G, Stankova J, et al. Changes in apoptosis of human polymorphonuclear granulocytes with aging. Mech Ageing Dev. 1997;96(1-3):15-34.

Haynes L, Maue AC. Effects of aging on $\mathrm{T}$ cell function. Curr Opin Immunol. 2009;21(4):414-7.

Koh AY, Kohler JR, Coggshall KT, Van Rooijen N, Pier GB. Mucosal damage and neutropenia are required for Candida albicans dissemination. PLoS Pathog. 2008;4(2):e35. 
Kullberg BJ, Netea MG, Vonk AG, van der Meer JW. Modulation of neutrophil function in host defense against disseminated Candida albicans infection in mice. FEMS Immunol Med Microbiol. 1999;26(3-4):299-307.

Licastro F, Candore G, Lio D, Porcellini E, Colonna-Romano G, Franceschi C, et al. Innate immunity and inflammation in ageing: a key for understanding age-related diseases. Immun Ageing. 2005;2:8.

Makihira S, Nikawa H, Nishimura M, Egusa H, Sadamori S, Rahayu RP, et al. Impact of components of denture acrylic resin on gingival cell growth and sensitivity to Candida albicans adhesion. Mycoses. 2002;45(8):300-5.

Moura JS, da Silva WJ, Pereira T, Del Bel Cury AA, Rodrigues Garcia RC. Influence of acrylic resin polymerization methods and saliva on the adherence of four Candida species. $\mathrm{J}$ Prosthet Dent. 2006;96(3):205-11.

Nathan C. Neutrophils and immunity: challenges and opportunities. Nat Rev Immunol. 2006;6(3):173-82.

Panda A, Arjona A, Sapey E, Bai F, Fikrig E, Montgomery RR, et al. Human innate immunosenescence: causes and consequences for immunity in old age. Trends Immunol. 2009;30(7):325-33.

Peltroche-Llacsahuanga H, Schnitzler N, Jentsch S, Platz A, De Hoog S, Schweizer KG, et al. Analyses of phagocytosis, evoked oxidative burst, and killing of black yeasts by human neutrophils: a tool for estimating their pathogenicity? Med Mycol. 2003;41(1):7-14.

Pires FR, Santos EB, Bonan PR, De Almeida OP, Lopes MA. Denture stomatitis and salivary Candida in Brazilian edentulous patients. J Oral Rehabil. 2002;29(11):1115-9.

Plackett TP, Boehmer ED, Faunce DE, Kovacs EJ. Aging and innate immune cells. J Leukoc Biol. 2004;76(2):291-9. 
Ramage G, Vande Walle K, Wickes BL, Lopez-Ribot JL. Biofilm formation by Candida dubliniensis. J Clin Microbiol. 2001;39(9):3234-40.

Saunus JM, Kazoullis A, Farah CS. Cellular and molecular mechanisms of resistance to oral Candida albicans infections. Front Biosci. 2008;13:5345-58.

Scalercio M, Valente T, Israel MS, Ramos ME. Estomatite protética versus candidíase: diagnóstico e tratamento. RGO. 2007; 55(4): 395-8.

Schaller M, Boeld U, Oberbauer S, Hamm G, Hube B, Korting HC. Polymorphonuclear leukocytes (PMNs) induce protective Th1-type cytokine epithelial responses in an in vitro model of oral candidosis. Microbiology. 2004;150(PTS 9):2807-13.

Shanley DP, Aw D, Manley NR, Palmer DB. An evolutionary perspective on the mechanisms of immunosenescence. Trends Immunol. 2009;30(7):374-81.

Shoham S, Levitz SM. The immune response to fungal infections. $\mathrm{Br} \mathrm{J}$ Haematol. 2005;129(5):569-82.

Webb BC, Thomas CJ, Willcox MD, Harty DW, Knox KW. Candida-associated denture stomatitis. Aetiology and management: a review. Part 2. Oral diseases caused by Candida species. Aust Dent J. 1998;43(3):160-6.

Wenisch C, Patruta S, Daxbock F, Krause R, Horl W. Effect of age on human neutrophil function. J Leukoc Biol. 2000;67(1):40-5. 





\section{ANEXOS}

\section{Universidade de São Paulo Faculdade de Odontologia de Bauru \\ PABX: (0XX14) 32358000 / FAX: (0XX14) 32234679}

\section{Prontuário no}

Nome:

Data de Nascimento:

Idade: Gênero:

Naturalidade:

Estado: Nacionalidade:

Ocupação:

Estado civil:

Endereço residencial:

Bairro:

Cidade: Estado:

Tel:

Tel recado:

Falar com/

Endereço Profissional:

Tel:

Bairro:

Cidade:

Estado: 


\section{CARTA DE INFORMAÇÃO}

A nossa pesquisa tem o objetivo de analisar os mecanismos de defesa das células do sangue e da saliva de idosos e jovens contra estomatite por dentadura. Assim, necessitaremos de amostras de sangue e de saliva de voluntários usuários de dentadura, sofrendo de estomatite ou não. A coleta de sangue será realizada uma única vez, por enfermeira profissional. Os riscos e o desconforto da coleta de sangue são mínimos e de total responsabilidade da pesquisadora responsável pelo projeto. A coleta de sangue é a mesma que se realiza em laboratório de análise, sendo muito segura. A coleta de saliva será feita em uma única sessão, em dia diferente da coleta de sangue. Para doação de saliva, o voluntário precisará bochechar solução salina, de sabor levemente salgado, e cuspir em um recipiente estéril. Esta etapa é feita por dez vezes seguidas, no mesmo dia. O voluntário que aceitar doar o sangue não será obrigado a doar saliva e vice-versa. Esta pesquisa pretende melhorar o entendimento da estomatite por dentadura, para tornar o tratamento desta doença mais rápido e confortável para os pacientes, proporcionando saúde bucal para todos.

Qualquer dúvida é só procurar a aluna Thais Helena Gasparoto, na disciplina de Microbiologia da Faculdade de Odontologia de Bauru - Universidade de São Paulo, ou pelo telefone (14) 3235-8271. E se você mudar de idéia e quiser sair da pesquisa, pode ficar a vontade que o tratamento da faculdade será feito da mesma maneira sem qualquer prejuízo.

“Caso o sujeito da pesquisa queira apresentar reclamações em relação a sua participação na pesquisa, poderá entrar em contato com o comitê de Ética em Pesquisa em Seres Humanos, da FOB-USP, pelo endereço da Al. Dr. Octávio Pinheiro Brisolla, 9-75 (sala no prédio da biblioteca, FOB/USP) ou pelo telefone (14) 3235-8356." 


\section{TERMO DE CONSENTIMENTO LIVRE E ESCLARECIDO}

Pelo presente instrumento que atende às exigências legais, o Sr. (a)

portador da cédula de identidade após leitura minuciosa da CARTA

DE INFORMAÇÃO AO SUJEITO DA PESQUISA, devidamente explicada pelos profissionais em seus mínimos detalhes, ciente dos serviços e procedimentos aos quais será submetido, não restando quaisquer dúvidas a respeito do lido e explicado, firma seu CONSENTIMENTO LIVRE E ESCLARECIDO concordando em participar da pesquisa proposta.

Fica claro que o sujeito da pesquisa ou seu representante legal, pode a qualquer momento retirar seu CONSENTIMENTO LIVRE E ESCLARECIDO e deixar de participar desta pesquisa e ciente de que todas as informações prestadas tornaram-se confidenciais e guardadas por força de sigilo profissional (Art. $9^{\circ}$ do Código de Ética Odontológica).

Por estarem de acordo assinam o presente termo.

Bauru-SP, de de 


\section{ANAMNESE}

1. Utiliza dentadura?

2. Há quantos anos utiliza dentadura?

3. Faz uso de alguma medicação?

4. Há quanto tempo usa esta medicação?

5. Terminou algum tratamento recentemente? O que você tinha?

6. Visita o médico com freqüência? Por quê?

7. Está com alguma doença? Qual?

8. Tem diabetes?

9. Já fez alguma cirurgia? De que natureza?

10. Sangrou muito?

11. A ferida da cirurgia demorou para cicatrizar?

12. O (a) sr. (a) se sente muito cansado com freqüência, mesmo sem ter se esforçado fisicamente?

13. Sente dores no corpo?

14. O (a) sr. (a) sente náuseas e / ou vomita com freqüência?

15. Tem sentido redução ou perda de apetite? Com que freqüência?

16. Houve perda de peso ultimamente?

17. Notou o aparecimento de algum inchaço no corpo? Onde? Por quê?

18. Faz uso de bebida alcoólica?

19. O (a) sr. (a) fuma? Quanto? Há quanto tempo?

20. Apresenta algum sangramento espontâneo?

21. Teve diarréia recentemente? Por quê? 
Exame clínico oral:

Descrição clínica da lesão:

Grupo

Nome do paciente:

Prontuário no

Observações 


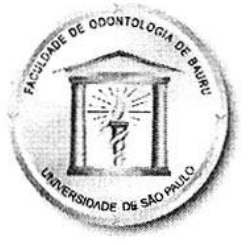

Bauru, 02 de dezembro de 2005.

\section{Processo $n^{\circ} 117 / 2005$}

\section{Universidade de São Paulo} Faculdade de Odontologia de Bauru

Al. Dr. Octávio Pinheiro Brisolla, 9-75 - Bauru-SP - CEP 17012-901 - C.P. 73

PABX (0XX14)3235-8000 - FAX (0XX14)3223-4679

Comitê de Ética em Pesquisa(3235-8356)

Senhora Professora,

Informamos que após o envio da documentação solicitada referente ao projeto de pesquisa encaminhado a este Comitê de Ética em Pesquişa "Estudo da função dos neutrófilos nos mecanismos de defesa contra a estomatite por dentadura em indivíduos idosos" de autoria de Thais Helena Gasparoto, sob sua orientação foi novamente analisado e considerado APROVADO por este Comitê em reunião realizada no dia 30 de novembro de 2005.

Informamos ainda, que após o envio do trabalho concluido, este Comitê enviará o parecer final, que será utilizado para publicação do trabalho.

Atenciosamente,

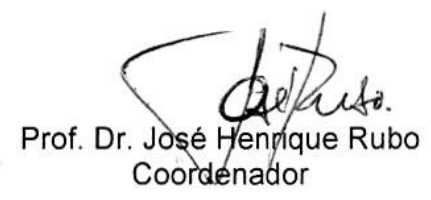

